Florida International University

FIU Digital Commons

FIU Electronic Theses and Dissertations

University Graduate School

$11-10-2011$

\title{
The Relationship between the Secondary Mathematics Curriculum, College Persistence, and Success at an Urban Community College
}

Avis R. Proctor

Florida International University, aproctor123@gmail.com

DOI: $10.25148 /$ etd.FI11120907

Follow this and additional works at: https://digitalcommons.fiu.edu/etd

\section{Recommended Citation}

Proctor, Avis R., "The Relationship between the Secondary Mathematics Curriculum, College Persistence, and Success at an Urban Community College" (2011). FIU Electronic Theses and Dissertations. 531.

https://digitalcommons.fiu.edu/etd/531

This work is brought to you for free and open access by the University Graduate School at FIU Digital Commons. It has been accepted for inclusion in FIU Electronic Theses and Dissertations by an authorized administrator of FIU Digital Commons. For more information, please contact dcc@fiu.edu. 


\section{FLORIDA INTERNATIONAL UNIVERSITY \\ Miami, Florida}

\section{THE RELATIONSHIP BETWEEN THE SECONDARY MATHEMATICS CURRICULUM, COLLEGE PERSISTENCE, AND SUCCESS AT AN URBAN COMMUNITY COLLEGE}

A dissertation submitted in partial fulfillment of the requirements for the degree of

DOCTOR OF EDUCATION

in

HIGHER EDUCATION

by

Avis Richards Proctor 


\section{To: Dean Delia C. Garcia \\ College of Education}

This dissertation, written by Avis Richards Proctor, and entitled The Relationship between the Secondary Mathematics Curriculum, College Persistence, and Success at an Urban Community College, having been approved in respect to style and intellectual content, is referred to you for judgment.

We have read this dissertation and recommend that it be approved.

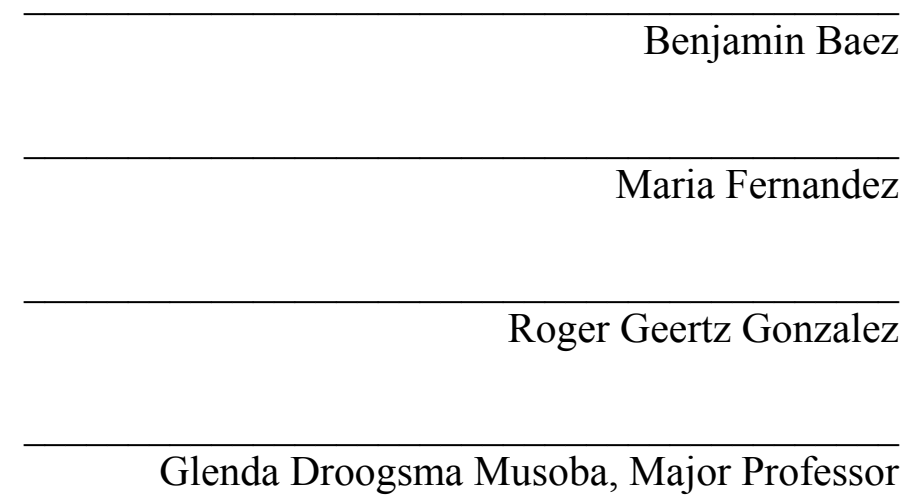

Date of Defense: November 10, 2011

The dissertation of Avis Richards Proctor is approved.

Dean Delia C. Garcia

College of Education

Dean Lakshmi N. Reddi

University Graduate School

Florida International University, 2011 


\section{DEDICATION}

This dissertation is dedicated to my husband and son as they allowed me to use precious time to complete this work. Thanks for your patience and many sacrifices over the years. Your words and selfless acts of encouragement helped me every step of the way. I love you both! 


\section{ACKNOWLEDGMENTS}

I first would like to thank God for giving me a spirit of commitment despite the multiple obstacles I faced to complete this work.

Secondly, I acknowledge my committee members, Dr. Benjamin Baez, Dr. Maria Fernandez, and Dr. Roger Geertz Gonzalez, for their good advice which helped to expand my worldview. Thanks for taking hours of your time to critically read my writings and provide meaningful feedback. I truly appreciate it! I also need to acknowledge Dr. Linda Bliss for her detailed and constructive feedback and Dr. Isadore Newman for bolstering my schema in multivariate statistics!

Thirdly, I want thank to my extended family and my colleagues at Broward College who encouraged me along the way, gave me tips on overcoming hurdles, and steadily rallied behind me to keep my eyes on the prize!

Last, but not least, I want to wholeheartedly thank my major professor, Dr. Glenda Droogsma Musoba, for being authentic and committed to making a difference in this world! I am privileged and honored to have had your guidance and patience throughout this process. Thanks for moving barriers that get in the way of students persisting. You are truly committed to your research in theory and in practice! I am honored that our paths crossed and am inspired to create opportunities for students to persist because of my work with you! 


\section{ABSTRACT OF THE DISSERTATION \\ THE RELATIONSHIP BETWEEN THE SECONDARY MATHEMATICS \\ CURRICULUM, COLLEGE PERSISTENCE, AND SUCCESS AT AN URBAN \\ COMMUNITY COLLEGE}

by

Avis Richards Proctor

Florida International University

Florida International University, 2011

Miami, Florida

Professor Glenda Droogsma Musoba, Major Professor

According to Venezia, Kirst, and Antonio (2003) and Barth's 2002 Thinking K16

Ticket to Nowhere report, the disconnect between K-12 and postsecondary education was a contributing factor to high attrition rates. Since mathematics emerged as a primary concern for college readiness, Barth (2002) called for improving student transitions from K-12 to postsecondary institutions through the use of state or local data. The purpose of the present study was to analyze mathematics course-taking patterns of secondary students in a local context and to evaluate high school characteristics in order to explore their relationships with Associate degree attainment or continuous enrollment at an urban community college. Also, this study extended a national study conducted by Clifford Adelman (The Toolbox Revisited, 2006) as it specifically focused on community college students that were not included his study. Furthermore, this study used the theoretical 
framework that human capital, social capital, and cultural capital influence habitus - an individual's or a group's learned inclination to behave within the parameters of the imposed prevailing culture and norms. Specifically, the school embedded culture as it relates to tracking worked as a reproduction tool of ultimate benefit for the privileged group (Oakes, 1994).

Using multilevel analysis, this ex post facto study examined non-causal relationships between math course-taking patterns and college persistence of public high school graduates who enrolled at the local community college for up to 6 years. One school-level variable (percent of racial/ethnic minorities) and 7 student-level variables (community college math proportion, remedial math attempts, race, gender, first-year credits earned, socioeconomic status, and summer credits earned) emerged as predictors for college persistence. Study results indicated that students who enter higher education at the community college may have had lower opportunities to learn and therefore needed higher levels of remediation, which was shown to detract students from degree completion. Community college leaders are called to partner with local high schools with high percentages of racial/ethnic minorities to design academic programs aimed at improving the academic preparation of high school students in mathematics and promote student engagement during the first year and summers of college. 


\section{TABLE OF CONTENTS}

CHAPTER

PAGE

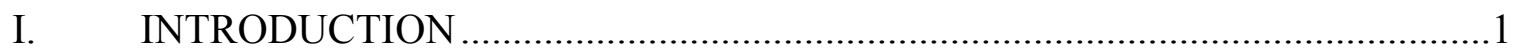

Background of the Problem .........................................................................

Purpose of the Study ……............................................................................

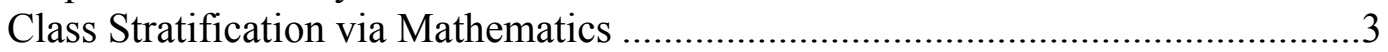

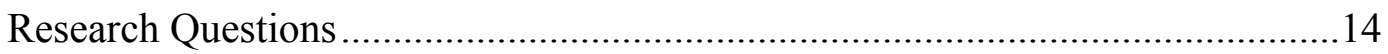

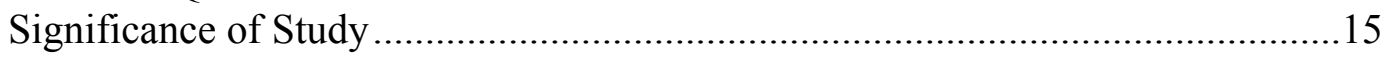

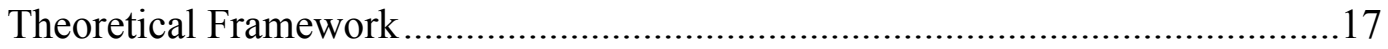

Human Capital .................................................................................

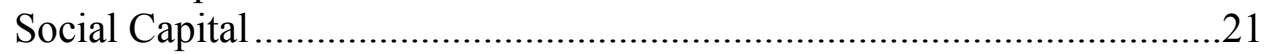

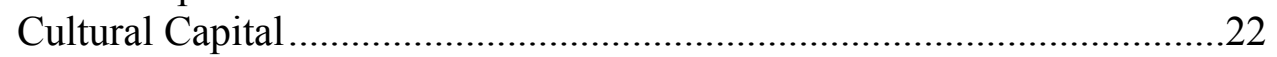

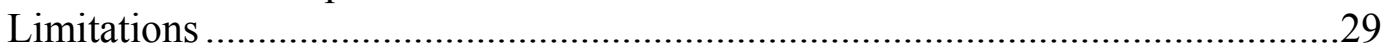

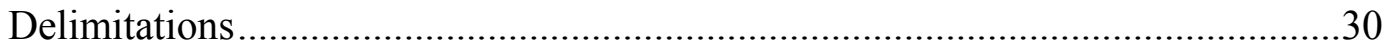

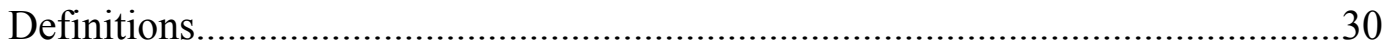

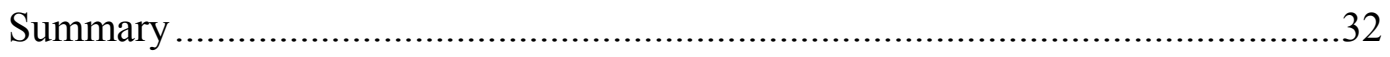

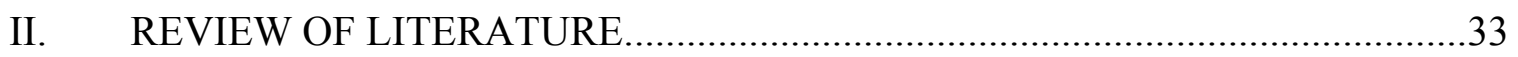

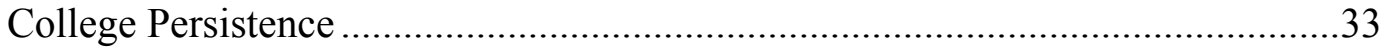

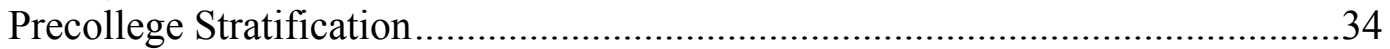

Aspirations versus Expectations ...............................................................34

Influences on Mathematics Achievement ...............................................38

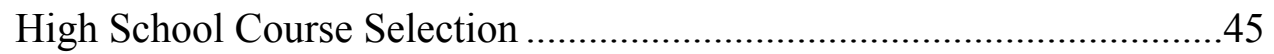

Navigating the System as a Minority .......................................................55

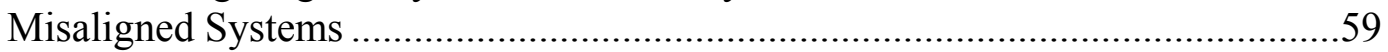

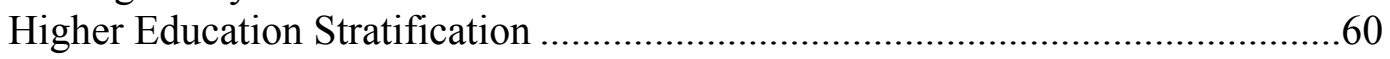

Transition to Postsecondary Education.....................................................60

Students' Academic Experiences.............................................................65

Mathematics and Persistence ………………………………...................66

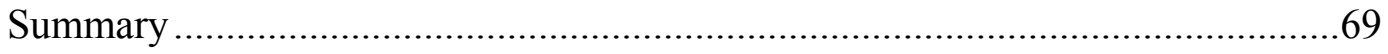

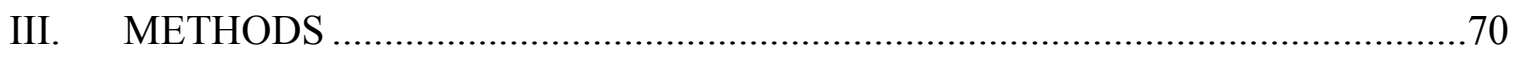

Research Questions ………………………………..................................71

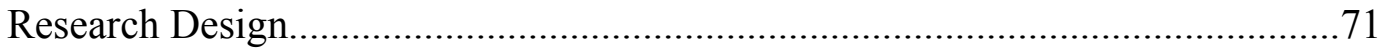

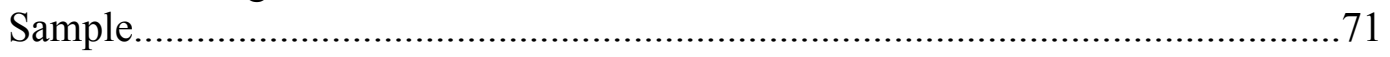

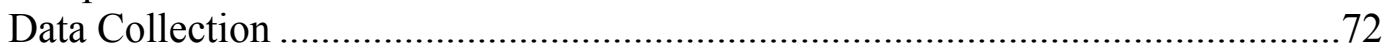

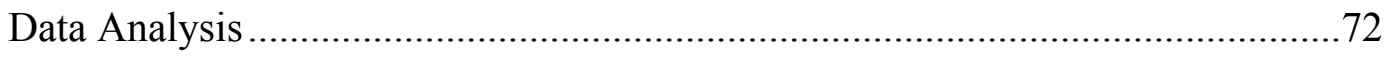

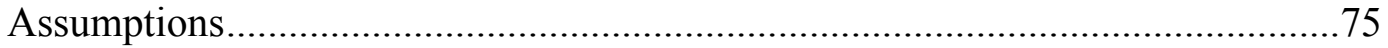

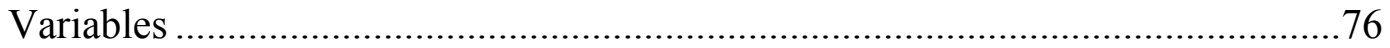

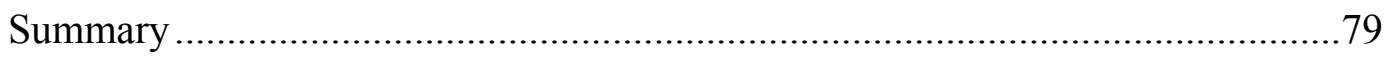

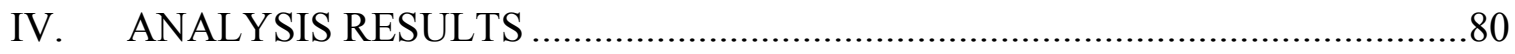

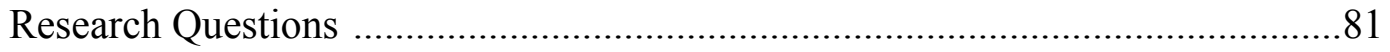




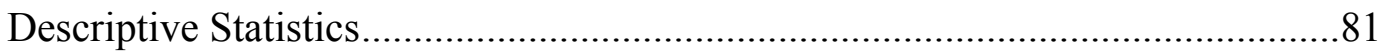

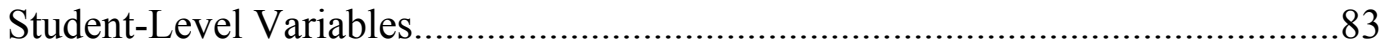

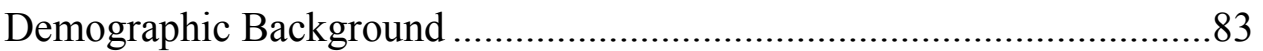

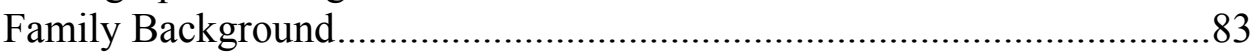

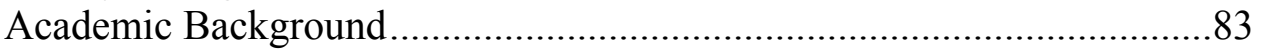

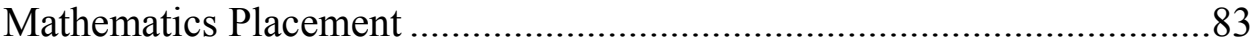

Mathematics and English Coursework ………………….........................84

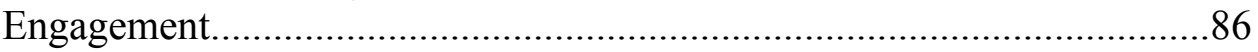

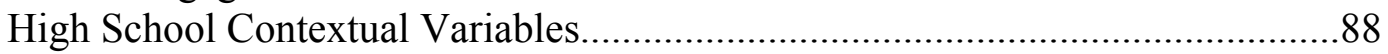

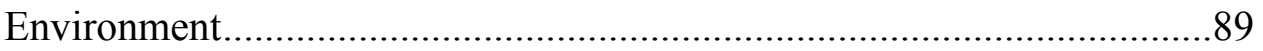

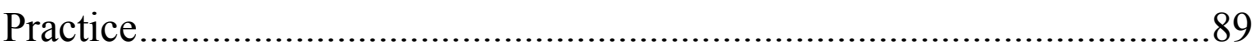

Hierarchical Generalized Linear Modeling and Model Development...................90

Step One: Unconditional Model (Random Intercept Model) ......................90

Intraclass Correlation Coefficient ..........................................................90

Step Two: Significance of Student-Level Variables...................................93

Step Three: Demographic Background....................................................94

Step Four: Demographic and Family Backgrounds ...................................96

Step Five: Demographic/Family Backgrounds and the High School

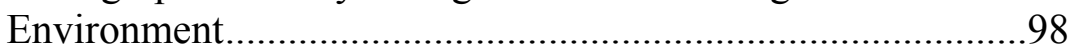

Step Six: Demographic/Family/Academic Backgrounds and Course-taking Patterns with High School Environment and Practices

Step Seven: Demographic/Family/Academic Backgrounds and Coursetaking Patterns with High School Environment and Practices and Student Engagement......................................................103

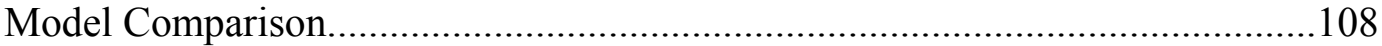

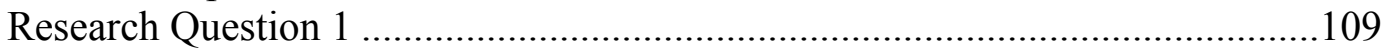

Research Question 2 ................................................................................... 110

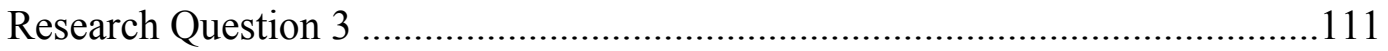

Research Question 4 ..........................................................................112

Theoretical Framework Revisited ...............................................................112

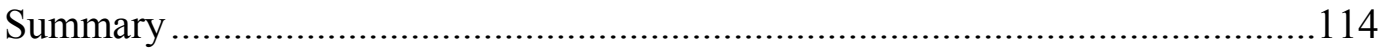

V. CONCLUSIONS and RECOMMENDATIONS

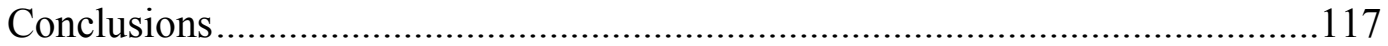

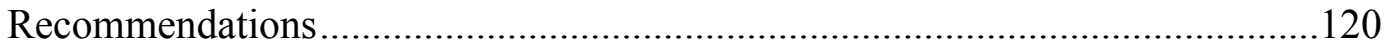

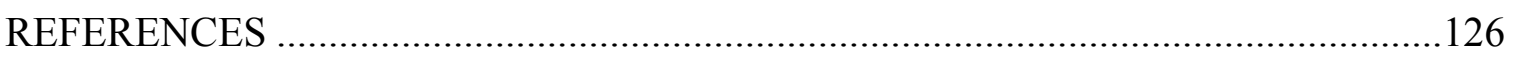

APPENDIX

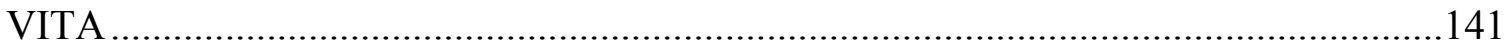




\section{LIST OF TABLES}

TABLE

PAGE

1. Descriptive Statistics for Class of 2002 Categorical Variables .82

2. Descriptive Statistics for Class of 2002 Continuous Variables .82

3. Mathematics Placement Levels

4. Relationship Between Remedial English and Remedial Mathematics .87

5. Unconditional Model: Final Estimation of Fixed Effects (Unit-Specific Model) .91

6. Unconditional Model: Final Estimation of Fixed Effects (Population-Average Model).

7. Unconditional Model: Final Estimation of Variance Components

8. Final Estimation of Variance Components in Descending Order for StudentLevel Variables

9. Demographic Background: Final Estimation of Fixed Effects (PopulationAverage Model).

10. Demographic Background: Final Estimation of Variance Components. .96

11. Demographic and Family Backgrounds: Final Estimation of Fixed Effects (Population-Average Model)..

12. Demographic and Family Backgrounds: Final Estimation of Variance Components.

13. Demographic/Family Backgrounds and High School Environment: Final Estimation of Fixed Effects (Population-Average Model)..

14. Demographic/Family Backgrounds and High School Environment: Final Estimation of Variance Components

15. Demographic/Family/Academic Backgrounds and High School Environment: Final Estimation of Fixed Effects (Population-Average Model).

16. Demographic/Family/Academic Backgrounds and High School Environment: Final Estimation of Variance Components 
17. Demographic/Family/Academic Backgrounds With High School Environment and Community College Engagement: Final Estimation of Fixed Effects (Population-Average Model).

18. Demographic/Family/Academic Backgrounds With High School Environment and Community College Engagement: Final Estimation of Variance Components

19. Deviance Statistics and Variance Reduction Between Models...................109

20. Student Persistence by High Schools ....................................... 115

21. Ordinary Least Squares Comparison Model Results ...........................123 


\section{CHAPTER I}

\section{INTRODUCTION}

\section{Background of the Problem}

The community college is a multi-purpose institution with a fourfold mission focused on transfer to the university, vocational/technical terminal degree or certificate programs, continuing/community service, and remedial education. Its primary function is to provide open access to students needing the Associate degree to transfer to the university, yet many students fail to realize this goal. Students entering the community college often need remediation in mathematics, but some critics view remediation as duplication in the use of taxpayer dollars. However, others have argued that remediation was not necessarily a repeat of what was supposed to be learned in high school as older adults do return to college (Bendickson, 2004).

Remediation has been present in higher education for centuries. Moreover, there has been a strong link between remediation and retention as well as graduation. Waycaster (2001) found that students who successfully complete developmental programs perform on par or better than their college-ready peers. In her study on five Virginia Community Colleges from fall 1997 through spring 2000, retention rates for developmental students $(61.9 \%$ to $80.6 \%)$ were at or above the retention rates of nondevelopmental students $(42.1 \%$ to $61.9 \%)$. The developmental faculty explained that this uncommon statistic occurred because of the additional counseling, advising, and teaching the developmental students receive. In terms of the teaching, students were enrolled in three levels of 5-credit developmental mathematics courses (Basic Arithmetic, Basic Algebra I, and Basic Algebra II) with small class sizes (mostly 12-24 students). 
This same study showed that $40 \%$ of the graduates in that time period were students previously enrolled in a developmental program. Since a sizeable portion of the graduates in that study were in a developmental program, community college leaders should focus on this growing body of students. In fact, the Fall Student Survey at a large Florida urban community college revealed that about $70 \%$ of the incoming students need at least one remedial course - a convincing reason to strategize on what to do with this high-needs group (Broward College, 2006). While the open access mission has remained prevalent, there have been at least two reasons why contentions may arise from focusing on these students alone: faculty may argue that students should be prepared from high schools and leaders may cite a lack of resources to adequately fund the growth in remediation/developmental programs. Yet, the reality has been that these students were not prepared for college.

\section{Purpose of the Study}

The purpose of this study was to review and analyze the mathematics coursetaking patterns of secondary students in an urban Florida school district in order to determine the relationship between these patterns and a student's: (a) enrollment in a community college or (b) successful attainment of at least a community college Associate degree. The study also examined the demographic profiles of high schools that are linked to high and low rates of persistence in fulfilling degree requirements so that concentrated efforts can be directed at particular institutions and groups of professionals and students in order to improve student academic achievement and ultimately lead to a significant increase in the number of students earning postsecondary credentials. 


\section{Class Stratification via Mathematics}

In order to address the success of the community college student in the mathematics curriculum, the evolution of the secondary mathematics college preparatory curriculum was analyzed. In the early nineteenth century, education in America was not open to all. Consequently, as more of the public, including girls and others previously denied access, began to attend school, there was some catching up to do. Senk and Thompson (2003) gave a comprehensive review of school mathematics and how it has evolved starting with an indictment of schooling by Horace Mann. In 1845, Horace Mann argued that the schools were not producing citizens who were capable of thinking mathematically. He expressed his concerns about the conditions of education in The Common School Journal in 1845.

Who of all the boys in the Boston Grammar and Writing schools, shall hereafter be city assessors, when not one of them can tell what tax shall be levied on a hundred thousand dollars, when all the conditions are given, with perfect precision and clearness? Who of all the boys, aye, or girls either, shall cast the interest on a note, either as borrower or lender, when not one of them knows there is any difference between the value of a note for $\$ 200$ payable in six months, and the value of two notes of $\$ 100$ each, - one payable in three and the other in nine months! (as cited by Senk \& Thompson, p. 3)

Also using a historical lens, Kliebard (2004) pointed to a decrease in algebra and geometry enrollments between 1921 and 1933 despite the enrollment booms in the early 1900s. More specifically, he gave an account of how high school registrations leaped from 203,000 in 1890 to $2,155,000$ in 1922 , and ultimately to $6,500,000$ by 1939 . To give this relevance, Kliebard (2004) brought the reader's attention to the Progressive Education Association's (PEA) Mathematics in General Education published in 1940. This report was written by the Committee on the Function of Mathematics in General 
Education of the Commission on Secondary School Curriculum. The committee clearly stated the intent of the report was "to help teachers of mathematics better meet the needs of boys and girls" (Commission on Secondary School Education, p. 15). However, the committee felt it necessary to include a section on their "loss of confidence in the educational values of mathematics" (Commission on Secondary School Education, p. 9). That is, the PEA committee thought a secondary education should be needs-based and not completely college bound. Chall (2000) confirmed this student-focused approach when she pointed to a 1995 study conducted by Angus and Mirel. Angus and Mirel's study of high school course enrollments pointed to a sharp decline in the percent of the high school curriculum pertaining to academic courses. This decline was evidence of high schools providing a "needs-based functional curriculum" (p. 53). With a strong emphasis on the needs of a wide variety of students versus a college-bound education, one cannot help but to ask what motivated the change.

According to the PEA committee, there were social and economic changes affecting the high school youth. Although they did not specify the social changes, by the time of publication, the country had already experienced the Civil War, the SpanishAmerican War, the First World War, the Second Industrial Revolution, and the Great Depression. Women were more outspoken and pushed to be educated alongside men leading to the woman's suffrage movement and the ratification of the $19^{\text {th }}$ Amendment. Also, there was an influx of immigrants into the country. The South, at a minimum, was in a post-slavery period shadowed by Jim Crow laws. Although this list was not exhaustive, it captured several major influences of the day. In sum, there was a need to 
bring social order in the country. However, the intent underlying the development of this social order has plagued us.

Recognizing that the number as well as the percent of students enrolled in mathematics was also less in 1934 than in 1928, a call for educational reform was sent out. In 1940, the PEA call proposed that the teaching of mathematics should address four categories: "personal living, immediate personal-social relationships, social-civic relationships, economic relationships" (p. 20). Consequently, mathematics courses beyond arithmetic were considered electives and were designed for students who aspired to be professionals who would use mathematics such as scientists and engineers $-\mathrm{a}$ decision that has been tough to reverse decades later.

To support this change, the PEA committee cited the high numbers of failures, economic and social developments, and the students' dislike for the subject as reasons for curriculum reform. For example, a real issue was the likely unemployment of the high school students. Being unemployed certainly has had a significant impact on families today never mind in a society that coped with the effects of the Great Depression and the attempted integration of an array of people in a society that sought to oppress groups such as women, Jews, African-Americans, and Native Americans. These actions seemed to propel public schools to develop two tracks in the secondary curriculum.

Across the country, there was secondary and postsecondary support for the twotrack curriculum from different entities and in different ways. For example, in the writings of President Woodrow Wilson, compiled by Arthur S. Link in 1974, President Wilson actually supported this position in his speech to the New York City Teachers High School Association in 1909 when he said: 
We want one class of persons to have a liberal education and we want another class of persons, a very much larger class of necessity, to forgo the privileges of a liberal education and fit themselves to perform specific difficult manual tasks. (p. 597)

As for the junior colleges in California, Brint and Karabel (1989) reported that the Carnegie Foundation had a clear focus on "creating a formal division of labor," pointing to the desire to vocationalize the junior college (p. 47). Tragically, this occurred amidst the dissent of students who were powerless to affect change. Additionally, Pedersen (2005) made note of opposing views of education historians. While some believed the junior college was founded to promote social mobility and establish a public good, others felt the junior college restricted social mobility. These critics believed it was the intent of the California state legislature to "lessen the benefit of a higher education for the largely middle- and lower-class students who have been diverted to community colleges because of their economic status" and it appropriated "an intentional and substantial subsidy of the generally affluent students who [attended] major state universities" (p. 6). Even tuition policies reflected a desire to limit the working class. Citing Hurt (1928), Pedersen (2005) also reported that tuition at a junior college in many states was substantially greater than tuition at the proximate state university. In particular, according to the Oklahoma Department of Education's 1940 Biennial report from the State Superintendent of Public Instruction, “Oklahoma's small town junior colleges were all forced to levy a substantial tuition charge." Specifically, students at these junior colleges were charged half the cost of instruction. On the other hand, the University of Oklahoma was tuitionfree for local residents. Burton Clark (1960) referred to this as the "cooling out" function of community colleges as they "cooled" or lowered the educational aspirations of their students. 
However, not everyone was in favor of creating a prescribed class difference. Vassar (1965) emphasized that John Dewey was against a curriculum designed for "intellectual training of the upper classes and practical education for the working class" (p. 230). Dewey was opposed on many fronts, but much of his work has resurfaced especially in regard to mathematics learning and multiple representation theory. Overall, tracking in the secondary curriculum contributed to restricting upward mobility. So again, community college practitioners have been called to capture what techniques, paths, resources, and affective qualities contribute to a student's success in completing a transfer degree and specifically his/her success within the mathematics curriculum.

To further demonstrate pre-college stratification, high school mathematics requirements have changed, but not with the support of learning more mathematics than in the past. Remember, despite the substantial growth in the number of students attending high schools in the early twentieth century, the percentage of students taking algebra and geometry declined. Kliebard (2004) further explained that students were simply not electing to take mathematics classes. He reported that around 1950, only one Carnegie unit of high school mathematics was required. At that time, $60 \%$ of students were taking algebra while the remaining students were taking general mathematics to meet this requirement. Using the needs-based approach, the two-track high school mathematics curriculum was solidified, leading to differences in learning opportunities for different racial/ethnic and social class groups.

From the many studies that compare the academic achievements of students with different racial/ethnic backgrounds, there has been a predominant story of greater academic opportunity and therefore achievement for White and Asian students compared 
to Black and Hispanic students (Marin and Lee, 2003). However, this historical context revealed a different story as to the underlying causes of such misleading outcomes that relate to available curriculum, teacher expectations, and socioeconomic status. For example, Ginsburg and Russell (1981) tested the mathematical cognitive abilities of 4and 5-year old Black and White students from middle- and lower-classes. They found that all groups were equipped with the prerequisite skills for "adequate performance in mathematics" (p. 29). Yet, there have been studies that conveyed the false message that there were, for example, racial/ethnic differences in abilities. Race and ethnicity variables were shown to be significant because they were measurable, yet the complicated differences between groups that were attributable to opportunities to learn (Burris, Heubert, and Levin, 2006), subtle and not so subtle teacher messages (Auerbach, 2002), differences in teacher quality and expectations (Watanabe, 2007) and racism (Cross, 2003) have been hard to measure.

In 1950, the National Science Foundation was "created by Congress ... 'to promote the progress of science; to advance the national health, prosperity, and welfare; to secure the national defense...'" (National Science Foundation, 2010). By the end of that decade, the United States issued the National Defense Education Act of 1958 in response to Russia's launch of Sputnik calling for another round of educational reform for advance preparation in mathematics and science. Since then, the high school graduation requirements for mathematics increased. In 1969, the National Assessment of Educational Progress was founded. Its first evaluation of mathematics achievement occurred in 1972. During the 1970s, there was much contention about the "new math", but it prevailed (Senk and Thomson, 2003). Although our nation advanced 
technologically and seemed to be globally competitive, the level of mathematics achievement of students in secondary schools was unsettling from multiple standpoints (A Nation at Risk, 1983; Adelman, 1999). Ingels, Planty, and Bozick (2005) gave a summary on the math achievements of the 2004 American senior class using a follow-up study on the Education Longitudinal Study of 2002 (ELS:2002):

Among the senior cohort in 2004, higher postsecondary educational expectations were associated with higher levels of math performance (table 2). However, 63 percent of seniors who expected to earn a 4-year college degree and 47 percent of seniors who expected to earn a professional degree did not exhibit a mastery of level 4 (understanding of intermediate-level mathematics concepts). In fact, 32 percent and 20 percent, respectively, had not mastered level 3 (simple problem solving requiring the understanding of low-level mathematical concepts). (p. 6)

In 2001, the federal government instituted the No Child Left Behind Act (NCLB) obligating each state to measure the academic performance of students in elementary and secondary public schools. Prior to NCLB, the state of Florida required 3 years of mathematics for high school graduation. In 2003, a Florida Department of Education (FLDOE) issued a memo that redefined high school graduation options in response to Senate Bill 30A, which called for school districts to inform parents of the accelerated options (Advanced Placement program, Dual Enrollment, International Baccalaureate program,...) available to their children. As a result, students had three routes to graduation: the standard 24-credit program, the three-year 18-credit standard college preparatory program, and the three-year 18-credit career preparatory program (FLDOE, 2003). Subsequently, the state of Florida issued a 2006 memo which indicated increased mathematics requirements for all high school students entering the 2007-2008 academic year and declared major by these students. Although it seemed as if these changes were implemented to extend exposure to the mathematics curriculum and to 
create paths of exposure to the advanced mathematics curriculum, it still remained that for students to graduate, they had to 24 credits, of which 4 credits were mathematics courses. Of these, students with one credit in Algebra I were eligible to graduate (FLDOE, 2007). The remaining three credits were mathematics electives that were not rigorous enough for college-bound students. However, the memo's author did not emphasize that the required mathematics coursework be college-bound, evidence that two-track curriculum remained prevalent in the large state of Florida. This document delineated the graduation requirements of

[f]our (4) credits in mathematics, one of which must be Algebra I, a series equivalent to Algebra I, or a high-level mathematics course. School districts are encouraged to set specific goals to increase enrollments in, and successful completion of, geometry and Algebra II. (p. 2)

According to the FLDOE, Algebra IA and Algebra IB was a series equivalent to Algebra I for which students could receive 2 of the 4 required credits (FLDOE, 2009). Hence, a student could have graduated without taking geometry or Algebra II as was emphasized in the memo that districts were to encourage students to pursue geometry or Algebra II. Adelman (1999) asserted that students needed Algebra II to be on the right path for college readiness. On the surface, the major requirement seemed like another iteration of the labor-division schema. Based upon these directives, the Florida Department of Education clearly did not require a college preparatory curriculum for all. From a national standpoint, Reys, Dingman, Nevels, and Teuscher (2007) reported from the Center for the Study of Mathematics Curriculum that about 39 states increased their high school mathematics curriculum standards. In the meantime, educators have had to reach within their creative capacities to apply sound research within the restrictions of state and federal guidelines. 
While precollege stratification has had many consequences, within college stratification has been evident at the community college. In a 1963 Junior College Advisory Board report on Florida's Community Junior Colleges, S.V. Martorana stated, "putting $40 \%$ of the enrollment in the transfer category and $60 \%$ in the terminal grouping may not be good for long range planning in Florida" (p. 15). Martorana's statement seemed to predict Clark's (1965) and Brint and Karabel's (1989) argument that an intentional diversion occurred in community colleges and ultimately reduced the number of transfers to the university.

In the latter part of the twentieth century, efforts were made to make transfer to the university more seamless through the use of articulation agreements. However, the rise in the number of articulation agreements in the 1980s and 1990s has not translated into more transfers according to Anderson, Alfonso, and Sun (2006). Digging beneath the surge in the number of articulation agreements during the 1980s and 1990s, Anderson et al. (2006) cited the works of Brint and Karabel (1989) and Dougherty (1994) pointed to the trend of students who had chosen the terminal certificate or occupational associate degree route even though they initially signed up for the AA transfer route. Additionally, many students dropped out. This trend was coined "cooling out" as early as 1960 by Burton Clark. Interestingly, Anderson et al. (2006) reported that the rise in articulation agreements occurs after years of silence. Anderson and colleagues also pointed out the paradoxical functions of the community college in that it has promoted upward mobility while at the same time it reproduced disparities in social/racial classes and gender. They presented several theoretical frameworks (Neo-Marxists, Institutionalists, Statists, and Functionalists) and gave the reader an overview of the initial purpose and the increased 
vocational element of community colleges. Using the 1996 Commission on National Investment in Higher Education report, they concluded that states were essentially forced into difficult situations as they responded to unfunded federal mandates such as Medicaid, Medicare, American Disabilities Act, and Occupational Safety and Health Administration. Consequently, state budgets were distorted. Looking further, the authors drew a connection between the "stagnation and decline of state appropriation for higher education as a share of total state expenditures, and the dramatic increase in statewide articulation agreements between 1985 and 1995" (p.431). They noted 23 states created or revised articulation agreements during this timeframe. From a historical perspective, these 23 agreements represented $79 \%$ of all existing agreements up to 1995 , an alarming statistic. Ultimately, the authors pointed out that state officials were seeking costeffective ways, like reduced full-time equivalent expenditures per student, by redirecting baccalaureate-degree-seeking students to the community colleges. However, this had an impact on access to higher education. The Commission on National Investment in Higher Education (1996) provided evidence that California, Texas, Florida, New York, and Illinois will soon be or already were states without a non-Hispanic White majority, yet nationally only $7 \%$ and $4 \%$ of baccalaureate degrees awarded go to AfricanAmericans and Hispanics, respectively. Since income inequities consistently grew since the mid-1970s, "the commission also warned that approximately half of the students in the United States seeking access to higher education will be unable to attend postsecondary institutions by 2015" (p. 439). Thus, Anderson et al. predicted a middleclass takeover and an enhanced cooling out process at the community college. They also concluded that in order for politicians to remain in office, they had to work delicately to 
please their constituents within fiscal constraints. That is, state officials promoted the creation of articulation agreements so that it appeared as if they supported the AA transfer when in reality these agreements were formed to cut back on costs so that other competing initiatives were funded and maintained privileges for 4-year institutions (their alma maters).

Last, with the rise of the Accountability movement amidst the long standing higher education financial concerns, the authors predicted that community colleges may be forced to limit access across the board, an act that conflicted with the mission of the community college. With redirected high-demand programs at the community college, these authors argued that this was a strategy that better managed the demand for access to a postsecondary education. Hence, it was a mechanism that offered these programs at a low cost to those students who looked for an education they would have normally pursued at the university. As a consequence, since racial/ethnic minority and poor students have been disproportionately enrolled at the community college, their open access have now become limited as students who were once university bound were now seeking an education at the community college. Anderson and colleagues (2006) called this the new cooling out process. So, once again, dreams could not be realized even if provided with a close to seamless transfer process. Unfortunately, tracking students, pricing students out of college via tuition rates, underfunding need-based aid, and setting up underused transfer articulation agreements all seemed to contribute to deep societal inequities today that may take generations to reverse. Intentional diversion to occupational fields, behind the façade of open access to the full experience of a postsecondary education, helped create this unfortunate phenomenon of undereducated 
citizens whose families, as a point of survival, valued working more than getting an education. Clearly, several generations have reaped the repercussions of this controlling act. Moses (2004) discussed how we as a nation have accepted mathematics illiteracy practically at the same degree that we have not accepted reading and writing illiteracy. That is, everyone has had to learn to read and write, while it was acceptable to not know mathematics. He also made note of the writings of two attorneys, Joseph B. Tulman and Mary G. Hynes, who linked poverty, illiteracy, and prison to an alarming proportion of poor children and children and adults of color in the criminal justice system. We cannot continue in this fashion and build more prisons; every human deserves an opportunity to live up to his/her full potential.

With increased high school graduation requirements that expanded learning opportunities for our future students, community college leaders were called to focus on building clear transfer paths for students to attend universities rather than solely emphasizing the work credentials students earned from career and technical education programs. However, since students have graduated from high schools with less rigorous coursework despite the increased graduation requirements, it was imperative for college practitioners to have an increased awareness of the specific factors that were related to students persisting to complete their Associate degrees.

\section{Research Questions}

Precollege characteristics, the socioeconomic status, the institutional effects (high school), and course-taking patterns of students were examined for predictive relationships to persistence and successful completion of the Associate degree. Overall, the researcher was interested in determining the student-level and institution-level variables that 
predicted degree attainment or lack thereof for students who began their postsecondary education at a 2-year institution.

Research Question 1: Is there a predictive relationship between high school mathematics course enrollment patterns and degree attainment?

Research Question 2: Is there a predictive relationship between community college enrollment patterns in mathematics courses and degree attainment?

Research Question 3: Is there a predictive relationship between a student's high school curriculum and his or her degree attainment?

Research Question 4: Is there a predictive relationship between the high school's racial/ethnic demographics or socioeconomic status and degree attainment?

\section{Significance of Study}

With high levels of remediation and low graduation rates, the researcher wanted to know what student-level and high school variables were predictive of the success of those students who were completing degree requirements so that effective policies and program could be implemented both prior to and during enrollment at the community college. Terenzini, Cabrera, and Bernal (2001) asserted that much of the persistence literature pointed to the secondary curriculum as a significant predictor of persistence and success in college. They also argued that the time had come and that

colleges and universities, both individually and in the aggregate, have a significant self-interest in the reformation of the $\mathrm{K}-12$ education system in the United States. The kinds of curricular and instructional partnerships suggested by Adelman and others now being implemented by the Education Trust (see www.edtrust.org) might be extended to other areas, including program planning and evaluation, administrative operations, technology, and instructional practices. (pp. 41-42) 
Furthermore, other scholars have issued the call to review the American education system across secondary and postsecondary sectors. Haycock, Barth, Mitchell, and Wilkins (1999) described the American system of education as a

journey of false trails, wrong turns, and bumps in the road. Students and teachers are caught between aspects of the system which not only don't talk to each other as much as they should, but also don't examine their own assumptions and practices. (p.28)

They also pointed out the rapid growth in college-level curricula that was offered in the high school while the largest growing sector of the college curricula was high school curricula - a clear misalignment of the two systems. Hence, the two systems have a need to communicate on a broader basis in the interest of student achievement and for community colleges' increased efforts toward delivering higher education. The authors called for states to evaluate course-taking patterns of students, their exposure to higherlevel coursework, and how different groups have varied access.

Under the high school preparation argument, mathematics emerged as a primary concern and has been regarded by many students as difficult and irrelevant. Barth (2002) delivered a call to action for systemic change with united agendas to aid current K-12 teachers, using state or local data (not national data) to motivate mathematics faculty to establish a collaborative plan to improve K-16 pedagogy and student achievement in their immediate communities. Research was needed to determine the effect of mathematics on the overall persistence of community college students. Were there any historical implications in the endemic failure rates in mathematics? For those students who were successful, what factors contributed to their earning at least an Associate degree? Having explored how the secondary mathematics curriculum has evolved in the United States, it was necessary to research the relationship between the secondary mathematics 
curriculum and persistence at 2-year institutions, and to investigate what factors were related to the success of community college students who earned at least their Associate degrees.

\section{Theoretical Framework}

So, what explained the rate of students needing remediation after graduating from high school? What explained students having to repeat remedial coursework multiple times at the community college? Why were remedial students more likely to be from families with low socioeconomic status or from racial/ethnic minorities? How were these high remediation rates related to persistence in the pursuit of one's higher education? Through the years, scholars have used different ideological explanations (human capital, social capital, and cultural capital theories) for the reasons why poor or minority students have lessened upward mobility in their academic achievements, educational pursuits, and employment choices.

\section{Human Capital}

Human capital has been described as the knowledge and skills possessed by an individual. Factors that contributed to human capital included schooling, socioeconomic status, and social and environmental factors. Some scholars argued that human capital was a function of one's choices (Becker, 1962; Blakeslee, 2005; Bowles and Gintis, 1975; Cunha and Heckman, 2007), where one was enrolled in school (Gamoran, 1987), and that schooling created more human capital by raising earnings and productivity (Becker, 1992). Becker (1962) also found that some persons earned more than others simply because they invested more in themselves. However, the investment in one's self arguably was affected by one's income. Haveman and Wolfe (1995) supported this claim 
when they found that children from a poor or low-income family tended to have lower educational and labor market attainment.

Bowles and Gintis (1975) critiqued human capital theory from a Marxist standpoint and infused a labor versus labor power analysis. They argued that labor was not in the equation when it came to exchangeable activities contrary to the labor power of an individual. They viewed an individual's life path as a "product of one's own or one's family's choices, limited only by one's 'abilities,' by the available learning technologies, and to a limited extent by one's family resources" (p.77). These authors argued that highskilled workers did not automatically yield a money-making labor force. In fact, they quickly moved to evaluating the role of education and described how it partitioned the labor force, hindered the awareness of the proletariat, and forced acceptance of monetary inequalities through the use of superficial merit-based policies in job placements while it maintained a social order that reflected the larger society. Although cast in a more positive light, Becker (1992) ultimately seemed to agree with Bowles and Gintis (1975) about the influence of education on human capital. He pointed out that small differences in schooling of young children multiplied into big differences by the time they were teens and, as a result, the social order remained unchanged.

However, Bowles and Gintis (1975) contended that human capital cannot alone explain maintenance of the status quo. They acknowledged that "families and schools teach different things to different people not simply more or less" (p. 79). Consequently, on this basis alone, one did not expect equal outcomes and that "sexism, racism, and elitism in our schools...[played] an essential role in the reproduction of the capitalist order, a role inseparable from the capacity of schools to produce 'good workers" (p. 82). 
This theory was supported with Gamoran's study in 1987 where he found that there were within-school effects on tracking and course-taking patterns which affected cognitive skill development.

Moreover, human capital had surfaced in studies in the context of the global economy. While the United States once led the world economically, Hershberg (1996) reported that the American human capital advancement system was weak. Yet, most of the Nobel Prize winners were from the U.S. (Bruner, 2011), most patents were held in the U.S. (WIPO, 2008), and knowledge flowed directly from the U.S. outward, not the other way around (Jaffe and Trajtenberg, 1996). Hershberg (1996) discussed economic gauges related to education which pointed to the U.S. that remained dominant, for good or bad, within the higher education realm regarding workforce training, knowledge production such as scientific discovery and/or technology transfer, and college graduation in general. In Doyon's (2001) review of higher education reform efforts in Japan, he highlighted the dehumanization of the Japanese and the highly stratified Japan's higher education system according to socioeconomic status (SES) beginning very early - meaning if someone would have place his/her child in Japan in an elite primary school, it was most likely the child would have been placed in an elite university and would have received a high status job.

Reviewing the K-12 system, Hershberg (1996) found, based upon the length of the school day, that the Japanese youth had 4 more years of education by the end of high school. Hershberg (1996) also argued that while the United States had top-notch universities, it lacked a strong mechanism which produced quality workers, in contrast to Japan and Germany. However, Germany was one of 29 European countries whose 
ministers of higher education had declared their intention to reform the European higher education system through the Bologna Process (Eurydice, 2009).

In the Bologna Declaration, ministers affirmed their intention to:

- Adopt a system of easily readable and comparable degrees;

- Implement a system based essentially on two main cycles;

- Establish a system of credits (such as ECTS);

- Support the mobility of students, teachers and researchers;

- Promote European cooperation in quality assurance;

- Promote the European dimension in higher education (in terms of curricular development and inter-institutional cooperation).

The Bologna Declaration also formulates the objective of increasing the international competitiveness of the European system of higher education and stresses the need to ensure that this system attracts significant attention from around the world. (p. 14)

A third argument given to demonstrate the deterioration of human capital in the United States related to our higher education system into which many high school graduates entered while lacking basic skills. That is, scholars argued that high school students were not as motivated to learn while in high school since college was still an option after graduation. For example, in a study on young adulthood functional literacy, Baydar, Brooks-Gunn, and Furstenberg (1993) argued that intervention programs such as voluntary pre-kindergarten were needed to abate adult illiteracy based upon their findings that social-behavioral, language and cognitive skills of preschoolers were robust predictors of young adulthood literacy. Similarly, Becker (1992) argued that over time small differences reproduced greatly by the time children were teenagers which resulted in dropouts and persons without good work habits. Hence, companies resorted to setting up training programs to prevent loss in productivity. Hershberg (1996) made a recommendation for corporations to allocate more of their budgets on employee training throughout an employee's tenure as opposed to hoping for the best out of his or her experience from the early educational opportunities in the first two decades of an 
employee's life. To the contrary, Blakeslee (2005), in a review of Heckman's rates of return to human capital investment focus, reported that job training yielded the lowest rate of return.

Finally, Cunha and Heckman (2007) developed an economic model, based on six skill building facts from previous studies, that addressed the early start of ability gaps for cognitive and noncognitive skills between individuals and across socioeconomic groups and the rates of return on interventions at specified times in a child's life. They asserted that an early intervention program, Perry Preschool Program, gave the greatest returns in high-school graduation and college enrollment and that "public job training programs and adult literacy and educational programs, like the GED, that attempted to remediate years of educational and emotional neglect among disadvantaged individuals had a low economic return and produced meager effects for most people" (p.33).

\section{Social Capital}

In an attempt to refocus researchers on Pierre Bourdieu's original definition of social capital, Portes (1998) described three functions of social capital: “(a) as a source of social control; (b) as a source of family support; (c) as a source of benefits through extrafamilial networks" (p. 9). The social control aspect of social capital had been established in the relations between parents and their children as they sought to exert control and encouraged obedience to established norms. An example of the family support or the lack thereof was given to describe the links between single versus multiple parents and "school achievement and attrition, teenage pregnancy, and other adolescent outcomes" (p. 11). The last portion of social capital was demonstrated in communities beyond the family network. "The most common use of this third form of social capital 
[was] in the field of stratification... as an explanation of access to employment, mobility through occupational ladders, and entrepreneurial success" (p. 12). However, Portes (1998) cited the work of Granovetter (1974) who suggested that the "strength of weak ties" was an unofficial job recommendation structure (p. 12). Portes (1998) continued to describe social capital as a resource of connections that groups and individuals used for collective and personal gains, respectively. However, he warned that at the same time, the relationships used by the privileged group limited access by another group to the same advantages. This exclusive privilege factor of social capital was an important component of Bourdieu's theory, and Portes (1998) argued that the more natural the arbitrary privileging of insiders over other groups appeared the more stable the social capital system remained. To shed light on his analysis of negative social capital, Portes (1998) gave an example of well-managed cities that prospered as a result of "high social capital" while "poorer cities [lacked] in this civic virtue" (p. 19). A parallel comparison in the American education system can be made comparing the high socioeconomic status (SES) students earning high academic achievements as a result of their group membership while the low SES students are mostly bound to low academic gains. This disconnect between ability and achievement has been obscured in this system.

\section{Cultural Capital}

Cultural capital referred to the learned skills of the elite different from the social capital gained or lost based upon group membership and one's access to resources and the benefits gained by individuals with access to these resources. There were several studies that linked cultural capital to academic achievement (Dumais, 2002; Farkas, Grobe, Sheehan, and Shuan, 1990; Lee and Bowen, 2006; Roscigno and Ainsworth- 
Darnell, 1999; Sullivan, 2001). Cultural capital was a construct first introduced by a French sociology scholar, Pierre Bourdieu. However, some scholars believed other researchers have digressed from Bourdieu's original meaning (Lareau and Weininger, 2003; Musoba and Baez, 2008). Lareau and Weininger (2003) critically reviewed several articles using cultural capital as the theory that grounded their studies and found a "dominant interpretation" of the meaning of cultural capital (p. 568). This perspective viewed cultural capital as knowledge of "highbrow" art and culture and that the "effects of cultural capital must be partitioned from those of properly educational 'skills,' 'ability,' or 'achievement"' (p. 568). Lareau and Weininger (2003) contended that this viewpoint missed a wider lens when looking at the micro-processes through which individuals functioned with or against the judgment of the principal culture or institution such as schools. They pointed to Bourdieu's (1989) work in The State Nobility where he argued that skill and status resources were forever intertwined. Musoba and Baez (2008) also argued that Bourdieu's view of cultural capital was grounded in the strategies used by the dominant group to maintain a social order in which they remained dominant. It was in these very processes that cultural capital was reproduced and was used as an oppressive tool.

Moreover, Apple (1995) claimed that while Bourdieu's cultural capital theory had its merits, it was missing an important element. That is, the school played a part in producing capital. However, in the preface of Bourdieu and Passeron (1990), Bourdieu clearly addressed the role of the school when he wrote, "Functioning in the manner of a huge classificatory machine which [inscribed] changes within the purview of the structure, the school [helped] to make and impose the legitimate exclusions and 
inclusions which form the basis of the social order" (p. x). In a different manner, Apple (1995) argued that "schools also act as one of the primary modes of production of the cultural commodities needed by a corporate society" (p. 42). He compared the corporate economy being efficient only when there was an appropriate level of unemployment to a school being efficient when the production of knowledge was maximized even with poor and minority students demonstrating low levels of achievement. So, "production of a particular 'commodity' (here high status knowledge) was of more concern than the distribution of that particular commodity" (p. 42). That is, the school was a cultural institution that "naturally" generated [deviance] and levels of poor achievement" (p. 43). Apple (1995) believed the school had three functions: (a) schools were mechanisms for distributing a hidden curriculum, (b) schools distributed people to their "proper" places outside of them, and (c) schools were integral parts in the mode of commodity production in a society.

Habitus, Cultural Capital, and Stratification. Harker, Mahar, and Wilkes (1990) examined Bourdieu's view on society's structure, which was seen as an element through which symbolic violence produced habitus - an individual's or a group's learned inclination to behave within the parameters of the imposed prevailing culture and norms. For example, schools embodied the habitus of the dominant group as the natural and expected disposition of all students and operate as if all children possessed the skills to retrieve and use it as necessary. Harker et al. (1990) explained that "[just] as our dominant economic institutions are structured to favour those who already possess economic capital, so our educational institutions are structured to favour those who already possess cultural capital, in the form of the habitus of the dominant cultural 
fraction" (p.87). Harker et al. (1990) continued to describe Bourdieu's five

nonmechanical levels at which schools reproduced economical, social, and political inequities:

Level 1: For under-privileged children there is a lower success rate expectations are adjusted accordingly, and become part of the habitus. Level 2: Where some success is attained, under-privileged children (and their families) tend to make the "wrong" option choices. These "wrong" choices are the unexpected choices for under-privileged children.

Level 3: Learned ignorance of schools and selection agents - recognizing only those who recognize them.

Level 4: Denigration of the academic - style over content.

Level 5: Devaluation of certificates - in favour of habitus, Where selection now turns on habitus (style, presentation, language, etc), these things then become a form of symbolic capital which acts as a multiplier of the productivity of educational capital (qualifications). (p. 89)

So at Level 1, under-privileged children were generally expected to perform lower than the majority on tests deemed to be measures of academic achievement. Then at Level 2, it was not expected for under-privileged children to choose advanced coursework.

Additionally, even for the under-privileged students who chose advance coursework, they still received limited recognition for their cognitive abilities. That is, at Level 3 , students who possessed the habitus of the dominant group were granted more habitus by teachers as they were recognized and advanced through the system thereby other students were ignored if they lacked the appropriate ways of operating. Level 4 addressed another layer at which social, economic, and political inequities were reproduced. Specifically, teachers who had the correct style who may have lacked content were more accepted than those who were ill-equipped with style and had substantial content. Finally, Level 5 pointed to finding other factors to reward since there were increased amounts of credentials on the market. That is, employers used other measures such as those gained 
from the habitus of the dominant group (style, presentation, dress, speech, ...) as preferred qualities when making hiring decisions.

The school embedded culture worked as a reproduction tool of ultimate benefit for the dominant group. Tracking students into low-level and high-level classes was a mechanism through which the dominant group maintained the social order and sought a differentiated curriculum for the benefit of their children. Oakes (1994) gave her readers a succinct history on tracking in schools where she identified the school's desire to foster workforce development and focus on the social, cognitive, and personal needs of its students. She reported on Lewis Terman's extreme view that minorities did not have the mental capacity for abstract thinking, but instead they were fit to be "efficient workers." While this may not be stated explicitly today in regard to minorities, taking a closer look at the practice of tracking revealed the separation of students based on race, social class, and cultural factors. Oakes (1994) indicated that "low-track students consistently have lower-quality opportunities to learn", the differences in curriculum and instruction to assorted groups "take the form of gross inequalities in access to knowledge, instructional resources, and well-qualified teachers", and the schools have a low regard for the abilities of low-track students and their success in school.

Track assignments were not only based upon cognitive and structural measures, but also on biased placement procedures which placed minority students in low tracks. For example, Farkas, Grobe, Sheehan, and Shuan (1990) investigated the "informal academic standards" used by teachers to remunerate students with generally accepted abilities, customs, and behaviors (p. 127). They found that teacher assessments of student work habits, a noncognitive judgement, highly influenced course grades. Additionally, 
the high SES parents pressured key personnel into placing their children into high-track courses even when their children had not met the criteria. Thus, the students with the most political clout were advantaged with the high-track curriculum that prepared them for college while the other students received an education that did not adequately prepare them for college or for work. Wells and Oakes (1996) described this push for separate and unequal classes as the dominant parents' demand for differentiation.

Consequences of Stratification. Societal stratification was a well-researched trend in connection to varying levels of human, social and cultural capital. Several studies have been conducted at the secondary level which gave insight on student course selections and the influence on these selections. From these studies, parental education (Useem, 1992a), parental involvement (Crosnoe and Houston, 2007; Useem, 1992b), instructional resources (Adelman, 2006; Useem, 1992a), student characteristics (Useem, 1992a, 1992b), and school practices (Auerbach, 2002; Gamoran, 1987; Oakes, 1994; Useem, 1992a, 1992b) all affected course selections which ultimately have had long-term consequences to include degree completion, high school dropouts, and college dropouts. Both students and their parents perceived that they had a choice in coursework and that they were choosing college bound courses; however, as these studies revealed, parental consultation, parental education levels, socioeconomic status, school placement polices especially in mathematics and science courses, and placement in the high or academic track curriculum, together stratified educational opportunities and limited the number of students bound for success in college. Hence, a closer look at mathematics course-taking patterns related to college degree completion was an absolute necessity. The relationship 
between course placement and race/ethnicity was also established, but merited further examination.

Minorities. According to the National Center for Education Statistics (NCES) Special Analysis 2008 report on community colleges, 59.9\% of the nation's community college students in the 2003-2004 academic year were White, 15.3\% Black, and 14.4\% Hispanic, and 5.3\% Asian. At 4-year colleges and universities, the percentages of White and Asian students were larger ( $70.2 \%$ and $5.9 \%$ respectively) while the percentages of Black and Hispanic students were smaller at the 4-year institutions (10.4\% Black and 8.9\% Hispanic). Using fall 2007 data from NCES, the student body demographics of the community college in this study were very different from the national demographics of community colleges in general. This institution was $29.5 \%$ White, $27.7 \%$ Black, $27.4 \%$ Hispanic, 3.7\% Asian, $0.3 \%$ American Indian or Alaskan Native, 4.3\% race-ethnicity unknown, and $7.1 \%$ non-resident alien.

Gender. Since women participate in higher education as much as men do, Ayalon (2003) emphasized that gender inequality was unlike the inequalities linked to socioeconomic status and the disadvantages of certain racial/ethnic groups. She cited the research of other scholars who claimed that the source of gender segregation was one's high school education. She argued that women were already at a disadvantage to major in "masculine" disciplines such as engineering and science (including mathematics) because they were not exposed to advance coursework in high school.

More specifically, Ayalon (2003) continued to assert the mere exposure to the advanced curriculum lent itself to reduced math anxiety in females; however, the data did not reveal this relationship. In fact, the exposure to advanced mathematics high school 
classes seemed related to increased applications to medicine and law schools by women. Destructive comments from teachers and counselors as well as the small number of female teachers in these disciplines also contributed to the low number of females who choose male-dominated fields of study. Female participation rates were reported by a gender coefficient. This gender coefficient was defined by the "ratio of the odds of women, compared to men, applying for a field of study, divided by the parallel odds of applying to humanities" (p. 282). Ayalon (2003) concluded that women tend to apply to selective non-mathematically oriented disciplines (medicine and law) when they surpassed the admission requirements. This contributed to the departure of some women from the feminine humanities field. Thus, a gender gap still remained in the mathematically oriented fields. She offered an explanation for the unexpected findings using Steele's (1997) "stereotype threat" phenomenon. She believed women fell prey to a stereotype threat as they exhibited a "perceived need for particularly high qualifications to apply for 'masculine' fields of study in general and for the mathematically oriented one in particular" (p. 281). Unfortunately, even in the fields (medicine and law) where it seemed great strides have been made, there was a substantial presence of women in the lower-paid public sector while men were more often found in the higher-paid private sector. Hence, gender inequality still existed in the disciplines where great progress had been documented.

\section{Limitations}

Since this was a retroactive quantitative study using data that had already been collected, certain measures that have been empirically shown to affect college persistence such as the level of parental education and student college aspirations was not captured. 
Also, the researcher lacked control of the independent variables, another consequence of conducting an ex post facto study. So, setting high participation rates for each high school was not possible.

\section{Delimitations}

The subjects of this study were students who were enrolled or have earned at least an Associate degree from a large urban Florida multicultural community college during the 2002 to 2008 academic years and who graduated from a high school in a specific Florida county for which electronic transcripts (high school and community college) were available. Since many of the academically stronger students have chosen to attend 4-year institutions, this study examined the path to degree for those students who for whatever reason chose to attend a community college.

\section{Definitions}

1. Persister Outcome: A student who earned at least a transfer Associate degree (AA), the occupational Associate degrees (AS or AAS) or was continuously enrolled in the study timeframe.

2. Race/ethnicity: Separated by Asian or Pacific Islander, Black (Not of Hispanic Origin), Hispanic, White (Not of Hispanic Origin), Non-Resident Alien, American Indian/Alaskan Native, Multiracial, Other (Not reported or unknown)

3. Gender: Male or female category

4. Immigration status: The student's citizenship categorized as a U.S. Citizen, Permanent Resident Alien, Non-resident Alien, or Unknown.

5. Student Socioeconomic status: A dichotomous variable used to determine a student's economic class based upon he/she being a needs-based financial aid recipient. 
6. High School Demographics: A measure determined by percent of enrolled racial/ethnic minorities at an institution in which the student earned secondary credit.

7. High School Socioeconomic Status: A measure that categorized high schools based upon percent of students on free and reduced lunch.

8. High School Breadth of Math Curriculum: A measure used to determine the number of students mathematics courses above Algebra 2 offered at each high school.

9. High School Exposure to Rigorous Math Curriculum: This variable measured the number of students enrolled in AP Calculus or AP Statistics.

10. Placement exam scores: These scores represented a student's level of being ready for college-level coursework.

11. Time to degree: The number of semesters it took for each student to complete an Associate degree as was applicable.

12. Entry: A measure that determined the number of years the student may have delayed entry into the community college.

13. First-year credits: The number of credits a student earned during his/her first year at the community college.

14. Remedial mathematics percentage: A percentage that represented the amount of remedial mathematics coursework out of all mathematics courses attempted, delineated by two levels.

15. Remedial English percentage: A percentage that represented the amount of remedial English coursework out of all English courses attempted, delineated by two levels.

16. Summer Enhancement: The number of summer credits earned at community college. 
17. Community College Math Proportion: The proportion of college-level mathematics classes taken measured by a ratio of completed to attempted courses at the community college.

\section{Summary}

In high schools, social structures were maintained as students were kept in their "proper" places via class stratification in mathematics and were generally unable to gain acceptance to a university. As a result, they turned to the open access community college where many of them have "cooled" aspirations and diverted their attention to workforce programs rather than university transfer programs. Moreover, as additional constraints were placed on community colleges to do more with less, the new cooling out process occurred as the doors of the open access institution began to close to students of low socioeconomic status and more middle class students were now in seats at the community college instead of the university. To reverse this trend, it was important to study student achievement as it related to the learning opportunities available to secondary students and the rigor of the courses they take. Hence, this study was critical to explore relationships that may exist between high school and college mathematics course-taking patterns and the realization of students earning at least an Associate degree. 


\section{CHAPTER II}

\section{REVIEW OF LITERATURE}

Research on persistence in higher education has been combined into four categories (Cabrera, Castaneda, Nora and Hengstler, 1992; Pascarella, Pierson, Wolniak, and Terenzini, 2004): (a) student demographic or precollege characteristics, (b) organizational or structural characteristics of institution attended, (c) students'academic experiences, and (d) students' nonacademic experiences. This study addressed student demographics, precollege characteristics, and students' academic experiences as measured by course selection and outcomes. Because this was a single institution study, institutional characteristics were constant across the sample of students. The focus of the study was academic rather than nonacademic. Therefore the prior literature reviewed was limited to those relevant academic experience studies.

\section{College Persistence}

Numerous studies on college persistence or intent to persist have been conducted to yield concrete evidence of what paths students were taking in higher education, be it entering college late, leaving, returning, or earning a degree. Persistence was defined in varied ways, but the umbrella definition essentially was continued enrollment through degree completion. Persistence has been defined as first semester to second semester or within-year enrollment (Cofer, 2001), to second year enrollment (Herzog, 2005), to degree completion (Astin, 1975; Adelman, 1999). Several variables were studied to capture this picture. These included precollege traits (background, family, gender, age, marital status, race/ethnicity, academic ability often measured through admissions test scores, socioeconomic status, students' secondary grades, degree aspirations, education 
anticipation, academic preparation), institutional characteristics (mainly 2-year vs. 4-year college attendance, college choice, college costs, selectivity), academic engagement (first-year seminars, remedial coursework, course attempts), social integration (enrollment status, summer enrollment, institutional commitment, and attendance at multiple institutions better known as 'swirling'), academic success (college grade point average), and financial aid or ability to pay. A common theme amongst several studies was that high school preparation weighed significantly on persistence in college (Adelman, 2006; Astin, 1975; Dowd and Coury, 2006; House, 2000; Pascarella et al., 2004; Terenzini et al., 2001). Other scholars explored the impact of financial aid, tuition, or financial hardships (Astin, 1975; Cabrera, 1993; Cofer and Somers, 2001; Dowd and Coury, 2006; Hu and St. John, 1988; Terenzini et al., 2001; Titus, 2006).

\section{Precollege Stratification}

\section{Aspirations versus Expectations}

Initially, scholars examined student aspirations and found links to increased persistence at the college level (Astin, 1975; Cofer and Somers, 2001; Terenzini, Cabrera and Bernal, 2001). However, researchers also looked at student expectations about finishing college (Adelman, 2006; Ingels, Planty, and Bozick, 2005). Cofer and Somers (2001) attempted to determine the impact of student goals as measured by desired degree level (college degree versus advanced degree) on within-year persistence at 2-year colleges as related to financial aid. Using the National Postsecondary Student Aid Surveys of 1992-93 (NPSAS:93) and NPSAS:96 databases and removing students at graduate and 4-year institutions along with those with missing loan amounts, Cofer and Somers (2001) narrowed their samples to $n=5006$ and $n=7505$ from the NPSAS:93 and 
the NPSAS:96, respectively. On student goal and achievement variables, desired degree level (college degree versus advanced degree) and SAT/ACT scores (high and low) were examined. Since the dependent variable had two outcomes, within-year (fall to spring) student persistence or lack thereof, logistic regression analysis was used in determining the effect of aspirations on within-year student persistence. Delta $p$ statistics were used to report the rate of change in probability of persistence. They found that students who desired an advanced college degree were 10.1 and 9.25 percentage points more likely to persist than those who desired lower degrees in the 1993 and 1996 samples, respectively.

In another study to determine what precollege and college aspects influence bachelor's degree attainment, Adelman (2006) compared the availability of bachelor's degree attainment data from three national sources: the National Education Longitudinal Study (NELS:88/2000) (1992-2000), the Cooperative Institutional Research Program (CIRP) (1994-2000), and Beginning Postsecondary Students (BPS 95/96-2001). He concluded that using the NELS:88/2000 data source was best since every bachelor degree completion mode had available data and the degree completion approached $70 \%$, higher than the $60.6 \%$ of the CIRP data and the $61.8 \%$ of the BPS data. Starting with a "universe" of 2.93 million eighth-graders, Adelman (2006) investigated 1.19 million students who: (a) were high school seniors in 1992, (b) attended a postsecondary institution by December 2000, (c) had complete transcripts (high school and postsecondary), test scores, and socioeconomic status data, and (d) attended a 4-year college at any point. The reader should note a common practice of weighting samples in NCES studies occurred in this study. Thus, Adelman states he is analyzing a "universe" of 2.93 million eight-graders when in fact there were at most 5800 students involved in 
the study. The NELS:88/2000 survey of a national sampling of eighth-graders was conducted in the spring of 1988 with four follow-up surveys in the years 1990, 1992, 1994, and 2000. Students were asked to give self reports on their educational and career aspirations, their experiences at home, school, and work, their access to educational materials and support; the influence of their parents and peers on their education; their neighborhood qualities; and other student opinions. While in middle and high school, the students were tested in major subject areas including mathematics. With low high school graduation rates, this "universe" excluded a significant portion of students who never reached $12^{\text {th }}$ grade, but may have earned a GED. Additionally, only looking at students who attended 4-year institutions at any time completely neglects a sizeable group of community college students. Furthermore, low SES students were more than likely in this excluded group. Adelman (2006) wrote that the universe:

constitutes roughly half who reach the 12 th grade ... It does not include students who failed to graduate from high school, those who earned General Education Diplomas (GEDs), those who had not enrolled in any postsecondary institution by the age of 26, and those who entered the postsecondary system but never attended a bachelor's degree-granting institution. (p. xvi)

Adelman (2006) acknowledged that his analysis in The Toolbox Revisited as compared to his Answers in the Toolbox (1999) made more sense as it began where the student's path commenced from high school to postsecondary education - he deemed it a more cumulative assessment. In a seven-step logistic regression analysis, Adelman (2006) evaluated student propensity to bachelor degree attainment based upon their backgrounds, entry (education obtained before entering postsecondary institutions, delayed entry, and selectivity of institution), type and amount of credits earned during their first year of postsecondary schooling, financing (work study), attendance patterns (community college and 4-year to 4-year transfers, summer enrollment, part-time enrollment, multiple school 
enrollment), extended performance (accumulation of college mathematics credits and type and extent of remedial problems), and final factors (continuous enrollment and ratio of withdrawals and repeats to all courses taken).

Beginning with student anticipations versus aspirations, Adelman (2006) argued that an answer to one aspiration question in eighth grade did not capture a student's anticipation. Different from other studies, he used answers to a series of questions throughout the tenth through twelfth grades to gauge student educational expectations - a time period closer to attending college and during high school academic experiences. No statistical significance was ever found to be associated with the anticipations variable throughout the seven-step logistic regression analysis.

In regard to earning their high school diplomas, Adelman (2006) reported that students had a false sense of momentum when they made the assumption that the diploma was a symbol of them having the necessary prerequisite knowledge to be successful in college. Citing Conley (2005), he argued that the main problem stems from poor articulation in curriculum from secondary to postsecondary levels. He asserted that the exposure to advanced coursework in the high school curriculum versus the number of courses taken was the key to building a strong impetus towards bachelor's degree completion. Gamoran (1987) came to this same conclusion, but specifically found that advanced mathematics and science significantly influenced student achievement. National studies have captured the content of high school coursework as defined by state departments of education; however, they cannot yield a true perspective as to what has been taught in an Algebra II classroom in Florida versus another state or between two schools in a local school district. An analysis of the number of courses taken using the 
HS\&B/So (High School Class of 1982) and the NELS:88/200 (High School Class of 1992) revealed that an increase in the number of mathematics courses led to better preparation for college and less remedial coursework in a 4-year college. Adelman (2006) cautioned the reader that this finding cannot be generalized to community college students as his study showed that $64.5 \%$ of the students that only attended community college needed at least one remedial class and $43.7 \%$ took more than one remedial class. In aggregate, his study showed greater success with greater mathematics coursework; yet beneath the surface a more nuanced picture appeared for community college students. In part, this may have occurred because Adelman structured his study to exclude all the students who did not anticipate going to college and those who internalized their school's message that they were not college material. A recent 2008 bill passed by the Florida legislature, Senate Bill 1908, addressed reducing postsecondary remediation in the Florida College System. Although the motivation behind passing this bill seemed to be linked to a budgetary crisis, it acknowledged that the K-12 education leaders in conjunction with their local community college must take responsibility for the college bound preparation for all students who showed an interest in attending college. Moreover, upon entry to the community college, students learned quickly that they should have been serious about preparing for college including taking more rigorous, college-bound coursework.

\section{Influences on Mathematics Achievement}

Reyes and Stanic (1988) reviewed the effects of race, sex, and socioeconomic status on mathematics achievement. Citing Michael Apple (1979), a critical sociologist, Reyes and Stanic (1988) discussed Apple's hidden curriculum which identified the 
education particular student groups would have received - some received lessons focused on problem solving while others received lessons requiring repetition and drill exercises. The upper social class were also able to "[exercise] authority" while the lower class students were trained to be "followers" (p. 28). The authors posited that this can have long-term psychological impact on the choices each group makes in regard to the seriousness of their high school studies, course selection, college versus work decisions, and more. Furthermore, Reyes and Stanic (1988) specifically warned mathematics educators about the roles they play in believing in or rejecting the disparate treatment of these two groups. They discussed the 'norm' in public schools citing the works of Bowles and Gintis (1976), Ginsburg and Russell (1981), Matthews, Carpenter, Lindquist, and Silver (1984), Willis (1977), and Yando et al. (1979). They reported on Bowles and Gintis' (1976) view that "schools mirror society" and the social inequities. Consequently, this study investigated what occurred within schools and how one's course of life was affected.

Clifford Adelman heeded this call by assessing high school learning outcomes. Adelman (2006) created a multipart variable, Academic Resources, which consisted of the strength of a high school student's curriculum, a student's class rank and grade point average, and student performance on a 90-minute assessment "best described as a mini, enhanced SAT" (p. xxii). Use of this variable separated Adelman's (2006) study from others in that the variable was not solely dependent upon high school evaluations and coursework. It also had an "external assessment" (p. 41). From its introduction into the logistic regression model, the Academic Resources variable remained statistically significant throughout the analysis although its contribution to increasing the chance of 
persistence to bachelor degree attainment declined from about $15 \%$ to $6 \%$ the closer the students were to earning the bachelor degree. However, the Academic Resources had the strongest influence on persistence to bachelor degree attainment in the first two steps of the logistic regression analysis. That is, in looking at a student's background, the Academic Resources variable was linked to a $15 \%$ increase in his/her chances of earning a bachelor degree. This chance decreased to about $13 \%$ when other entry variables were considered in the second step of the investigation - a pattern Adelman (2006) described as "a natural consequence of the introduction of other competing curricular and gradebased variables" (p. 49). However, using the HS\&B national data set, DesJardins, McCall, Ahlburg and Moye (2002) found that after controlling for performance in college, the influence of Adelman's (1999) Academic Resources index on bachelor degree attainment declined and passed its effects on completing the bachelor's degree through a student's grade point average.

Throughout the seven-step logistic regression analysis, the impact of socioeconomic status (SES) as an independent variable predicting persistence to earn the bachelor degree remained statistically significant and the probability of increasing this persistence stayed around 6\%. Adelman (2006) argued that

the most promising engine of momentum for [low socioeconomic] students is a strengthened high school curricular background, and achieving that objective requires greater attention to the provision of curriculum and the quality of learning environments in schools attended by these students, no matter where those schools are located. (p. 96)

However, low socioeconomic status may have been proven to have a stronger influence on degree attainment for community college students. Per a 2006 ACSFA policy brief, Adelman's Toolbox (2006) was missing the SES lens. That is, high SES students move 
through the educational pipeline at a rate that is at least ten times that of low SES students. Hence, the need remained for a study on the effects of low socioeconomic status on community college students and Associate degree attainment.

In sum, Adelman's 2006 study unveiled several conclusions that were recommended for students to gain the necessary momentum to complete a Bachelor's degree. Students should:

a) complete mathematics beyond Algebra II in high school,

b) enroll in college immediately, preferably at a 4-year institution, and complete 20 credit hours including at least one college-level mathematics course during the first year,

c) earn summer credits ( a statistically significant factor linked to degree completion for African-American and White students, but not for Asian or Latino students),

d) keep withdrawal and repeated courses to a minimum as it would extend their time to degree completion, and

e) sustain continuous enrollment missing at most one semester.

While Adelman (2006) addressed many important issues that were primarily relevant to a 4-year college student, he acknowledged that his sample excluded "the other half" (p.

14). That is, the excluded group of students was significant in size and demographically different. Adelman (2006) described the excluded group as having the following characteristics:

a) A higher proportion of minority students than white students;

b) A higher proportion of students who were 20 years old or older in 1992 than 
those who were less than 20 years old;

c) A higher proportion of students from the lowest third of family income distribution than those from higher income levels;

d) A higher proportion of first-generation students than those whose parents had either some college or who had earned at least a bachelor's degree;

e) A higher proportion of nonnative speakers of English than those from English monolingual backgrounds;

f) A higher proportion of those with three or more siblings than those who were either only children or had one or two siblings;

g) A higher proportion of those who became parents by age 20 than those who did not;

h) A higher proportion of those who had been retained in grade at least once than those who were never held back;

i) A higher proportion of those who came from high schools in urban areas than those from suburban or rural areas. (Appendix E, p. 146.)

The community college in this study can be described with many of the above categories and from a social justice and equity standpoint these were precisely the students who should have been studied. This study was necessary to see if Adelman's findings hold true for students who primarily attended an urban community college with a diverse student body.

Similarly, Ingels, Planty, and Bozick (2005) analyzed another national data set, the American High School Senior Class of 2004 in a follow-up study on the ELS:2000 national data set. They defined five mastery levels of mathematics: 
Level 1: Simple operations - whole numbers often associated with prealgebra.

Level 2: Simple operations - decimals, fractions, roots, and powers often associated Algebra I.

Level 3: Simple problem solving often associated with Algebra I.

Level 4: Understanding of intermediate-level concepts often associated with Algebra 2.

Level 5: Complex problem solving, advanced knowledge often associated with precalculus and above. (p. 5)

Within the students who expected to earn a 4-year degree, $63 \%$ did not demonstrate level 4 mastery of mathematics. For those who planned to attend 4 -year institutions, $24 \%$ did not demonstrate level 3 mastery of mathematics. This number increased to $56 \%$ for students that planned to attend a community college. Lower aspirations seem to be linked to low levels of mathematics achievement.

Such trends in the twenty-first century should have prompted a movement for fundamental change across the American education system to include communication across secondary and postsecondary systems. As such, scholars called for educational leaders to take a closer look at the high school curriculum offerings and fill gaps and create better alignment (Adelman, 2006; Ingels, Planty, and Bozick, 2005; Terenzini, Cabrera, and Bernal, 2001). Terenzini et al. (2001) called upon private and public entities to inform parents about programs such as TRIO, but stressed that this was not sufficient. They believed college or university faculty members teaching the course needed at the high school or offering dual enrollment programs for students who have exhausted the curriculum at the high school may have produced significant strides in 
student persistence in higher education institutions. However, careful attention was necessary to ensure that students have increased access to the college-bound curriculum including accelerated programs such as dual enrollment which offers an increased chance to persist while in college. However, the availability of dual enrollment courses also became a roadblock that led some school systems to develop virtual course offerings. That is, a student could have taken a course that was not available at his/her school online, eliminating geographic hurdles. The effects of these implementations need to be examined. Consequently, all of these factors have been shown to weigh on student aspirations, beliefs, and self-efficacy especially for first-generation students. However, because of inadequate secondary mathematics skills, many students still lacked the requisite momentum needed for college persistence as Adelman (2006) described.

Minorities' Educational Expectations on Postsecondary Outcomes. Students' early educational aspirations and expectations also played a role in college attainment. Looking at the high school class of 2004, Ingels, Planty, and Bozick (2005) reported that $86.2 \%$ of Blacks and $80.1 \%$ of Hispanics in their study expected to complete some college, a 4-year degree or graduate school compared to $88.3 \%$ of Whites and $90.7 \%$ of Asians. Interestingly enough, only $67.4 \%$ of Blacks and $57 \%$ of Hispanics in their study expected to complete a 4-year degree or graduate school compared to $71 \%$ of Whites and $80.3 \%$ of Asians. However, this study did not consider community college degree attainment. Similarly, Venezia, Kirst, and Antonio (2003), researchers for The Stanford Bridge Project, reported that in general $88 \%$ of eight-graders in six states (California, Georgia, Illinois, Maryland, Oregon, and Texas) expected to attend some postsecondary institution while over $80 \%$ of African American and Latino students in each of the states 
within the study planned to attend a postsecondary institution. So, while the majority of the students expected to attend college, a smaller fraction actually expected to complete a postsecondary degree. So although Venezia, Kirst, and Antonio (2003) addressed community college degree completion, it only focused on the course-taking patterns (remedial reading, remedial mathematics, and no remedial courses) at the community college. Clearly, aspirations and expectations, while slightly different between racial/ethnic groups, did not explain the larger differences in actual attainment. So, it is important to determine how the high school curriculum influenced the enrollment rates.

\section{High School Course Selection}

Since differences in tangible assets have been well-researched and documented as contributors to unequal outcomes in one's life course, Crosnoe and Huston (2007) conducted a very detailed study on the stratification in American society and its impact on the life trajectories of American citizens. These authors sought to qualitatively assess the effects of personal control and parental consultation upon mathematics and science course selection from the eighth grade to the end of high school and explored differences across socioeconomic levels. Personal control referred to the degree to which an adolescent used resources to make informed and independent decisions particularly about mathematics/science courses. Parental consultation referred to the degree to which an adolescent sought guidance from parents in mapping out their current and future goals and activities. Crosnoe and Huston (2007) defined the combination of personal traits and social supports which enabled students to achieve their goals in high school as an adaptive pathway while they defined the maladaptive pathway as the path of students who missed the mark. In reviewing the maladaptive versus adaptive combined pathways, 
the data revealed that students who exhibited high levels of personal control may not have obtained help from parents which ultimately impacted course selection. Moreover, students with high levels of parental consultation may have remained dependent upon parents and delayed their autonomy. Crosnoe and Huston (2007) argued that this latter outcome "[interrupted] intrinsic motivation of those adolescents to achieve" (p. 1106). In the last phase of their study, the authors hypothesized that "moderate, increasing pathways of personal control" along with "high, stable pathways of parental consultation" would have been less regular in lower socioeconomic levels. They also predicted that personal control, parental consultation, and the adaptive pathways combinations of them both would have contributed to forecasting credit growth in the lower socioeconomic levels in better fashion. Contradictory to their beliefs, correlations between each pathway and credit accumulation were absent in the lowest SES quartile. However, their hypothesis was confirmed in the highest SES quartile. In fact, the higher SES parents cultivated goal-setting students who learned how to navigate the system while the lower SES parents were not working to "empower" their children to make strategic choices at school. Bourdieu would have argued that placing the blame on the lower SES parents was a disguise which covered the fact that schools did not bring awareness to the parents that their students' placements would have further limited their educational opportunities especially their chances to earn postsecondary credentials. Although acknowledged, the authors' lack of specific consideration in the research to the ways in which schools structured opportunity was a substantial limitation. Interestingly enough, the authors noted that success was "decoupled from ability" which suggested other factors were influencing the outcome (p.1107). They also suggested that these findings should alert 
researchers to focus on the middle SES quartiles to achieve greater impact. Several admissions were made by the authors in regard to missing components of the study such as the role of the school and its impact on students' course selections as well as internal and external studies of schools and these connections to the student's adjustments in course selection, parental consultation, and credit accumulation. While this study addressed the impact of SES on course selections, it did not reveal the course selections of minority or low-income students. This dissertation research reviewed the coursetaking patterns of minorities at a high schools based upon the unique environments and practices within each school.

Tracking. In balance to their analysis, Useem (1992b) focused on parental involvement and institutional behavior, but specifically in mathematics placement. She also discussed the direct impact of track placement and course-taking on the academic achievement of students in middle and secondary schools. She cited several advantages in being placed in the "fast track" (high track) in seventh grade. These included exposure to more mathematics despite achievement level, a challenging high school curriculum, higher standardized test scores, advantages for calculus students in the college admission process, and higher pass rates for college calculus courses which were classified as 'gateway' courses. Useem's (1992b) study revealed that parents of low-track students were less educated, were generally not aware of intervention methods that they can employ to 'override' the placement of their children in remedial courses and were not aware of their children's' low-track status and the consequences. Low income parents had tendencies to leave the decision-making up to the school personnel and their children versus the parents, with a higher score on the parental education index, who actively 
intervened to override school choices to place their children in higher level mathematics classes. While the amount of education a parent had affected the mathematics placement, Useem (1992b) acknowledged that highly restrictive mathematics sequences and broad criteria for placement in the higher level mathematics courses also affected the mathematics careers of students dependent upon when and how strict these policies were implemented. In fact, in another study in the same year, Useem (1992a) described the school's placement policies as a "forced deceleration" for seventh and eighth "regular" mathematics students as the "regular" mathematics course was basically a repeat of elementary school mathematics.

Useem (1992a, 1992b) called upon the schools to ensure an institutionalized, regular, pervasive communication about a child's placement and about the consequences of parents, student, or school personnel who were not paying deliberate attention to the educational trajectories that would maximize the learning opportunities for each student. As Useem (1992a, 1992b) and Crosnoe and Houston (2007) recognized the important role that the school played in the upward mobility of its students, Gamoran (1987) researched the effects of schools and found that schools with wealthier students tend to offer more academic programs of study in which college-bound students had more access to advanced curricula. He also looked at the effects of schooling and found that students had the greatest advantage in mathematics achievement within the academic track in a school. In fact, he found that stratification had the most profound effect especially in mathematics and science. Contrary to the study conducted by Burris, Heubert, and Levin (2006) in which students at all levels benefited significantly from detracking, Gamoran (1987) found that low-achieving students have a smaller, but 
improved, chance of gaining from more coursework. His study addressed the number of mathematics and science courses taken in addition to the number of advanced mathematics and science courses taken. Gamoran (1987) found that the advanced levels of mathematics and science coursework have significant effects on improved achievement more than the amount of coursework. Also, high school sophomores stood a better chance of closing the "coursework gap" than students who just began advanced coursework in their senior year. However, for low-achieving students, there were different results in some cases due to the smaller sample size. This study was conducted to determine if there were distinguished relationships between the type of high school as measured by demographics and the mathematics course exposure in predicting persistence at the community college.

Detracking. While there have been several studies on tracking and its negative effects on student academic performance, life trajectories, and other "non-cognitive aspects", Watanabe (2007) sought to determine teachers' perspectives on tracking in response to the charge given by Oakes, Wells, Jones, and Datnow (1997) to reveal teachers' subconscious ideas about student aptitude and intellect (p. 2138). The noncognitive characteristics included "student placement practices..., student aspirations, self-esteem, attendance, [and] discipline and school retention rates" (p. 2138). There has also been research on detracking reform which exposed the resistance from teachers, students, and class privileged, educated parents. With the support of a University of California Office of the President grant, 6 of 47 teachers were given a \$2500 stipend to participate in the yearlong study. There was no random selection of participants. Basically, any teacher who responded to a solicitation email that was sent to the 47 
teachers by a fellow teacher was allowed in the inquiry group once he/she was able to commit time to meet throughout the school year. The inquiry group makeup reflected the teacher demographics of their school, mostly White, and from "middle- to upper-middleclass backgrounds" (p. 2141). Watanabe (2007) arranged for eleven meetings from which the teachers earned professional development and was careful to meet at the school since Darling-Hammond (1998) suggested it would increase the chance of having thought-provoking and hopefully perspective-changing discussions using their reflections on current practices versus having a one-day workshop. Using the suggested framework from Oakes (1992), the technical (curriculum and pedagogy), normative (perceptions of ability, student choice, and the role of schooling), and political dimensions (teacher, school, and parent relationships) of detracking were discussed. The study site, Meredith High School, was a majority minority college-preparatory school with efforts to implement a detracked curriculum with higher graduation requirements than the school district. In order to graduate, Meredith High School students had to complete four instead of the three years of mathematics, four instead of two years of science, and three instead of two years of a foreign language. The teacher participants were required to review current research on tracking and reflect upon their beliefs about what makes a tracked school. Interestingly enough, the school's mission statement seemed to support the notion of detracking even though it is not overtly mentioned. Although the school community supported the mission that everyone can learn despite their prior experiences, a "vertical curriculum differentiation" plan was being discussed for the mathematics courses since some persons believed not everyone could do well in one level of 
mathematics. This was obvious tracking as was pointed out by a student to a principal as he announced the plan.

Watanabe (2007) identified seven factors which influenced course selection: the master course schedule, teacher sanctions, student and parent inclination, prior academic achievement, pre-assessments, prior coursework, and the main concerns of the staff involved. Using three case studies which spanned the views of all participants, Watanabe (2007) sought to build theory in this qualitative study and cautiously warned that the results may not be generalizable. One teacher believed that the school was not tracked since students had a choice as to what courses to take except in mathematics. Another teacher believed the school was indeed tracked based upon the uniform demographics and abilities in her classroom. This teacher further emphasized that a limited variety of course levels and the course schedule restricted student choices. A third teacher held the view that the school had varying degrees of tracking. This teacher believed students' self perceptions, relationships with teachers, and course performance requirements (summer work, test scores, midterm grade) affected their ultimate placements.

Unfortunately, a clear definition of tracking was not identified by the focus group; however, the study did add a construct that was not included in the different explanations of Oakes (1985) and Lucas (1999) - student choice in course selection. Watanabe (2007) concluded that "heterogeneity in student racial/ethnic backgrounds and skill level come to signal detracking for teachers like Samantha and Roxie while these characteristics do not appear as central to definitions of tracking for academic researchers such as Oakes and Lucas" (p. 2157). However, a mixed race classroom does not necessarily mean it is not tracked as the students may fall along the same social class lines. Watanabe (2007) 
suggested that more structured inquiry group sessions were needed for teachers and researchers to "unpack their definitions of tracking", that more attention should be given to researching the realities behind student choice in selecting courses, and that teachers should review professional community literature to gather tools on how to reach an agreement while engaging in conflict. Watanabe's 2007 study demonstrated that student choice was an illusion since many could have selected lower-level courses without contention versus needing permission and facing discouragement to take higher-level courses. Hence, this study evaluated course-taking patterns of high school students and their influence on community college outcomes as it relates to poor and minority students. In another detracking effort to improve learning outcomes for all students, Burris, Heubert, and Levin (2006) conducted a six-year quasi-experimental time series study to measure the impact of detracking - offering one curriculum to all students using heterogeneous grouping with middle school mathematics students. With the encouragement of a national 'standards' movement, inconsistent findings in detracking studies, and international studies that revealed that tracking suppressed the mathematics abilities of American students, Burris, Heubert, and Levin (2006) were motivated to: (a) determine if more students took advanced mathematics courses as a result of the universal acceleration curriculum, (b) ascertain the impact of the heterogeneous grouping on the high-achieving students post-implementation, (c) measure the long-term effects of the program, and (d) review the course-taking patterns of the high achieving students before and after the program was implemented. In their majority white high school with about 1100 students, only 2\% were Asian, 8\% African-American, and 12\% Latino. Over the six years, about $13 \%$ of the high school students qualified for free or reduced lunch 
prices. Of these students, more than $98 \%$ were students of color. Two 3-year cohorts (pre-treatment: 1995, 1996, 1997 and post-treatment: 1998, 1999, 2000) were followed as a result of New York state implementing a universal curriculum (Sequential Math I, II, III), in the 1980s, from which all students were required to partake of an algebra-based course by the eighth grade, reducing the time spent in basic mathematics courses from three to two years. The state created a test for each level to measure each student's mathematics achievement. Also, the New York's Board of Regents gradually moved from districts annually deciding which 50 strong math students would be privileged to take accelerated mathematics classes to requiring all students to enroll in Sequential Math I in the eighth grade since the minority student participation rates were still relatively low (11\% African-American and 15\% Latino). The first universal acceleration cohort entered grade eight in 1997.

Since the study did not use random assignment of students to their heterogeneous groups and since student enrollments change, the researchers recognized there could be "selection effects" even with a pretty stable environment in which there was little teacher or administrative staff turnover, little change in teaching assignments and no change in textbooks (p. 113). Consequently, only students in the regular education program who were continuously enrolled from fifth to $12^{\text {th }}$ grade with complete records were included (477 pre-treatment and 508 post-treatment). Complete records were required to include fifth-grade stanine scores, initial score on the Sequential Math I exam, AP Calculus exam score (if taken), grades 8-12 mathematics courses, ninth grade academic year to measure time of entry before universal acceleration was implemented, ethnicity, and socioeconomic status (measured by whether or not the student receives free or reduced 
lunch prices). As a result, transfer and special education students were not included in the study.

The Sequential Math I exam was administered in January, June, and August from 1998 to 2002 . Students needed a $65 \%$ to pass and $85 \%$ to pass with a mastery level. Students were able to retake the exam to improve scores even if they had already passed the exam. This may have had an impact on the final results of the study. Did the students learn the test or did they learn the mathematics?

To address the first research question, Burris, Heubert, and Levin (2006) tried to determine if the percentage of students taking advance mathematics courses in the second three-year cohort was higher than the percentage of students taking advance mathematics courses in the first three-year cohort at the initial low achiever, initial average achiever, initial high achiever, ethnicity, and low-SES levels. Not only did the data reflect an increased proportion of students taking advanced mathematics classes, but the data also showed a decreased proportion of students avoiding mathematics courses or taking courses beneath grade levels. Burris, Heubert, and Levin (2006) used regression analysis to determine the impact of universal acceleration on the high achievement students. Looking at student performance on the Sequential Mathematics I Regents exam and on the Advanced Placement Calculus exam, there were no significant differences between the pre- and post-acceleration groups. In fact, the AP exam scores increased by "one third of a point on a 5-point scale" (p. 127). Therefore, the formerly privileged students did not suffer academically by the change. Further, the formerly average and lowachieving students strongly benefited. Using binary logistic regression, the authors were able to assess the contribution of covariates to the chance that certain students would 
complete advanced mathematics courses. Among the several results that were obtained, post-acceleration students were almost three times as likely to pass a course in precalculus and twice as likely to pass AP Calculus. To be sure the results can be attributed to the implementation of the universal acceleration, comparisons with six analogous schools were made using New York State Education data. Examining the average grade enrollment passing rate for each school, the data revealed a remarkable increase (69\% to $96 \%$ ) for the study site versus a decline in the passing rate for the other schools collectively ( $57 \%$ to $54 \%)$.

Overall, Burris, Heubert, and Levin (2006) demonstrated the possibilities of detracking. These positive results provided evidence for researchers, educators, and policymakers to challenge common notions of high achieving students suffering from detracking as well as low achieving students needing to master basics before taking an algebra-based course. Their study offered public school systems evidence that successful college-bound academic achievement was possible across all groups of students (including poor students and minority students) despite their initial achievement levels.

\section{Navigating the System as a Minority}

Auerbach (2002) conducted a longitudinal qualitative study focusing on the voices of Latino parents and their actions in supporting positive academic college-bound experiences for their children in response to bureaucratic schooling at "Pacific High" (fictitious name) in Los Angeles. Pacific High, known for its excellent college preparatory curriculum, was a "large, racially and socioeconomically diverse high school" with the following makeup: Asian American (8\%), Black (12\%), Latino (34\%), and White (46\%). There were several methods of data collection which included detailed 
semi-structured parent interviews in English or Spanish during the students' sophomore to senior years, monthly Futures \& Families meetings on college access issues, and field notes that covered three years of the researcher's observations of family-school relations. Once the data were collected, the narratives were combed for themes that surfaced and categories were formed. Additional patterns and "irregularities in the data" were found through the use of "case summaries, data displays, and narrative analysis" (p. 1375). All interviews were recorded and transcribed word for word in English or Spanish. While there was no mention of any obstacles in collecting data, Auerbach (2002) believed the length of the study (three years), detailed accounts from parents and students, other data collection methods used for triangulation, "colleague checks, member checks, and analytical memos to monitor researcher subjectivity" helped to increase the trustworthiness and credibility of the study.

From the parent narratives, three story categories emerged: cautionary tale, story of rebuff, and counterstory. While 16 "working-class Latino and Black parents of Futures students who had no 4-year college experience" parents were involved in the "larger" study, the stories of four parents were discussed in the article (p. 1374). One description of the 16 parent narratives was given alluding to their general relevance to the emerging theme. However, Auerbach (2002) indicated that, for purposes of this particular article, she searched all of her qualitative data for parent narratives that contained occasions that involved a "social actor, an action, and a goal or predicament that [were] told to convey a moral or conviction" (p. 1374). Parent selection was based upon educational accomplishments, fluency in the English language, student GPA, gender, and minority status in terms of race and ethnicity. Auerbach (2002) was careful 
to note that the sample was not representative of the Futures parents, minority parents at Pacific High, or blue-collar minority parents on the whole and that generalizations to the population was not a goal of the study. Instead, her main goal was to develop a theory on family-school relations in the minority families.

The cautionary tale category described parents" desires to "push" their children to do the work that is necessary to excel in school such as doing homework before going outside to play and making decisions which may contradict prior family practices so as to avoid what seems to be the predetermined fate of Latino children. The featured parent described how she did not get the "extra push" from her parents and established a resolve to raise her children as the families with "big homes" did (p. 1377). Auerbach (2002) warned that the cautionary tale was ineffective when it was only a warning and that it included encouraging mechanisms such as "strong family reading habits, to contribute to student success" (p. 1378).

The stories of rebuff category captured a continual concern of parents - their disappointment in relations with school personnel, particularly guidance counselors. A parent's account of a counselor ignoring phone calls and the counselor's resistance to placing her daughter in a college-prep biology class was given. Auerbach (2002) described this story as one of many “power struggles over students' educational fates that are especially threatening - and alarmingly commonplace - for families of color" ( $\mathrm{p}$. 1381). Auerbach cited Lamont and Lareau (1988) who described these experiences as “'moments of social exclusion' in which perceived differences in cultural capital are used to deny access to educational opportunity" (p. 1381). As a result of this narrative at the family meetings, other parents were able to recount similar experiences they perceived to 
be demeaning and gained an awareness of the social order within their children's schools "even in routine matters, such as buying discount lunch tickets or changing students' class schedules" (p. 1381). That is, as a collective group, parents became aware that the bureaucracy of school served to maintain a greater social structure as scholars posited (Apple, 1995; Bourdieu, 1990).

Lastly, the counterstory section encapsulated the struggles of parents seeking an equal opportunity for their children to have access to a college-bound education as well as the enlightenment of some parents that the structure of this school's system in academic placement was in many ways unjust. Parents strived to make certain their students attended Pacific High either by special permission or by use of a false home address because of its strong college-prep curriculum, yet were stifled by the school systems. Even amidst the principal's campaign to eradicate the "two-schools" within the school, the parents "learned that resources were unequally distributed within the school and that participation in a so-called college-prep curriculum did not guarantee eligibility for university" (p. 1382). Auerbach (2002) concluded that the family meetings created a neutral space where the Latino parents' voices were heard and collectively empowered these parents to "[build] and [strengthen] social networks, [negotiate] conflict with the school, and [imagine] new family roles and identities (pp.1386-7). The following recommendations were made for policymaker and educators:

1. learn about the families within a school,

2. create neutral grounds where parents can communicate, gain negotiating skills, and reflect on school experiences with others including parents and receptive educators, 
3. revamp high school counseling departments to focus on knowing individual students and guiding the college pathways of all students while being inclusive of parents in the decision-making processes, and

4. expect and work to reduce conflict between families of color and schools while recognizing the value of conflict.

While Auerbach (2002) gave a qualitative view of the experiences of minorities, the current study used quantitative methods to shed light on the course selections of a huge minority population in Florida and how these course selections affected their persistence at the community college.

\section{Misaligned Systems}

According to Venezia, Kirst, and Antonio (2003) and Haycock, Barth, Mitchell, and Wilkins (1999) Thinking K16 Ticket to Nowhere report, the disconnect between K-12 and postsecondary education was a contributing factor to high attrition rates especially for students of color. They cited different curriculum expectations of the two systems, different assessment types, different learning outcomes on these assessments, and unequal college preparatory opportunities as prevalent features of what was occurring in the vacuum between high school matriculation and college admission. Venezia, Kirst, and Antonio (2003) pointed out that the high school diploma was more important as a credential for work as opposed to being used for college entry. They also found that there were significant gaps in what students perceived about college expectations and that these gaps fell along which academic track a student was in as well as his/her socioeconomic status. Students in the lower tracks were denied the information given to the students in the higher track. 


\section{Higher Education Stratification}

\section{Transition to Postsecondary Education}

As stated earlier, Cofer and Somers (2001) addressed precollege effects (such as student degree aspirations) on within-year persistence at 2-year colleges as related to financial aid by analyzing the impact of student background, goals, and accomplishment. The background variable was measured based upon a student's ethnicity, gender, age, income, marital status, individual parent's educational level, and financial dependency as defined by financial aid parameters. On ethnicity, there were four categories in the study: Black, Hispanic, and Other compared to Caucasian students. The Other group consisted of students that were multiethnic (different from being White or African-American as defined by the researchers). The analysis on the 1993 sample revealed that students in the Other category were 7.3 percentage points more likely to persist, Hispanics were straddling the fence in comparison to Whites on whether or not to persist with -0.07 percentage points, and Blacks were 5.18 percentage points less likely to persist. Similar results occurred in the 1996 investigation for Blacks (-4.38 percentage points) and Hispanics (0.37 percentage points) while the Other group had a smaller likelihood of within-year persistence (1.47 percentage points). On achievement, students with high ACT/SAT scores hovered within 1.3 percentage points of zero (1.28 and -1.12) while students with low ACT/SAT scores hovered within 2.6 percentage points (2.22 and -2.52) of zero not revealing much about the relationship between ACT/SAT scores and likelihood to persist. A weakness of this study was found in the inconsistencies of the results that were reported, but not discussed such as the likelihood to persist from fall to spring for low GPA students and full-time students. In the 1993 sample, the low GPA 
students were almost twenty (-19.67) percentage points less likely to persist while in the 1996 sample they were 5.08 percentage points more likely to persist. Moreover, the fulltime students were 2.89 percentage points less likely to persist in the 1993 data versus the 1996 full-time students being 28.82 percentage points more likely to persist from the fall to spring semester. Cofer and Somers (2001) failed to address these irregularities. While studies using national databases were important, they did not reveal the intricate complexities of a student's path from high school to college on a local level (Useem, 1992a). This pointed to the need for deeper analysis on a local basis across student ethnic and socioeconomic backgrounds.

Yando et al. (1979) considering race, sex, and socioeconomic status (SES) studied how eight-year olds were able to solve problems. Their results pointed to the varying achievements of low- versus high-SES students. The low-SES students used creativity to problem solve while the high-SES group modeled school "activities" to problem solve (p. 29). While these studies (Auerbach, 2002; Cofer and Somers, 2001; Yando et al. 1979) may not be generalizable, they did emphasize the need for educators: (a) to know their students using research to tear down certain "beliefs" that have been systematically communicated through what seems normal in school systems and through false generalizations from studies that were not conducted on their populations and (b) to use this research to improve practices and relationships within and between institutions to allow students to grow and maximize their full potential. This would ultimately improve student achievement.

Besides these findings, Terenzini et al. (2001) also shed light on the negative effect schooling has on the aspirations of poor children: 
By the ninth grade (perhaps as early as the seventh grade), most students have developed occupational and educational expectations that are strongly related to SES. These SES-based differences subsequently manifest themselves in differences in college-going, persistence, and degree attainment rates, all of them unfavorable to low-SES students in comparison with their more affluent counterparts. Parental encouragement appears to be a powerful player in the development of students' expectations, as do high school preparation, parental occupation(s), and perceptions of access to financial aid... Nearly one-half of the lowest-SES high school graduates do not enroll the following fall in any postsecondary institution, a nonenrollment rate nearly five times higher than that of highSES students (48 versus 11 percent). (p. v)

So similar to Stanford's Bridge project (Venezia, Kirst, and Antonio, 2003), most poor children in this national study limited their expectations early (no later than their first year of high school) and about one in every two did not elect to attend college.

Terenzini et al. (2001) also found a clear pattern when investigating pre-college academic abilities of students based upon socioeconomic status. When looking at ACT and SAT scores, the higher socioeconomic status was reportedly linked to higher academic achievement (p. 21s).

In addition, recall that Ingels, Planty, and Bozick (2005) found that high mathematics skills were connected to high postsecondary expectation. Conversely, not even half (47\%) of the American High School Senior Class of 2004 had "intermediatelevel" mathematics skills (p. 6). That is, less than 50\% were able to do "simple problem solving, requiring the understanding of low level math" (p. 15). This has remained to be a major issue. If high mathematics skills were linked to high expectations and many students did not have high skills, this is problematic and requires further examination. Such trends in the twenty-first century should have prompted a movement for fundamental change across the American education system. 
Terenzini et al. (2001) also exposed the high tuition and low aid barrier that many low-SES students face. Consequently, all of these factors have been shown to weigh on student aspirations, beliefs, and self-efficacy especially for first-generation students. Pascarella, Pierson, Wolniak, and Terenzini (2004) contend that first-generation students have to cope with transitioning to college as other students; however, they also have had "social and academic transitions" to manage (p. 250). In sum, high-SES was linked to high achievement which was linked to high expectations for postsecondary attainment. However, because of inadequate secondary mathematics skills, students still lacked the requisite momentum needed for college persistence as Adelman (2006) described. More research was needed on the role of mathematics on community college students that simultaneously considers anticipation. This study only addressed quantitative measures.

Roth, Crans, Carter, Ariet, and Resnick (2000) examined 19,736 high school transcripts of 1994 high school graduates in Florida who attended high school for four consecutive years without interruption to determine how course selection, grades, scores on the Grade Ten Achievement Test (GTAT), extent of academic achievement measured by Mathematics and English High School Performance (HSP), race, and gender affected pass rates on the College Board College Placement Test (CPT) taken upon admission to the community college in the fall of 1994. These authors reported on the growing trend that secondary academic preparation seemed to increasingly become weaker as evidence pointed to students needing more and more remediation in higher education. Florida's 1994-1995 community college freshmen essentially were in the same predicament. That is, $64 \%$ of this group needed remediation in at least one of the three subjects measured by the CPT (mathematics, reading, and writing). The authors carefully constructed the 
sample by establishing criteria that would remove students who repeated grades and those with missing information. Of the remaining students, only Blacks, Whites, and Hispanics were included in the study as the sizes of the other ethnic groups were too small for the required statistical analysis. Additionally, students included in the study had to meet the minimum 1.5 cumulative high school GPA required for graduation. Using four statewide data sets, the authors were able to merge the GTAT data with the FLDOE demographic data, High School Transcripts, and Community College CPT scores into a final set with a $100 \%$ match rate. This was accomplished as a result of their meticulous sample guidelines requiring all students in the study to be Black, Hispanic, or White and to have completed four full years of high school. These meticulous samplings possibly had deleted cases from schools with poor recordkeeping, which can often occur in high poverty schools distorting the generalizability.

Although Roth et al. (2000) identified six variables to predict CPT performance, they never provided a definition of what it meant to pass the CPT. They did, however, employ several levels of statistical analysis. First, their ANOVA results revealed all six variables had significant main effects at the 0.05 alpha level. Secondly, the adjusted odds ratios showed that, within this sample, males had a higher chance than females of passing the CPT subtests while Blacks and Hispanics had lower odds than Whites. Third, the authors computed the "maximum and average difference between high and low pass rate probabilities for each gender-by-ethnicity combination" for the three subtests (p. 78).

From this analysis, the most important predictor of passing the CPT was the Math HSP. The Math HSP variable measured degree of academic achievement based upon course difficulty as established by the FLDOE high school course code directory, the 
number of mathematics courses taken, and grades earned. This variable increased a student's chance of passing the mathematics subtest of the CPT by a minimum of $42.5 \%$ regardless of race or gender, a very important finding. In all, based upon their findings, these authors suggested that students would have been better prepared academically by the mere exposure to higher level mathematics courses even at the expense of having a lower GPA. Finally, the authors made recommendations for community colleges, universities, and high schools to work together in advising students about the potential outcomes of their academic choices in high school and to use this data on students' course-selections to predict how many graduates will likely need remediation in order to set up programs or other initiatives to counteract the increasing number of students that have shown a need developmental education. They also recommended for the state to execute an evaluation system of high school students' achievement in mathematics and English, a measure similar to the HSP variables in their study.

Collectively, these studies pointed to a need for more studies and while Roth et al. (2000) examined CPT scores as the outcome, a more important outcome and the one used in this study was college persistence. This data was needed for higher education institutions to partner with the local K-12 schools to reverse the effects of stratification, lowered expectations, and ultimately poor course selections that were strongly related to postsecondary attainment and academic outcomes.

\section{Students' Academic Experiences}

Adelman (2006) concluded that a student who earned at least 20 credits in the first year of postsecondary schooling was more likely to persist to earn a bachelor degree. Students earning less than 20 credits reduced their probability to persist by $33.3 \%$. Since 
persistence has often been defined as continuously enrollment from semester to semester within the first year of college, Adelman (2006) argued that this definition "reveals an extremely high rate of persistence" (p. 58). Thus, he contended that the second year of schooling gave students a chance to correct their mistakes from their first year. But within community colleges with higher levels of first-generation students, remember that Pascarella et al. (2004) found that first-generation students were striving to adjust to the academic and social changes. So, achieving first year momentum was critical to a community college student deciding to persist to earn a degree. So, within-year persistence of community college students was important to study.

When examining attendance patterns, Adelman (2006) supported institutional contextualized research. He described the attempts that were made to evaluate the effects of students attending multiple institutions and concluded that the results of such studies were debatable. He further argued that one should research the effects of students attending several colleges in the "context of individual institutions (no matter where else the student goes to school)" (p. 83). He continued and asserted that a result of this type of research would be of tremendous help in determining the types of "environmental adjustments likely to intensify student involvement with institutional services as well as to heighten student satisfaction with instruction, even if the student was present for only 24 credits" (p.83).

\section{Mathematics and Persistence}

By far, Adelman's 2006 use of the NELS:88 data seemed to be the most illuminating as it followed a longitudinal study conducted over 10 years covering multiple types of institutions including 2-year colleges. The studies revealed more of the 
same a decade later. In his Toolbox Revisited, Adelman (2006) offered suggestions that higher education institutions, secondary schools, and students should follow. He confirmed that the amount and depth of what one studied was strongly related to degree attainment. Consequently, he implored the higher education institutions to partner with secondary schools to maximize "opportunity-to-learn" (p. 108). He went as far as stating "the first year of postsecondary education has to begin in high school" and that "advanced quantitative literacy" was a must across college-bound and vocational curricula (p. 108). In addition, he concluded that the student affairs division within postsecondary institutions should have intensely engaged students prior to or in their first academic year with a goal of each student getting correct course placement, earning 20 credits, by helping students develop success strategies such as individual education plans and having specific discussions on minimizing withdrawals and repeats that hindered students from earning the degree. One of his most telling finds was the course descriptions of what Precalculus meant in high school: “ 'precalculus' on a transcript could mean any mathematics prior to calculus, including Algebra 1" (p. 97). When a course labeled Precalculus was essentially a first-year course in Algebra 1, it misled students attending those high schools to believe they were on a college-bound track with this course in, say, their $10^{\text {th }}$ to $12^{\text {th }}$ grade years, especially when Adelman (1999) asserted that mathematics beyond Algebra II was where the momentum began for college-ready students (p. 31).

Moreover, Adelman was not the only academic to recognize the importance of mathematics. Reyes and Stanic (1988) also asserted that mathematics was critical and should be studied by all. They also declared that mathematics achievement was directly 
related to the mathematics curriculum that was available to the student. They further explained its importance when they argued "math knowledge allows individuals to participate fully in our democratic processes and to be unrestricted in career choice and advancement" (p. 26).

Ingels, Planty, and Bozick (2005) demonstrated that mathematics was strongly associated with postsecondary degree attainment when they found that high degree expectations were linked to higher levels of mathematics performance. The two-track curriculum established in Florida's K-12 system only required students to complete Algebra I or its equivalent as a part of the required 4 years of mathematics to meet graduation requirements. Thus, Florida's high school graduation requirements still did not have the beyond Algebra II catalyst to propel all students to postsecondary degree attainment as Adelman (2006) described. The lack of this human capital has indelible effects on the course of one's life to the point of maintaining social structures that benefit a dominant group (Musoba and Baez, 2008). Becker (1992) reminded us that small differences in schooling multiply into large gaps that students with low achievement levels have difficulty overcoming later in life. Hence, poor and minority students could not have demonstrated high levels of achievement if the advanced curriculum was not available to them. Bourdieu would have argued this as the genius of the dominant group to use this social reproduction of maintaining the status quo as a suppressive tool.

Further, these students and their parents, who were lacking the social capital to be adamant about getting on the college-bound track in high school to enroll in advanced mathematics classes, get a hidden curriculum instead (Auerbach, 2002; Crosnoe and Houston, 2007; Gamoran, 1987; Oakes, 1994; Useem, 1992a, 1992b). That is, schools 
and the teachers within send the message of certain student groups not being college material (Apple, 1995). Hence, despite having aspirations to earn a postsecondary credential, their expectations embodied a stark reality of not being able to get the degree. This phenomenon showed up in the cooling out process (Anderson, G., Alfonso, M., and Sun, J., 2006; Clark, 1960). Consequently, students did not reach their full potential.

\section{Summary}

Since community colleges have had a higher concentration of poor and minority students and Adelman's 2006 study only addressed 4-year degree attainment with SES as a statistically significant factor throughout the different steps of analysis without strong influence on degree attainment, evaluating the effect of the high school context and mathematics course-taking patterns of students at an urban community college with a large minority population revealed a different story about persisting to earn an Associate degree for students across all demographic and financial backgrounds (Terenzini et al., 2001). 


\section{CHAPTER III}

\section{METHODS}

Precollege characteristics, socioeconomic status, institutional effects (high school), and course-taking patterns were investigated for possible relationships to persistence and successful completion of at least the Associate degree. While Adelman (2006) looked at persistence at 4-year institutions and Roth et al. (2000) only considered the impact of the high school curriculum on CPT performance, no one looked at how the high school mathematics curriculum served as a predictor of the mathematics course selections among community college students with a large immigrant and diverse local population. Hence, it was critically important to examine the failure of alignment between K-12 and postsecondary institutions and to research the journey of underprepared students and the relationship of their prior coursework to their persistence at the community college (Associate degree attainment or continuous enrollment). Overall, the researcher was interested in determining the variables that are related to degree attainment or lack thereof within an urban Florida Community College. This study analyzed the mathematics course-taking patterns of secondary students in a Florida public school district in order to determine if they were predictors of students' successful attainment of an Associate degree from or continuous enrollment at a large urban community college. This study also examined which high school characteristics are linked to high and low rates of persistence in fulfilling degree requirements. 


\section{Research Questions}

Research Question 1: Is there a predictive relationship between high school mathematics course enrollment patterns and degree attainment?

Research Question 2: Is there a predictive relationship between community college enrollment patterns in mathematics courses and degree attainment?

Research Question 3: Is there a predictive relationship between a student's high school curriculum and his or her degree attainment?

Research Question 4: Is there a predictive relationship between the high school's racial/ethnic demographics or socioeconomic status and degree attainment?

\section{Research Design}

This was an ex post facto study which examined possible relationships between mathematics course-taking patterns in high school and community college degree attainment. Causal relationships were not assumed. Instead, the results informed researchers about the specific independent variables that should be included in future experimental studies, particularly those performed on students at large urban diverse community colleges. Newman and Newman (1994) suggested that this benefit outweighed the limitation of an ex post facto analysis.

\section{Sample}

The students in this study were limited to those who graduated on time from a county high school with 4 years of schooling and enrolled at the local community college from 2002 to 2008 in Florida. Based upon a Florida County 2001-2002 Twentieth Day Enrollment report, there were 13,379 seniors enrolled in a high school, charter, or center in this school district. According to the 2002-2003 No Child Left Behind School Public 
Accountability report, this school district was 38.5\% White, 35.8\% Black, $20.9 \%$ Hispanic, $2.9 \%$ Asian, $0.3 \%$ Native American, and 1.7\% Multicultural with $48.4 \%$ of students being female during the 2001-02 school year. Using the district's $64 \%$ graduation rate, 8,563 students graduated. Of these, the researcher only used students with 4 years of high school records in a specific Florida county. Students who did not complete 4 years at a particular high school remained in the study and the high school at which they spent the most years was be used as the home school as these schools stood to have the greatest effect on his/her academic performance.

\section{Data Collection}

Permissions were obtained from the Florida International University's Institutional Review Board and the College of Education Office of Research and Graduate Studies to conduct research on human subjects prior to data collection. The State of Florida archived K-20 data in an Education Data Warehouse with a mission to "provide stakeholders in public education-including, but not limited to, administrators, educators, parents, students, state leadership, and professional organizations-with the capability of receiving timely, efficient, consistent responses to inquiries into Florida's Kindergarten through University education" (FLDOE, 2008). A data request was submitted to and approved by the FLDOE Education Data Warehouse. The data included high school and community college transcripts with financial aid information over 6 years of potential college enrollment.

\section{Data Analysis}

Since mathematics was shown to contribute to the reason why students failed to persist, the researcher examined particular variables and how they related to persistence 
at a large urban community college with a large minority population. A summary of descriptive statistics was included. In a good portion of the articles reviewed in this dissertation, logistic regression was recommended when analyzing persistence since it is a binary variable (Peng, So, Stage, and St. John, 2002). However, as noted previously, parental education (Useem, 1992a), parental involvement (Crosnoe and Houston, 2007; Useem, 1992b), instructional resources (Adelman, 2006; Useem, 1992a), student characteristics (Useem, 1992a, 1992b), and school practices (Auerbach, 2002; Gamoran, 1987; Oakes, 1994; Useem, 1992a, 1992b) all affected course selections which ultimately have had long-term consequences to include degree completion, high school dropouts, and college dropouts. Consequently, since mathematics course-taking patterns have been a product of student experiences within schools and the availability of the curriculum at a particular school, this study required multilevel analysis using hierarchical linear modeling in which the student was evaluated at level 1 and the schools at level 2 as the contextual variable (Field, 2009; Raudenbush and Bryk, 2002;). Using the framework that the collective Associate degree attainment of students in a particular school have been shaped by their experiences at that school and the curriculum offered at the school, this method allowed the researcher to determine the proportion of the total variance in student-level outcomes attributed to between-student and between-school variance (Field, 2009; You, 2007). Based on the size of the intraclass correlation, the researcher estimated the potential effects of school-level factors on outcomes (Field, 2009). A chisquare likelihood ratio test was performed to gauge the model fit as recommended by Field (2009). Since multicollinearity across levels have been shown to pose a problem if cross-level interactions exist, individual level predictors were grand mean centered to 
increase the likelihood of achieving stability and independence in estimates from the models (Field, 2009). The unconditional model was analyzed first to determine if significant variance existed between schools which substantiated between-school variance modeling.

\section{Unconditional Model (Random Intercept Model)}

$$
\begin{aligned}
& \text { Level 1: } \eta_{i j}=\operatorname{logit}(p)=\ln \left(\frac{p}{1-p}\right)=\operatorname{logistic}\left(\beta_{0 j}+\varepsilon_{i j}\right) \\
& \text { Level 2: } \beta_{0 j}=\gamma_{00}+u_{0 j}
\end{aligned}
$$

for the $i$ th student in school $j, \beta_{0 \mathrm{j}}$ is the intercept, $\gamma_{00}$ was the grand mean, $\varepsilon_{\mathrm{ij}}$ and $\mathrm{u}_{0 \mathrm{j}}$ were student-level and school-level error terms.

\section{Random intercept and random slope model}

$$
\begin{aligned}
& \begin{array}{l}
\eta_{i j}=\operatorname{logistic}\left(\beta_{0 \mathrm{j}}+\beta_{1 \mathrm{j}} \text { demographic }_{\mathrm{ij}}+\beta_{2 \mathrm{j}} \text { family }_{\mathrm{ij}}+\beta_{3 \mathrm{j}} \text { academicbackground }_{\mathrm{ij}}\right. \\
\left.\quad+\beta_{4 \mathrm{j}} \text { engagement } \mathrm{ij}_{\mathrm{j}}+\varepsilon_{\mathrm{ij}}\right) \text { where } \beta_{0 \mathrm{j}} \text { is the intercept. }
\end{array} \\
& \beta_{0 \mathrm{j}}=\gamma_{00}+\gamma_{01} \text { Environment }+\gamma_{02} \text { Practice }+\mu_{0 \mathrm{j}} \text { (Estimate for Intercept variability } \\
& \text { around school means using grand mean centering) }
\end{aligned}
$$

The $\beta_{\mathrm{ij}}$ coefficients were estimates for slope variability or the random effects of the specified student-level variable for school $\mathrm{j}$ and $\gamma_{\mathrm{ij}}$ were the cross-level interaction coefficients for student-level variable $\mathrm{i}$ and school-level variable $\mathrm{j}$.

Since Adelman (2006) suggested at least 20 credits should be earned in the first academic year which included the summer and it typically took 60 credits to earn an Associate degree, at least three years were needed to graduate. Second, three additional years were added to this timeframe. This gave part-time students an opportunity to complete their degree requirements. The common benchmark of 1.5 times the expected degree completion time gave the students 3 years to complete. This study used a more generous measure of 6 years. Field (2009) suggested that missing data were not a 
problem in multilevel modeling. However, as appropriate, listwise deletion was used for missing data (Dedrick et al. 2009).

Taking precaution to consider the social reality of the students being nested in schools, the researcher also used multilevel modeling to reduce the bias in standard errors that led to results that have been erroneously labeled significant when a single-level approach was applied. Statistical significance was set at the $\alpha=0.05$ level. Ingels et al. (2006) described how small differences in large samples have been shown to yield statistical significance, but not "substantive significance" (p. 4). That is, the significant differences may not have generated meaningful information. Thus, the $\alpha=0.05$ level reduced the chances of this occurring. Consequently, there was a 5\% chance a Type I error will occur. Since this study was not based upon life or death situations, this was appropriate.

\section{Assumptions}

Since the researcher conducted this study at one institution, the reader should be cautious when generalizing the findings to other community colleges. However, a large sample alleviated the fear of making false generalizations. It was assumed that enough students met the persister definition in the 6-year period. Dedrick et al. (2009) indicated that comparing subgroup results provided a generalizability measure. Similar to ordinary least squares assumption, the hierarchical linear modeling method had built-in assumptions on linearity, homoscedasticity, normality, and independence (Hox and Mass, 2005). Linearity was assumed at the student and school levels while homoscedasticity was assumed at the student level with the residual variance constant. For this study, normality was not assumed as the dependent variable, Associate degree attainment or 
continuous enrollment, was dichotomous. Finally, for independence, the nested nature of the data violated this assumption at the student-level while the school-level observations were assumed to be independent of each other (Hox and Mass, 2005). An unstructured covariance structure was assumed since the model involved random slopes and intercepts (Field, 2009).

\section{Variables}

For this study, a persister was defined as a student who earned the transfer Associate degree (AA) or higher, the occupational Associate degrees (AS or AAS), or was continuously enrolled in major semesters within the study timeframe. Hence, the dependent variable (DV) was a dichotomous variable - a student was either persisting to earn at least an Associate degree (transfer or occupational or higher) or not (Coded: Yes $=1$ and $\mathrm{No}=0)$.

The student-level variables were:

\section{Demographic Background}

a. Race/ethnicity: Separated by Asian or Pacific Islander, Black (Not of Hispanic Origin), Hispanic, White (Not of Hispanic Origin), American Indian/Alaskan Native, Multiracial, Other (Non-Resident Alien, not reported or unknown) using White (Not of Hispanic Origin) and Asian as the reference group since these students were shown to outperform the underrepresented minorities in multiple persistence studies. Gender: Male $=0$ and Female $=1$. 


\section{Family Background}

a. Student Socioeconomic status: A dichotomous variable defined by being a need-based financial aid recipient: $\mathrm{Yes}=1$ and $\mathrm{No}=0$. For this study, need-based financial aid was the Federal Pell Grant. Students who did not apply for aid were included in the "no" group and this group included all students who did not apply for aid as well as those who did not qualify. Students may not have applied for aid because they assumed they were not eligible, which is true of wealthy students, or because they were not aware of aid policies.

b. Immigration status: U.S. Citizen $=1$, Permanent Resident Alien $=2$, or Other $($ Non-resident Alien $=3$ or Unknown $=4)$.

3. Academic Background

a. Placement exam scores: The College Assessment Cut Score Chart (2006) was used to place students into the following categories based upon the state's College Entry-level Placement Test (CPT) scale, and ACT/SAT scores: Lowest remedial mathematics course (CPT 0-32, ACT 0-9, SAT 200-349), Higher remedial mathematics course (CPT 33-71, ACT 10-18, SAT 350-439), Intermediate mathematics (CPT 72+, ACT 19-20, SAT 440-489), and college-level mathematics (ACT21+, SAT 490+).

b. Remedial math attempts: The number of remedial math course attempts.

c. Remedial English percentage: A percentage that represented the amount of remedial English coursework out of all English courses attempted, delineated by two levels. 
d. Community College Math Proportion: Completed proportion of mathematics classes taken measured by a ratio of completed to attempted courses at the community college.

4. Engagement

a. Entry: Used to determine if the student delayed entry into the community college by subtracting graduation year from enrollment year. Coded: Immediate entry $=0$ and Delayed entry $=1$.

b. First-year credits: The number of credits earned after 12 months.

c. Summer Enhancement: The number of summer credits was shown to contribute to persistence in Adelman's (2006) study.

The school-level variables were:

1. Environment

a. High School Demographics: Measured as a continuous variable based on the percent of enrolled racial/ethnic minorities.

b. High School Socioeconomic status: Measured as a continuous variable based on the percent of students on free or reduced lunch.

2. Practice

a. High School Breadth of Math Curriculum: This variable measured the number of courses offered above Algebra 2 at each high school yielding a limited measure of rigor. This was a pseudo continuous variable which included courses such as trigonometry, precalculus, calculus, AP Calculus, AP Statistics. 
b. High School Exposure to Rigorous Math Curriculum: This variable measured the percent of students enrolled in an AP Calculus or AP Statistics class.

\section{Summary}

These methods enabled the researcher to determine how precollege traits at the student and high school levels predicted a student's persistence to earn at least an Associate degree at a community college. College academic experiences were also evaluated to determine predictors of student persistence towards degree completion. 


\title{
CHAPTER IV
}

\begin{abstract}
ANALYSIS RESULTS
As previously asserted, it was critically important to examine the misalignment between K-12 and postsecondary institutions by researching the journey of underprepared students and the relationship between their prior coursework and their degree attainment. In reviewing students' demographic, family, and academic backgrounds as well as their levels of engagement at the community college and in the context of their high school practices and environments, the analysis results used to determine which factors were related to degree attainment at the local community college have been described in this chapter.
\end{abstract}

First, a descriptive analysis of the sample was conducted. Next, an unconditional model was reviewed prior to evaluating student-level and school-level variables to evaluate the intraclass correlation coefficient which explained what proportion of the variance was attributed to between-school differences. However, since the dependent variable was dichotomous and a logit link function was desirable, Raudenbush and Bryk (2002) concluded that the intraclass correlation coefficient was "less informative in the case of nonlinear link functions, because the level-1 variance [was] now heteroscedastic" (p. 298). So, a step-by-step analysis was conducted and culminated in a review of the random intercept and random slopes model with appropriate introduction of level-2 contextual variables. Non-significant variance components were dropped from the model based upon corresponding p-values and findings in the literature review. The results were then used to answer the following research questions. 


\section{Research Questions}

Research Question 1: Is there a predictive relationship between high school mathematics course enrollment patterns and degree attainment?

Research Question 2: Is there a predictive relationship between community college enrollment patterns in mathematics courses and degree attainment?

Research Question 3: Is there a predictive relationship between a student's high school curriculum and his or her degree attainment?

Research Question 4: Is there a predictive relationship between the high school's racial/ethnic demographics or socioeconomic status and degree attainment?

\section{Descriptive Statistics}

Reviewing the 2002 high school graduates that completed 4 years of high school in a specific school district and attended the local community college, there were 2,683 students in the sample who attended 31 high schools. A multilevel modeling approach was employed because of the nature of the students (level 1) nested in the context of schools (level 2). Since the research focus was to determine the probability that a student will earn at least an Associate degree or was continuously enrolled based upon his/her mathematics course-taking patterns in high school and at the local community college, Hox (2002) indicated that the dichotomous dependent variable (DV) required a nonlinear approach with a canonical link function. As there was more than one canonical link function that could be used for dichotomous data, the logit link function was used in this study. Further, while there were 4 general categories (demographic background, family background, academic background, and engagement) for the student-level variables, there were 11 level-1 variables and four level-2 contextual variables used to determine if 
predictive relationships existed between the independent variables and the dependent variable. See Table 1 and Table 2 for an overview of the sample's descriptive statistics at both levels of this study.

Table 1

Descriptive Statistics for Class of 2002

\begin{tabular}{lcc}
\hline & Level-1 & \\
\hline Variable Name & Category & Frequency \\
Race & Asian & 122 \\
& Black & 735 \\
& Hispanic & 654 \\
Gender & White & 1172 \\
& Female & 1585 \\
Delayed Entry & Male & 1098 \\
& Yes & 671 \\
Socioeconomic Status & No & 2012 \\
& Pell Grant Recipient & 1300 \\
Citizenship & No need-based aid & 1383 \\
& American Citizen & 2327 \\
& Non-resident Alien & 31 \\
Persist & Unknown Citizenship & 47 \\
& Permanent Resident & 278 \\
& Yes & 1351 \\
& No & 1332 \\
\hline
\end{tabular}

Table 2

Descriptive Statistics for Class of 2002 Level-1 Descriptive Statistics

\begin{tabular}{|c|c|c|c|c|c|}
\hline & $N$ & Mean & $S D$ & Minimum & Maximum \\
\hline First-year credits earned & 2683 & 8.42 & 5.79 & 0.00 & 45.00 \\
\hline Entry Math Level & 2683 & 2.68 & 1.03 & 1.00 & 4.00 \\
\hline $\begin{array}{l}\text { Completed to Attempted Math } \\
\text { Proportion }\end{array}$ & 2683 & 49.82 & 37.10 & 0.00 & 100.00 \\
\hline Remedial Math Attempts & 2683 & 1.83 & 2.24 & 0.00 & 12.00 \\
\hline $\begin{array}{l}\text { Remedial English Percent of English } \\
\text { Courses }\end{array}$ & 2683 & 21.13 & 35.32 & 0.00 & 100.00 \\
\hline Summer Credits Earned & 2683 & $\begin{array}{l}7.04 \\
\text { S Statis }\end{array}$ & 7.77 & 0.00 & 44.00 \\
\hline Variable Name & $J$ & Mean & $S D$ & Minimum & Level-2 Descriptive Statistics \\
\hline Curriculum Breadth & 31 & 4.03 & 2.46 & 0.00 & 7.00 \\
\hline Curriculum Rigor & 31 & 2.91 & 3.07 & 0.00 & 11.59 \\
\hline Percent Minority & 31 & 61.12 & 21.63 & 15.50 & 94.50 \\
\hline Percent on Free and Reduced Lunch & 31 & 22.49 & 12.33 & 2.70 & 60.40 \\
\hline
\end{tabular}




\section{Student-Level Variables \\ Demographic Background.}

This study used race/ethnicity as well as gender to describe the demographic background of the sample. Regarding race/ethnicity, the sample was $43.7 \%$ White (Not of Hispanic Origin), 27.4\% Black (Not of Hispanic Origin), 24.4\% Hispanic, 4.5\% Asian. The majority of the students $(59 \%)$ were female.

\section{Family Background.}

Need-based financial aid was used to determine each student's socioeconomic status. $48 \%$ of the students received this type of aid. As this sample was pulled from a very diverse community, the researcher thought that many students were not American citizens. To the contrary, the students in the sample were mostly American citizens $(86.7 \%)$ while $10.4 \%$ are permanent resident aliens, $1.2 \%$ are aliens, and the remaining $1.8 \%$ had an unknown citizenship status. Consequently, only socioeconomic status was used for the family background category as the most of the citizenship categories were too small to yield meaningful information.

\section{Academic Background.}

Mathematics Placement. Initial placement has been shown to be critical to the success of students (Blair, 2006). There were four levels of possible mathematics placement in college based upon standardized test scores. As the researcher was not able to secure the placement cut scores for all of the students, the first mathematics course in which the student enrolled (entry math level), if they enrolled, was used as a proxy for the placement score when data were missing. As shown in Table 3, 70.7\% of the students in the sample were not academically prepared to take a college-level mathematics course 
that satisfied the mathematics requirements of the Associate degree which underscored the need for this study.

Mathematics and English Coursework. Taking the lens a bit further, the number of remedial course attempts gave more insight into the depth of the problem regarding academic preparedness. Analyzing the data for course enrollments, the range for remedial math attempts was six (See Table A1). That is, students had as many as six attempts to complete a remedial math course. While the state of Florida's maximum attempt rule limits most students to three attempts, there were legitimate avenues for students to exceed this limit based upon institutional policies that could consider other life factors to include extenuating circumstances. About $2.9 \%(n=80)$ of the students in this study were allowed fourth $(n=66)$, fifth $(n=11)$, and sixth $(n=3)$ attempts.

Different from multiple remedial math attempts, some students made choices to enroll or not to enroll in remedial mathematics courses even with college-level placement. Almost three-tenths $(n=787)$ of the students in this sample were college-ready based upon their entry math levels. The researcher found that $0.5 \%$ (4 out of 787 ) of these students chose to take a remedial course. On the other hand, a substantial portion of the sample $(49 \%, n=1316)$ did not attempt a remedial mathematics course because they either placed at college-level or made a conscious decision not to enroll in a mathematics course. More specifically, 533 students, who were not placed at the college-level, made a choice not to enroll in a remedial mathematics course. This group represented about $20 \%$ of the students in the sample (533 out of 2683). Since such a large number of students made the decision to not take mathematics, more exploration is needed to determine whether this was a result of the "forced deceleration" school practices described by 
Useem (1992a), the lower-quality learning opportunities for low-track students explained by Oakes (1994), or the student's choice of avoidance due to high school experiences in mathematics classrooms and/or college experiences different from the findings of Useem (1992a) and Oakes (1994).

Regarding those who did attempt remedial mathematics courses, $25 \%$ of the study sample $(n=660)$ had one remedial math course attempt with $82.1 \%(n=542)$ of these students placed in the upper-level remedial course followed by $11.2 \%(n=74)$ in the lower-level remedial mathematics course, $6.1 \%(n=40)$ in the intermediate-level course, and $0.6 \%(n=4)$ who placed at college-level. Furthermore, $16 \%(n=423)$ of the study sample attempted a remedial mathematics course twice with $73.5 \%(n=311)$ of these students placed in the upper-level remedial mathematics course, $25.5 \%(n=108)$ in the lower-level mathematics course, and $0.9 \%(n=4)$ in intermediate-level mathematics. Additionally, $8 \%(n=204)$ of the study sample attempted a remedial mathematics course three times with $56.4 \%(n=115)$ placed in the upper-level remedial mathematics course, $42.5 \%(n=86)$ in the lower-level mathematics course, and 1.5\% $(n=3)$ in intermediatelevel mathematics. Finally, $85 \%(n=68)$ of the 80 students with four to six attempts were placed in lower-level remedial mathematics.

Regarding remedial English courses, the remedial English percentage variable was used to determine how many remedial English courses were taken out of all English courses attempted. The mean remedial English percentage was 21.13 with a standard deviation of 35.32 while $72.4 \%(n=1,942)$ of the study sample had less than $25 \%$ of their English courses as remedial coursework. Of the 2,683 students in this study, 9.5\% $(n=256)$ had $100 \%$ of their English courses as remedial English coursework. Of these, 
90.2\% $(n=231)$ placed into remedial mathematics classes, $6.3 \%(n=16)$ placed in intermediate-level mathematics, and 3.5\% $(n=9)$ placed at the college-level. At the other end of the spectrum, $71.2 \%(n=1909)$ of the study sample had no remedial English classes with $6 \%(n=114)$ placed into the lower-level remedial mathematics course, $29.5 \%$ $(n=564)$ placed in the upper-level remedial mathematics course, $24.8 \%(n=473)$ placed in the intermediate mathematics course, and 39.7\% $(n=758)$ placed in college-level mathematics. The data revealed a strong negative relationship between remedial English percentage and entry math levels $(r=-0.786, \mathrm{p}<0.01)$. That is, as the remedial English percent of English courses increased, the percentage of students placed into lower levels of mathematics increased (See Table 4).

Once students completed their remedial coursework, they proceeded to take the college-level courses toward their degree programs. As such, the community college math proportion variable gave a measure of how long it took a student to complete the mathematics requirements for a degree including their remedial mathematics coursework. The mean community college math proportion was 49.82 with a standard deviation of 37.10. This indicated that on average about half of a student's mathematics course attempts were remedial math courses.

Engagement. Three variables were used to measure a student's level of engagement at the community college: delayed entry, first-year credits earned, and summer credits earned. The mean for delayed entry was 0.25 years with a standard deviation of 0.43 . So, students on average delayed their entry to the community college after graduating from high school for about three months which was about one semester. Students earned an average of 8.42 credits in their first-year of enrollment including the 
summer semester and an average of 7.04 credits in total across summers from 2002 to 2008. These findings suggested that on average these students were not gaining sufficient momentum to persist and complete at least an Associate degree based upon the findings of Adelman (2006). Recall that Adelman (2006) found that students at 4-year institutions need to accumulate 20 credits within the first year of college to have adequate impetus to persist and complete a Bachelor's degree whereas in this study the students were not earning half that amount in their first year toward their Associate degrees.

Table 3

Mathematics Placement Levels

\begin{tabular}{lcc}
\hline Math Course Levels & $n$ & Percentage \\
Lower-Level Remedial Course & 336 & 12.5 \\
Upper-Level Remedial Course & 981 & 36.6 \\
Intermediate-Level Course & 579 & 21.6 \\
College-Level Courses & 787 & 29.3 \\
\hline \multicolumn{1}{c}{ Total } & 2683 & 100
\end{tabular}

Table 4

Relationship between Remedial English and Remedial Mathematics

\begin{tabular}{lcccccc}
\hline \multicolumn{7}{c}{ Entry Math Levels } \\
\hline Remedial \\
$\begin{array}{l}\text { English } \\
\text { Percent of } \\
\text { English }\end{array}$ & $\begin{array}{c}\text { Lower- } \\
\text { Level } \\
\text { Remedial } \\
\text { Courses }\end{array}$ & $\begin{array}{c}\text { Math } \\
\text { Upper- }\end{array}$ & $\begin{array}{c}\text { Level } \\
\text { Remedial }\end{array}$ & $\begin{array}{c}\text { Intermediate- } \\
\text { Level Math }\end{array}$ & $\begin{array}{c}\text { College- } \\
\text { Level Math }\end{array}$ & $\begin{array}{c}\text { Totals } \\
\text { Macentage } \\
\text { placed in } \\
\text { Math }\end{array}$ \\
\hline 100 & 103 & 128 & 16 & 9 & 256 & 90.2 \\
$75-99$ & 7 & 20 & 0 & 0 & 27 & 100 \\
$50-74$ & 72 & 134 & 32 & 3 & 241 & 85.5 \\
$25-49$ & 39 & 113 & 51 & 14 & 217 & 70.0 \\
$1-24$ & 1 & 22 & 7 & 3 & 33 & 69.7 \\
0 & 114 & 564 & 473 & 758 & 1909 & 35.5 \\
\hline \multicolumn{1}{c}{ Totals } & 336 & 981 & 579 & 787 & 2683 & \\
\hline & & & & & & \\
\hline
\end{tabular}


This calls attention to the need to further evaluate student engagement levels with postsecondary institutions and their persistence rates and strongly suggested that the story on student persistence is largely known by the end of the first year in college.

\section{High School Contextual Variables}

The previous 11 student-level variables were evaluated in the context of the schools in which the students were enrolled for 4 years of high school and the local community college. The two contextual variable groups for this study were defined as high school environment and high school practice. The high school environment was described by the high school demographics as measured by the percent of enrolled racial/ethnic minorities and the high school socioeconomic status as measured by the percent of students who received free or reduced lunch. The high school practice was defined by both the breadth and rigor of the mathematics curriculum offered at the school. The breadth of the high school mathematics curriculum was defined by the number of courses offered above Algebra 2 while the rigor of the high school mathematics curriculum was defined by the percent of students enrolled in AP mathematics.

\section{Environment.}

Across thirty-one schools, there was an average of $22.49 \%$ of students receiving free or reduced lunch with a standard deviation of 12.33 while the average racial/ethnic minority percentage was $61.12 \%$ with a standard deviation of 21.63 . The range for high school socioeconomic status was broad with the minimum percent of students on free and reduced lunch as $3 \%$ and the maximum of $60 \%$. The range for percent of racial/ethnic minorities in the high school was also large with the lowest percent as $16 \%$ and the highest at $95 \%$. 


\section{Practice.}

Across 31 schools, the mean breadth score was 4.03 courses above Algebra 2 with a standard deviation of 2.46 and the mean rigor was $2.91 \%$ of students taking AP Calculus and Statistics with a standard deviation of 3.07. While the mean was 4 courses, some schools offered no courses beyond Algebra 2 and the highest school had 7 . There was also wide variability in AP enrollment with some schools having no students taking AP mathematics and one school having $12 \%$ of their students enrolled.

\section{Hierarchical Generalized Linear Modeling and Model Development}

Since the students were nested in high schools and the predictive value of the previous variables was evaluated on how they related to successful degree attainment, the outcome variable was categorical and required hierarchical generalized linear modeling (HGLM). As recommended by Raudenbush and Bryk (2002), the first step of HGLM was to run an analysis on an unconditional model that did not contain any predictors at either level and evaluate the level-2 variance component to determine if HGLM was necessary. This particular case of HGLM was a Bernouilli model since the dependent variable was binary. The main purpose of this step was to estimate the intercept, $\beta_{0 .}$ A nonlinear model was set up in HLM 7 software using the Bernouilli option and the Laplace estimation method. Two sets of estimates for the fixed effects were generated: the Unit-Specific Model and the Population Average Model. Rumberger and Palardy (2004) pointed out that the unit-specific estimate gave the estimated log odds ratio with random effects fixed at zero while the population average model estimated the true population average. They also gave direction with which estimate was more appropriate depending upon the researcher's intent: 
In general, unit-specific estimates are more useful for analyzing differences in the effects of Level 1 and Level 2 predictors across Level 2 units, whereas population-average estimates were more useful for estimating average probabilities for the population as a whole. (p. 253)

The population estimates were used in evaluating the unconditional model. An incremental analysis was conducted looking at each student-level variable and its contribution to the variance while the others were not entered into the regression analysis. Then, additional variables (demographic background, family background, academic background, and level-2 variables) were entered and non-significant ones removed from subsequent analyses as appropriate using guidance from the literature review.

\section{Step One: Unconditional Model (Random Intercept Model)}

The main goal of this step was to estimate the intercept, $\beta_{0 j}$. In this model, $\eta_{i j}$, was the log-odds of degree attainment and $\beta_{0 j}$ was the average log-odds of degree attainment across all high schools while $\tau_{00}$ was the variance between schools in school-average logodds of degree attainment. The following equations were entered into HLM7 to run the analysis.

\section{Level-1 Model.}

$$
\begin{aligned}
& \operatorname{Prob}\left(\text { PERSIST }_{i j}=1 \mid \beta_{j}\right)=\phi_{i j} \\
& \log \left[\phi_{i j} /\left(1-\phi_{i j}\right)\right]=\eta_{i j} \\
& \eta_{i j}=\beta_{0 j}
\end{aligned}
$$

\section{Level-2 Model.}

$$
\beta_{0 j}=\gamma_{00}+u_{0 j}
$$

In the Level-2 model, $\gamma_{00}$, was the intercept and $u_{0 j}$ was the variance component or residual term and was approximately normally distributed with a mean of zero and between-school variance $\tau_{00}$. So, $\beta_{0 j}$ and $\gamma_{00}$ were average log-odds of degree 
attainment within and across schools respectively and $u_{0 j}$ represented the random effects of school $j$. The statistical significance of these random effects was reviewed at each step in the incremental analysis to determine if they remained in future steps. To convert to odds in favor of degree attainment, one should compute exp(log-odds). To convert to predicted probabilities $\left(\varphi_{i j}\right)$ of degree attainment, the equation $\varphi_{i j}=\frac{1}{1+\exp \left(-Y_{i j}\right)}$ was used.

Results. The estimated values, based on the HLM output, presented in Table 5 and Table 6, were based upon the unit-specific and population-average models, respectively.

Table 5

Unconditional Model: Final estimation of fixed effects Unit-specific model

\begin{tabular}{llrrrr}
\hline Fixed Effect & Coefficient & $\begin{array}{r}\text { Standard } \\
\text { error }\end{array}$ & $t$-ratio & $\begin{array}{r}\text { Approx. } \\
\text { d.f. }\end{array}$ & $p$-value \\
\hline $\begin{array}{c}\text { For INTRCPT1, } \beta_{0} \\
\text { INTRCPT2, } \gamma_{00}\end{array}$ & -0.080082 & 0.072359 & -1.107 & 30 & 0.277 \\
\hline
\end{tabular}

Table 6

Unconditional Model: Final estimation of fixed effects

Population-average model

\begin{tabular}{lrrrrr}
\hline Fixed Effect & Coefficient & $\begin{array}{r}\text { Standard } \\
\text { error }\end{array}$ & $t$-ratio & $\begin{array}{r}\text { Approx. } \\
\text { d.f. }\end{array}$ & $p$-value \\
\hline $\begin{array}{c}\text { For INTRCPT1, } \beta_{0} \\
\text { INTRCPT2, } \gamma_{00}\end{array}$ & -0.079928 & 0.071581 & -1.117 & 30 & 0.273 \\
\hline
\end{tabular}

So, specifically in the unconditional model, the estimated population-average log-odds of degree attainment is $\hat{\gamma}_{00}=-0.079928$. Because the average values are in the middle of the distributions of each predictor, this meant that the population estimate, -0.079928 , was the grand-mean value for a student with average values on each predictor. This converted to the expected odds of a student that earned at least an Associate degree of 
$\exp (-0.079928)=0.92339$, which was about 23 successes to 25 failures. Further, this corresponded to a predicted probability $\varphi_{i j}=\frac{1}{1+\exp (0.079928)}=0.480029$. That is, one can project from this sample a population probability of students having a $48 \%$ chance of completing at least an Associate degree when no predictors were considered at the student or high school levels. The average log-odds across schools, $\beta_{0 \mathrm{j}}$, was approximately normally distributed with mean -0.079928 and standard error 0.071581 , the $95 \%$ confidence interval is $(0.798,1.069)$ with $p$-value 0.273 . As shown in Table 7 , the level-2 variance component was found to be significant $(\mathrm{p}<0.001)$. Thus, the HGLM approach was necessary. The reliability estimate for the random level-1 coefficient, $\beta_{0 j}$, was 0.544 and was at a satisfactory level.

Table 7

Unconditional model: Final estimation of variance components

\begin{tabular}{rrrrrr}
\hline Random Effect & $\begin{array}{r}\text { Standard } \\
\text { Deviation }\end{array}$ & $\begin{array}{r}\text { Variance } \\
\text { Component }\end{array}$ & d.f. & $\chi^{2}$ & $p$-value \\
\hline INTRCPT1, $u_{0}$ & 0.29644 & 0.08788 & 30 & 95.03988 & $<0.001$ \\
\hline
\end{tabular}

\section{Intraclass Correlation Coefficient}

The intraclass correlation coefficient, $\rho$, measured the proportion of the total variance that was due to differences between schools. Kreft and De Leeuw (1998) described it as a

measure of the degree of dependence of individuals. The more individuals share common experiences due to closeness in space and/or time, the more they are similar, or to a certain extent, duplications of each other (p. 9). In multilevel models with a binary outcome, Raudenbush and Bryk (2002) and Hox (2002) pointed out that the portion of the variance due to between-student differences is 
always $\frac{\pi^{2}}{3} \approx 3.29$. Thus, the intraclass correlation coefficient was computed as $\rho=\frac{\sigma_{\mu}^{2}}{\sigma_{\mu}^{2}+\sigma_{e}^{2}} \approx \frac{0.08788}{0.08788+3.29}=0.026016$. This implied that $2.6 \%$ of the variance was due to between-school differences and the remaining $97.4 \%$ of the variance was due to between-student differences. Raudenbush and Bryk (2002) asserted that this measure was "less informative in the case of nonlinear link functions" as was used in this study (p.299). Further, this low percentage of the variance linked to school-level variables was contrary to the school effects research of Auerbach (2002), Gamoran (1987), Oakes (1994), and Useem (1992a, 1992b). Thus, it was important to explore at a deeper level to determine what factors may be predictive of degree attainment.

\section{Step Two: Significance of Student-Level Variables}

Since $97.4 \%$ of the variance was estimated to be due to between-student differences, the researcher reviewed the correlations between degree attainment and the student-level predictors as well as the variance components' significance levels for the predictors. As a result of running 10 separate analyses, socioeconomic status, the number of summer credits earned, gender, the number of first-year credits earned, and delayed entry were the top five level-1 variables in terms of their contributions to the variance as shown in Table 8. The variance component for entry math level did not have statistical significance while controlling for the other variables. Also, the correlation between entry math level and remedial math attempts was strong and negative $(r=-0.786, \mathrm{p}<0.01)$ and both variables were retained in the study. 
Table 8

Final estimation of variance components in descending order for Student-Level Variables

\begin{tabular}{rrrrrrr}
\hline & Random Effect & $\begin{array}{r}\text { Standard } \\
\text { Deviation }\end{array}$ & $\begin{array}{r}\text { Variance } \\
\text { Component }\end{array}$ & d.f. & $\chi^{2}$ & $p$-value \\
\hline $\begin{array}{r}\text { Socioeconomic } \\
\text { Status (SES) }\end{array}$ & INTRCPT1, $u_{0}$ & 0.333 & 0.111 & 30 & 112.24 & $<0.001$ \\
Summer Credits & INTRCPT1, $u_{0}$ & 0.312 & 0.097 & 30 & 83.50 & $<0.001$ \\
Gender & INTRCPT1, $u_{0}$ & 0.309 & 0.096 & 30 & 99.75 & $<0.001$ \\
First-Year Credits & INTRCPT1, $u_{0}$ & 0.300 & 0.090 & 30 & 95.67 & $<0.001$ \\
Delayed Entry & INTRCPT1, $u_{0}$ & 0.294 & 0.086 & 30 & 93.65 & $<0.001$ \\
Underrepresented & INTRCPT1, $u_{0}$ & 0.242 & 0.059 & 30 & 71.25 & $<0.001$ \\
Minority & INT & & & & & \\
Percent Remedial & INTRCPT1, $u_{0}$ & 0.207 & 0.043 & 30 & 57.84 & 0.002 \\
$\begin{array}{r}\text { College-Level } \\
\text { Math Proportion }\end{array}$ & INTRCPT1, $u_{0}$ & 0.205 & 0.042 & 30 & 52.73 & 0.007 \\
Remedial Math & INTRCPT1, $u_{0}$ & 0.177 & 0.031 & 30 & 50.08 & 0.012 \\
Entry Math Level & INTRCPT1, $u_{0}$ & 0.130 & 0.017 & 30 & 38.20 & 0.145 \\
\hline
\end{tabular}

\section{Step Three: Demographic Background}

In this stage of the study, all demographic variables were entered at once. The model used from this point forward is known as the Random Intercept and Random Slopes Model. This model considered student backgrounds (demographic, family, and academic) as well as student engagement at level 1 while also evaluating the high school curriculum practices and environment at level 2. The equations below represented this model as the level-1 model has the random intercept, $\beta_{0 j}$, and random slope coefficients, $\beta_{i j}$, while the level-2 model defined the random slope coefficients used in level-1 as a function of the high school practices and environment. The $\beta_{i j}$ coefficients were estimates for slope variability or the random effects of the specified student-level variable for school $\mathrm{j}$ and $\gamma_{i j}$ were the cross-level interaction coefficients for student-level variable $i$ 
and school-level variable $j$. Again, when using the logit link function, one can compute $\exp \left(\ln \left(\frac{p}{1-p}\right)\right)$ and $\varphi_{i j}=\frac{1}{1+\exp \left(-Y_{i j}\right)}$ to convert to odds in favor of persistence and the predicted probabilities $\left(\varphi_{i j}\right)$ of persistence, respectively. The following equations were entered into HLM7 to run the analysis.

\section{Level-1 Model.}

$$
\begin{aligned}
& \operatorname{Prob}\left(P E R S I S T_{i j}=1 \mid \beta_{j}\right)=\phi_{i j} \\
& \log \left[\phi_{i j} /\left(1-\phi_{i j}\right)\right]=\eta_{i j} \\
& \eta_{i j}=\beta_{0 j}+\beta_{l j}{ }^{*}\left(R A C E B_{i j}\right)+\beta_{2 j} *\left(H I S P_{i j}\right)+\beta_{3 j} *\left(G E N D E R_{i j}\right)
\end{aligned}
$$

\section{Level-2 Model.}

$$
\begin{aligned}
& \beta_{0 j}=\gamma_{00}+u_{0 j} \\
& \beta_{1 j}=\gamma_{10}+u_{1 j} \\
& \beta_{2 j}=\gamma_{20}+u_{2 j} \\
& \beta_{3 j}=\gamma_{30}+u_{3 j}
\end{aligned}
$$

Results. With persistence as the dependent variable, the HGLM analysis produced the estimated values presented in Table 9 and Table 10 based upon the HLM7 output. In Table 10 the variance component (residual term) estimates were given. The slope for Black and Hispanic students did not have significant variance components. Thus, these equations were fixed for future steps of the analysis.

Based upon 26 of the 31 schools with sufficient data for computation, the reliability estimates were moderate for gender (0.414) and the intercept (0.421) and lower for the race coefficients, 0.175 for Black students and 0.090 for Hispanic students. 
Table 9

Demographic Background: Final estimation of fixed effects

Population-average model

\begin{tabular}{llrrrr}
\hline Fixed Effect & Coefficient & $\begin{array}{r}\text { Standard } \\
\text { error }\end{array}$ & $t$-ratio & $\begin{array}{r}\text { Approx. } \\
\text { d.f. }\end{array}$ & $p$-value \\
\hline $\begin{array}{l}\text { For INTRCPT1, } \beta_{0} \\
\quad \text { INTRCPT2, } \gamma_{00}\end{array}$ & -0.036035 & 0.061655 & -0.584 & 30 & 0.563 \\
$\begin{array}{l}\text { For RACEB slope, } \beta_{1} \\
\quad \text { INTRCPT2, } \gamma_{10}\end{array}$ & -0.550031 & 0.117020 & -4.700 & 30 & $<0.001$ \\
$\begin{array}{l}\text { For HISP slope, } \beta_{2} \\
\quad \text { INTRCPT2, } \gamma_{20}\end{array}$ & -0.069506 & 0.081162 & -0.856 & 30 & 0.399 \\
$\begin{array}{l}\text { For GENDER slope, } \beta_{3} \\
\text { INTRCPT2, } \gamma_{30}\end{array}$ & 0.550780 & 0.112682 & 4.888 & 30 & $<0.001$ \\
\hline
\end{tabular}

Table 10

Demographic Background: Final estimation of variance components

\begin{tabular}{rrrrrr}
\hline Random Effect & $\begin{array}{r}\text { Standard } \\
\text { Deviation }\end{array}$ & $\begin{array}{r}\text { Variance } \\
\text { Component }\end{array}$ & $d . f$. & $\chi^{2}$ & $p$-value \\
\hline INTRCPT1, $u_{0}$ & 0.236 & 0.056 & 25 & 58.324 & $<0.001$ \\
RACEB slope, $u_{1}$ & 0.303 & 0.092 & 25 & 37.664 & 0.050 \\
HISP slope, $u_{2}$ & 0.174 & 0.030 & 25 & 23.506 & $>0.500$ \\
GENDER slope, $u_{3}$ & 0.393 & 0.154 & 25 & 46.633 & 0.006 \\
\hline
\end{tabular}

\section{Step Four: Demographic and Family Backgrounds}

All race and gender variables were carried over into this step with level-2

equations fixed for the intercept and slope for Hispanic students. The socioeconomic status (SES) variable was added to the regression analysis. The following equations were used in the HLM7 software.

\section{Level-1 Model.}

$\operatorname{Prob}\left(\right.$ PERSIST $\left._{i j}=1 \mid \beta_{j}\right)=\phi_{i j}$ $\log \left[\phi_{i j} /\left(1-\phi_{i j}\right)\right]=\eta_{i j}$ $\eta_{i j}=\beta_{0 j}+\beta_{1 j} *\left(R A C E B_{i j}\right)+\beta_{2 j}^{*}\left(H I S P_{i j}\right)+\beta_{3 j}^{*}\left(G E N D E R_{i j}\right)+\beta_{4 j} *\left(S E S_{i j}\right)$

\section{Level-2 Model.}

$\beta_{0 j}=\gamma_{00}+u_{0 j}$

$\beta_{l j}=\gamma_{10}$ 


$$
\begin{aligned}
& \beta_{2 j}=\gamma_{20} \\
& \beta_{3 j}=\gamma_{30}+u_{3 j} \\
& \beta_{4 j}=\gamma_{40}+u_{4 j}
\end{aligned}
$$

Results. In this stage, being female continued to have a positive effect, although reduced, on persistence at a statistically significant level $\left(\gamma_{30}=0.488, \mathrm{p}<0.001\right)$.

Race/ethnicity also continued to have a statistically significant increased negative effect for Black students $\left(\gamma_{10}=-0.583, \mathrm{p}<0.001\right)$ and a statistically non-significant and decreased negative effect for Hispanic students $\left(\gamma_{20}=-0.069, \mathrm{p}=0.402\right)$ as compared to the reference group of Whites and Asian Americans (See Table 11). Introducing socioeconomic status in the model revealed a positive effect on persistence $\left(\gamma_{40}=0.262\right.$, $\mathrm{p}=0.031)$. The variance components, as presented in Table 12, were all statistically significant and were carried over into the next step of this study. Based upon 28 of 31 schools with sufficient data, the reliability estimates were moderate for gender $(0.328)$ and the newly introduced SES variable (0.398) and reasonably large for the intercept (0.546).

Table 11

Demographic and Family Backgrounds: Final estimation of fixed effects Population-average model with robust standard errors

\begin{tabular}{lrrrrr}
\hline Fixed Effect & Coefficient & $\begin{array}{r}\text { Standard } \\
\text { error }\end{array}$ & $t$-ratio & $\begin{array}{r}\text { Approx. } \\
\text { d.f. }\end{array}$ & $p$-value \\
\hline $\begin{array}{l}\text { For INTRCPT1, } \beta_{0} \\
\quad \text { INTRCPT2, } \gamma_{00}\end{array}$ & -0.050211 & 0.067897 & -0.740 & 30 & 0.465 \\
$\begin{array}{l}\text { For RACEB slope, } \beta_{1} \\
\quad \text { INTRCPT2, } \gamma_{10}\end{array}$ & -0.582712 & 0.132618 & -4.394 & 2588 & $<0.001$ \\
$\begin{array}{l}\text { For HISP slope, } \beta_{2} \\
\quad \text { INTRCPT2, } \gamma_{20}\end{array}$ & -0.068952 & 0.082232 & -0.839 & 2588 & 0.402 \\
$\begin{array}{l}\text { For GENDER slope, } \beta_{3} \\
\quad \text { INTRCPT2, } \gamma_{30}\end{array}$ & 0.488288 & 0.109182 & 4.472 & 30 & $<0.001$ \\
$\begin{array}{l}\text { For SES slope, } \beta_{4} \\
\quad \text { INTRCPT2, } \gamma_{40}\end{array}$ & 0.262406 & 0.115818 & 2.266 & 30 & 0.031 \\
\hline
\end{tabular}


Table 12

Demographic and Family Backgrounds: Final estimation of variance components

\begin{tabular}{rrrrrr}
\hline Random Effect & $\begin{array}{r}\text { Standard } \\
\text { Deviation }\end{array}$ & $\begin{array}{r}\text { Variance } \\
\text { Component }\end{array}$ & $d . f$. & $\chi^{2}$ & $p$-value \\
\hline INTRCPT1, $u_{0}$ & 0.28167 & 0.07934 & 27 & 82.47060 & $<0.001$ \\
GENDER slope, $u_{3}$ & 0.33700 & 0.11357 & 27 & 45.25565 & 0.015 \\
SES slope, $u_{4}$ & 0.40171 & 0.16137 & 27 & 53.03171 & 0.002 \\
\hline
\end{tabular}

\section{Step Five: Demographic/Family Backgrounds and the High School Environment}

At this stage, the students' high school environment was introduced in the model. The following equations were entered into HLM7.

\section{Level-1 Model.}

$\operatorname{Prob}\left(P E R S I S T_{i j}=1 \mid \beta_{j}\right)=\phi_{i j}$

$\log \left[\phi_{i j} /\left(1-\phi_{i j}\right)\right]=\eta_{i j}$

$\eta_{i j}=\beta_{0 j}+\beta_{l j} *\left(R A C E B_{i j}\right)+\beta_{2 j}^{*}\left(H I S P_{i j}\right)+\beta_{3 j} *\left(G E N D E R_{i j}\right)+\beta_{4 j} *\left(S E S_{i j}\right)$

\section{Level-2 Model.}

$$
\begin{aligned}
& \beta_{0 j}=\gamma_{00}+\gamma_{01} *\left(\text { PCTMINORITY }_{j}\right)+\gamma_{02} *\left(\text { PCTFREEREDLUNCH }_{j}\right)+u_{0 j} \\
& \beta_{l j}=\gamma_{10} \\
& \beta_{2 j}=\gamma_{20} \\
& \beta_{3 j}=\gamma_{30}+u_{3 j} \\
& \beta_{4 j}=\gamma_{40}+u_{4 j}
\end{aligned}
$$

Results. This tier of the analysis revealed that the newly introduced contextual variable, percent of racial/ethnic minority students attending a high school, was the only statistically significant institutional effect on the average log-odds of degree attainment. Since Auerbach (2002), Useem (1992a,1992b), and Gamoran (1987) asserted that minority and SES statuses influenced student achievement outcomes, the percent of students on free and reduced lunch contextual variable remained in subsequent steps of the study even though it did not emerge as a statistically significant variable. Student 
variables on race (Black students), gender, and socioeconomic status remained as statistically significant variables at this point in the investigation. The estimated parameters have been presented in Table 13 and Table 14 based upon the HLM7 output. In Table 14 the variance component (residual term) estimates were given. The intercept and slopes for gender and socioeconomic status continued to have significant variance components. Thus, the related level-2 slope equations were carried over to the next step of the analysis with their residual terms.

Table 13

Demographic/Family Backgrounds and High School Environment Final estimation of fixed effects: Population-average model with robust standard errors

\begin{tabular}{lrrrrr}
\hline Fixed Effect & Coefficient & $\begin{array}{r}\text { Standard } \\
\text { error }\end{array}$ & $t$-ratio & $\begin{array}{r}\text { Approx. } \\
\text { d.f. }\end{array}$ & $p$-value \\
\hline $\begin{array}{l}\text { For INTRCPT1, } \beta_{0} \\
\quad \text { INTRCPT2, } \gamma_{00}\end{array}$ & -0.085872 & 0.057658 & -1.489 & 28 & 0.148 \\
$\quad$ PCTMINORITY, $\gamma_{01}$ & -0.009396 & 0.003768 & -2.493 & 28 & 0.019 \\
$\quad$ PCTFREEREDLUNCH, $\gamma_{02}$ & -0.001957 & 0.008903 & -0.220 & 28 & 0.828 \\
$\quad \begin{array}{l}\text { For RACEB slope, } \beta_{1} \\
\quad \text { INTRCPT2, } \gamma_{10}\end{array}$ & -0.514582 & 0.136769 & -3.762 & 2588 & $<0.001$ \\
$\quad \begin{array}{l}\text { For HISP slope, } \beta_{2} \\
\quad \text { INTRCPT2, } \gamma_{20}\end{array}$ & -0.054697 & 0.085338 & -0.641 & 2588 & 0.522 \\
$\quad \begin{array}{l}\text { For GENDER slope, } \beta_{3} \\
\quad \text { INTRCPT2, } \gamma_{30}\end{array}$ & 0.494454 & 0.110304 & 4.483 & 30 & $<0.001$ \\
$\quad$ For SES slope, $\beta_{4}$ & & & & & \\
$\quad$ INTRCPT2, $\gamma_{40}$ & 0.286113 & 0.120523 & 2.374 & 30 & 0.024 \\
\hline
\end{tabular}

Table 14

Demographic/Family Backgrounds and High School Environment Final estimation of variance components

\begin{tabular}{rrrrrr}
\hline \multirow{2}{*}{ Random Effect } & $\begin{array}{c}\text { Standard } \\
\text { Deviation }\end{array}$ & $\begin{array}{r}\text { Variance } \\
\text { Component }\end{array}$ & d.f. & $\chi^{2}$ & $p$-value \\
\hline INTRCPT1, $u_{0}$ & 0.23794 & 0.05662 & 25 & 62.62409 & $<0.001$ \\
GENDER slope, $u_{3}$ & 0.34044 & 0.11590 & 27 & 45.02456 & 0.016 \\
SES slope, $u_{4}$ & 0.41327 & 0.17080 & 27 & 52.21772 & 0.003 \\
\hline
\end{tabular}




\section{Step Six: Demographic/Family/Academic Backgrounds and Course-taking Patterns with High School Environment and Practices}

At this juncture, the high school course-taking patterns were introduced at level-2 and the community college course-taking patterns were brought in at the student-level. The variance components for entry math level, community college math proportion, remedial math attempts and percent of remedial English were also included. The following equations were entered into the HLM7 software.

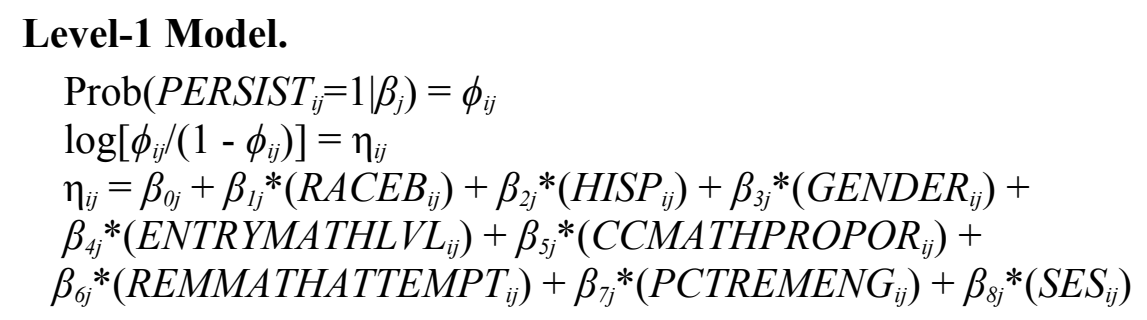

\section{Level-2 Model.}

$$
\begin{aligned}
& \beta_{0 j}=\gamma_{00}+\gamma_{01} *\left(\text { BREADTH }_{j}\right)+\gamma_{02} *\left(\text { RIGOR }_{j}\right)+\gamma_{03} *\left(\text { PCTMINORITY }_{j}\right)+ \\
& \gamma_{04} *\left(\text { PCTFREREDLUNCH }_{j}\right)+u_{0 j} \\
& \beta_{1 j}=\gamma_{10} \\
& \beta_{2 j}=\gamma_{20} \\
& \beta_{3 j}=\gamma_{30}+u_{3 j} \\
& \beta_{4 j}=\gamma_{40}+u_{4 j} \\
& \beta_{5 j}=\gamma_{50}+u_{5 j} \\
& \beta_{6 j}=\gamma_{60}+u_{6 j} \\
& \beta_{7 j}=\gamma_{70}+u_{7 j} \\
& \beta_{8 j}=\gamma_{80}+u_{8 j}
\end{aligned}
$$

Results. At the institutional level, the percent of racial/ethnic minorities attending a high school continued to be the only high school environment variable that 
had statistical significance. Although curriculum breadth and curriculum rigor were entered into the model, neither emerged as statistically significant institutional effects. In addition to gender and socioeconomic status, all of the newly introduced college coursetaking variables (entry math level, completed to attempted college-level math proportion, remedial math attempts, and percent of remedial English courses) were statistically significant variables at this point in the investigation. The estimated parameters have been presented in Table 15 and Table 16 based upon the HLM7 output. The variance component (residual term) estimates were given in Table 16. The intercept and slopes for gender, socioeconomic status, and all of the course-taking patterns did not have significant variance components. Therefore, all level-2 slope equations were fixed during the next step of the analysis. 
Table 15

Demographic/Family/Academic Backgrounds with High School Environment Final estimation of fixed effects: Population-average model with robust standard errors

\begin{tabular}{|c|c|c|c|c|c|}
\hline Fixed Effect & Coefficient & $\begin{array}{r}\text { Standard } \\
\text { error }\end{array}$ & $t$-ratio & $\begin{array}{r}\text { Approx. } \\
\text { d.f. }\end{array}$ & $p$-value \\
\hline \multicolumn{6}{|l|}{ For INTRCPT1, $\beta_{0}$} \\
\hline INTRCPT2, $\gamma_{00}$ & -0.039781 & 0.045941 & -0.866 & 26 & 0.394 \\
\hline BREADTH, $\gamma_{01}$ & -0.018494 & 0.033967 & -0.544 & 26 & 0.591 \\
\hline RIGOR, $\gamma_{02}$ & 0.005105 & 0.017610 & 0.290 & 26 & 0.774 \\
\hline PCTMINORITY, $\gamma_{03}$ & -0.005399 & 0.002184 & -2.472 & 26 & 0.020 \\
\hline PCTFREEREDLUNCH, $\gamma_{04}$ & 0.001186 & 0.006252 & 0.190 & 26 & 0.851 \\
\hline \multicolumn{6}{|l|}{ For RACEB slope, $\beta_{1}$} \\
\hline INTRCPT $2, \gamma_{10}$ & -0.076964 & 0.146097 & -0.527 & 2464 & 0.598 \\
\hline \multicolumn{6}{|l|}{ For HISP slope, $\beta_{2}$} \\
\hline INTRCPT $2, \gamma_{20}$ & 0.144331 & 0.080283 & 1.798 & 2464 & 0.072 \\
\hline \multicolumn{6}{|l|}{ For GENDER slope, $\beta_{3}$} \\
\hline INTRCPT $2, \gamma_{30}$ & 0.341551 & 0.115507 & 2.957 & 30 & 0.006 \\
\hline \multicolumn{6}{|l|}{ For ENTRYMATHLVL slope, $\beta_{4}$} \\
\hline INTRCPT $2, \gamma_{40}$ & 0.682384 & 0.082646 & 8.257 & 30 & $<0.001$ \\
\hline \multicolumn{6}{|c|}{ For CCMATHPROPOR slope, $\beta_{5}$} \\
\hline INTRCPT $2, \gamma_{50}$ & 0.021584 & 0.001362 & 15.842 & 30 & $<0.001$ \\
\hline \multicolumn{6}{|c|}{ For REMMATHATTEMPT slope, $\beta_{6}$} \\
\hline $\begin{array}{l}\text { INTRCPT2, } \gamma_{60} \\
\text { For PCTREMENG slope, } \beta_{7}\end{array}$ & 0.301756 & 0.068658 & 4.395 & 30 & $<0.001$ \\
\hline INTRCPT $2, \gamma_{70}$ & -0.010555 & 0.001222 & -8.640 & 30 & $<0.001$ \\
\hline For SES slope, $\beta_{8}$ & & & & & \\
\hline INTRCPT2, $\gamma_{80}$ & 0.443236 & 0.080701 & 5.492 & 30 & $<0.001$ \\
\hline
\end{tabular}

Table 16

Demographic/Family/Academic Backgrounds with High School Environment Final estimation of variance components

\begin{tabular}{rrrrrr}
\multicolumn{1}{l}{ Random Effect } & $\begin{array}{r}\text { Standard } \\
\text { Deviation }\end{array}$ & $\begin{array}{r}\text { Variance } \\
\text { Component }\end{array}$ & $d . f$. & $\chi^{2}$ & $p$-value \\
\hline INTRCPT1, $u_{0}$ & 0.10970 & 0.01203 & 22 & 27.05152 & 0.209 \\
GENDER slope, $u_{3}$ & 0.38490 & 0.14815 & 26 & 38.19657 & 0.058 \\
ENTMLVL slope, $u_{4}$ & 0.21625 & 0.04676 & 26 & 37.35016 & 0.069 \\
CCMATHPROPOR slope, $u_{5}$ & 0.00359 & 0.00001 & 26 & 24.60110 & $>0.500$ \\
REMMATHATTEMPT slope, $u_{6}$ & 0.19357 & 0.03747 & 26 & 29.64423 & 0.282 \\
PCTREMENG slope, $u_{7}$ & 0.00367 & 0.00001 & 26 & 23.69139 & $>0.500$ \\
SES slope, $u_{8}$ & 0.14837 & 0.02201 & 26 & 23.57008 & $>0.500$ \\
\hline
\end{tabular}




\section{Step Seven: Demographic/Family/Academic Backgrounds and Course-taking}

\section{Patterns with High School Environment and Practices and Student Engagement}

In this final stage of the analysis, the engagement variables (delayed entry, firstyear credits earned, and summer credits earned) were entered in the model while the level-2 slope equations for the college-course taking patterns (community college math proportion, remedial math attempts, percent of remedial English) were fixed for this step. The following equations were entered into the HLM7 software.

\section{First Attempt.}

\section{Level-1 Model.}

$\operatorname{Prob}\left(P E R S I S T_{i j}=1 \mid \beta_{j}\right)=\phi_{i j}$

$\log \left[\phi_{i j} /\left(1-\phi_{i j}\right)\right]=\eta_{i j}$

$\eta_{i j}=\beta_{0 j}+\beta_{l j} *\left(R A C E B_{i j}\right)+\beta_{2 j}^{*}\left(H I S P_{i j}\right)+\beta_{3 j} *\left(G E N D E R_{i j}\right)+$

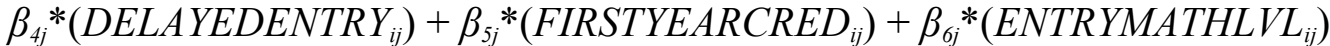

$+\beta_{7 j} *\left(C C M A T H P R O P O R_{i j}\right)+\beta_{8 j} *\left(\right.$ REMMATHATTEMPT $\left._{i j}\right)+$

$\beta_{9 j} *\left(P C T R E M E N G_{i j}\right)+\beta_{10 j} *\left(S U M M E R C R E D E A R N E D_{i j}\right)+\beta_{I l j} *\left(S E S_{i j}\right)$

\section{Level-2 Model.}

$$
\begin{aligned}
& \beta_{0 j}=\gamma_{00}+\gamma_{01} *\left(\text { BREADTH }_{j}\right)+\gamma_{02} *\left(\text { RIGOR }_{j}\right)+\gamma_{03} *\left(\text { PCTMINORITY }_{j}\right)+ \\
& \gamma_{04} *(\text { PCTFREEREDLUNCH }) \\
& \beta_{1 j}=\gamma_{10} \\
& \beta_{2 j}=\gamma_{20} \\
& \beta_{3 j}=\gamma_{30} \\
& \beta_{4 j}=\gamma_{40}+u_{4 j} \\
& \beta_{5 j}=\gamma_{50}+u_{5 j} \\
& \beta_{6 j}=\gamma_{60} \\
& \beta_{7 j}=\gamma_{70} \\
& \beta_{8 j}=\gamma_{80}
\end{aligned}
$$




$$
\begin{aligned}
& \beta_{9 j}=\gamma_{90} \\
& \beta_{10 j}=\gamma_{100}+u_{10 j} \\
& \beta_{11 j}=\gamma_{110}
\end{aligned}
$$

Results. This final step of the analysis had convergence issues perhaps as a result of missing related variables (Kim and Frees, 2007) or multicollinearity between the independent variables (Shieh and Fouladi, 2003). So, for this study, student aspirations can be considered as a missing variable that is related to the outcome variable as it has been shown to influence persistence in other studies (Astin, 1975; Cofer and Somers, 2001; Terenzini et al., 2001). Reviewing the correlations between the student-level variables, entry math level and remedial math attempts had the strongest linear relationship $(r=-0.786, \mathrm{p}<0.01)$. Shieh and Fouladi (2003) asserted:

Although there is no agreement about what constitutes "too high" of a correlation between predictor variables, when multicollinearity is present in a small amount, there is no concern about its impact. However, as the degree of multicollinearity increases, its consequences become more destructive. (p.954)

Since entry math level and remedial math attempts had a strong linear correlation, this implied that one was effectively a linear combination of the other. So, only the remedial math attempts variable was kept in the model to reduce the effects of multicollinearity. Thus, the following equations were used in the second part of this step.

\section{Second Attempt.}

\section{Level-1 Model.}

$$
\begin{aligned}
& \operatorname{Prob}\left(\operatorname{PERSIST} T_{i j}=1 \mid \beta_{j}\right)=\phi_{i j} \\
& \log \left[\phi_{i j} /\left(1-\phi_{i j}\right)\right]=\eta_{i j} \\
& \eta_{i j}=\beta_{0 j}+\beta_{1 j} *\left(R A C E B_{i j}\right)+\beta_{2 j} *\left(\operatorname{HISP}_{i j}\right)+\beta_{3 j} *\left(G E N D E R_{i j}\right)+
\end{aligned}
$$




$$
\begin{aligned}
& \beta_{4 j}^{*}\left(\text { DELAYEDENTRY }_{i j}\right)+\beta_{5 j} *\left(\text { FIRSTYEARCRED }_{i j}\right)+\beta_{6 j}^{*}\left(\text { CCMATHPROPOR }_{i j}\right) \\
& +\beta_{7 j} *\left(\text { REMMATHATTEMPT }_{i j}\right)+\beta_{8 j} *\left(\text { PCTREMENG }_{i j}\right)+ \\
& \beta_{9 j}{ }^{*}\left(\text { SUMMERCREDEARNED }_{i j}\right)+\beta_{10 j} *\left(\text { SES }_{i j}\right)
\end{aligned}
$$

\section{Level-2 Model.}

$$
\begin{aligned}
& \beta_{0 j}=\gamma_{00}+\gamma_{01} *\left(\text { BREADTH }_{j}\right)+\gamma_{02} *\left(\text { RIGOR }_{j}\right)+\gamma_{03} *\left(\text { PCTMINORITY }_{j}\right)+ \\
& \gamma_{04} *\left(\text { PCTFREERELUNCH }_{j}\right) \\
& \beta_{1 j}=\gamma_{10} \\
& \beta_{2 j}=\gamma_{20} \\
& \beta_{3 j}=\gamma_{30} \\
& \beta_{4 j}=\gamma_{40}+u_{4 j} \\
& \beta_{5 j}=\gamma_{50}+u_{5 j} \\
& \beta_{6 j}=\gamma_{60} \\
& \beta_{7 j}=\gamma_{70} \\
& \beta_{8 j}=\gamma_{80} \\
& \beta_{9 j}=\gamma_{90}+u_{9 j} \\
& \beta_{10 j}=\gamma_{100}
\end{aligned}
$$

Results. The model still did not converge with the removal of the entry level math variable. Using Adelman's 2006 findings on first-year momentum and summer credits and the fact that persistence was ultimately a function of completing college-level courses, the researcher retained two of the three engagement variables (first-year credits and summer credits earned), remedial math attempts, and the community college math proportion and removed delayed entry and percent of remedial English courses to attain a parsimonious model that would hopefully converge. The following equations were entered into the HLM7 software. 


\section{Third Attempt.}

\section{Level-1 Model.}

$\operatorname{Prob}\left(P E R S I S T_{i j}=1 \mid \beta_{j}\right)=\phi_{i j}$

$\log \left[\phi_{i j} /\left(1-\phi_{i j}\right)\right]=\eta_{i j}$

$\eta_{i j}=\beta_{0 j}+\beta_{1 j} *\left(R A C E B_{i j}\right)+\beta_{2 j} *\left(H I S P_{i j}\right)+\beta_{3 j}{ }^{*}\left(G E N D E R_{i j}\right)+$

$\beta_{4 j}^{*}\left(\right.$ FIRSTYEARCRED $\left._{i j}\right)+\beta_{5 j} *\left(\right.$ CCMATHPROPOR $\left._{i j}\right)+$

$\beta_{6 j}{ }^{*}\left(R E M M A T H A T T E M P T_{i j}\right)+\beta_{7 j}{ }^{*}\left(S U M M E R C R E D E A R N E D_{i j}\right)+\beta_{8 j} *\left(S E S_{i j}\right)$

\section{Level-2 Model.}

$$
\begin{aligned}
& \beta_{0 j}=\gamma_{00}+\gamma_{01} *\left(\text { BREADTH }_{j}\right)+\gamma_{02} *\left(\text { RIGOR }_{j}\right)+\gamma_{03} *\left(\text { PCTMINORITY }_{j}\right)+ \\
& \gamma_{04} *(\text { PCTFREEREDLUNCH }) \\
& \beta_{1 j}=\gamma_{10} \\
& \beta_{2 j}=\gamma_{20} \\
& \beta_{3 j}=\gamma_{30} \\
& \beta_{4 j}=\gamma_{40}+u_{4 j} \\
& \beta_{5 j}=\gamma_{50} \\
& \beta_{6 j}=\gamma_{60} \\
& \beta_{7 j}=\gamma_{70}+u_{7 j} \\
& \beta_{8 j}=\gamma_{80}
\end{aligned}
$$

Results. This model converged without any of the variance components being significant and with the percent of minorities attending a high school as the only statistically significant institutional effect on the average log-odds of persistence. All student variables except for Hispanic students emerged as statistically significant variables at this level of the investigation. Similar to Adelman's 2006 findings on student engagement, the first-year credits and summer credits earned variables emerged as statistically significant predictors of persistence. Black students and remedial math attempts were the only level-1 variables with negative coefficients while the community 
college math proportion variable had a positive coefficient. This suggested that students with higher amounts of remedial math attempts were linked to lower persistence rates and the accumulation of college-level math credits was linked to higher persistence rates. It also indicated that Black students with more remedial math attempts were linked to even lower rates of persistence. That is, as each of these independent variables were entered into the model, the persistence rate lowered. The estimated parameters have been presented in Table 17 and Table 18 based upon the HLM7 output. In Table 18 the variance component (residual term) estimates were given. The reliability estimate for summer credits earned was moderate (0.348) but stronger than that of first-year credits (0.137). 
Table 17

Demographic/Family/Academic Backgrounds with High School Environment and Community College Engagement:

Final estimation of fixed effects with robust standard errors

\begin{tabular}{|c|c|c|c|c|c|}
\hline Fixed Effect & Coefficient & $\begin{array}{r}\text { Standard } \\
\text { error }\end{array}$ & $t$-ratio & $\begin{array}{r}\text { Approx. } \\
\text { d.f. }\end{array}$ & $p$-value \\
\hline \multicolumn{6}{|l|}{ For INTRCPT1, $\beta_{0}$} \\
\hline INTRCPT $2, \gamma_{00}$ & 0.023636 & 0.061446 & 0.385 & 2610 & 0.701 \\
\hline BREADTH, $\gamma_{01}$ & -0.012052 & 0.033318 & -0.362 & 2610 & 0.718 \\
\hline RIGOR, $\gamma_{02}$ & 0.014594 & 0.015269 & 0.956 & 2610 & 0.339 \\
\hline PCTMINORITY, $\gamma_{03}$ & -0.008116 & 0.002283 & -3.555 & 2610 & $<0.001$ \\
\hline PCTFREEREDLUNCH, $\gamma_{04}$ & 0.004936 & 0.007071 & 0.698 & 2610 & 0.485 \\
\hline \multicolumn{6}{|l|}{ For RACEB slope, $\beta_{1}$} \\
\hline INTRCPT2, $\gamma_{10}$ & -0.358987 & 0.174771 & -2.054 & 2610 & 0.040 \\
\hline \multicolumn{6}{|l|}{ For HISP slope, $\beta_{2}$} \\
\hline $\begin{array}{l}\text { INTRCPT2, } \gamma_{20} \\
\text { For GENDER slope, } \beta_{3}\end{array}$ & 0.051451 & 0.093330 & 0.551 & 2610 & 0.581 \\
\hline $\begin{array}{l}\text { INTRCPT } 2, \gamma_{30} \\
\text { For FIRSTYEARCRED slope }\end{array}$ & 0.291228 & 0.123631 & 2.356 & 2610 & 0.019 \\
\hline $\begin{array}{l}\text { INTRCPT } 2, \gamma_{40} \\
\text { For CCMATHPROPOR slope, }\end{array}$ & 0.019781 & 0.009421 & 2.100 & 30 & 0.044 \\
\hline INTRCPT $2, \gamma_{50}$ & 0.015628 & 0.001663 & 9.399 & 2610 & $<0.001$ \\
\hline \multicolumn{6}{|c|}{ For REMMATHATTEMPT slope, $\beta_{6}$} \\
\hline INTRCPT $2, \gamma_{60}$ & -0.333549 & 0.041416 & -8.054 & 2610 & $<0.001$ \\
\hline \multicolumn{6}{|c|}{ For SUMMERCREDEARNED slope, $\beta_{7}$} \\
\hline INTRCPT $2, \gamma_{70}$ & 0.135299 & 0.008767 & 15.433 & 30 & $<0.001$ \\
\hline \multicolumn{6}{|l|}{ For SES slope, $\beta_{8}$} \\
\hline INTRCPT $2, \gamma_{80}$ & 0.239300 & 0.108547 & 2.205 & 2610 & 0.028 \\
\hline
\end{tabular}

Table 18

Demographic/Family/Academic Backgrounds with High School Environment and Community College Engagement: Final estimation of variance components

\begin{tabular}{crrrrr}
\hline Random Effect & $\begin{array}{r}\text { Standard } \\
\text { Deviation }\end{array}$ & $\begin{array}{r}\text { Variance } \\
\text { Component }\end{array}$ & d.f. & $\chi^{2}$ & $p$-value \\
\hline FIRSTYEARCRED, $u_{4}$ & 0.02356 & 0.00055 & 30 & 38.498 & 0.137 \\
\hline SUMMERCREDEARNED slope, $u_{7}$ & 0.02183 & 0.00048 & 30 & 32.416 & 0.348 \\
\hline
\end{tabular}

\section{Model Comparison}

Kreft and De Leeuw (1998) explained that the parameter estimates of the unconditional model were used as a "yardstick" which yielded a measure of variance reduction as more models were introduced (p. 64). The researcher determined if the 
model fit improved as predictors were added and the percent change in the deviances from the unconditional model to the final random intercept and random slopes model was evaluated. As shown in Table 19, there was an overall 7.7\% reduction in the variance component. Most of the reduction occurred in the second to last step of the multilevel regression analysis when course-taking patterns were entered at the student-level in the model. Unfortunately, a maximum likelihood estimate could not be computed for the last step, so the effect of the engagement variables could not be measured in terms of model fit.

Table 19

Deviance Statistics and Variance Reduction between Models Model Deviance (Number of estimated parameters)

Percent Change

\begin{tabular}{clc}
\hline 1 & $8617.628(2)$ & $\mathrm{n} / \mathrm{a}$ \\
2 & $8539.334(14)$ & $-0.91 \%$ \\
3 & $8518.618(11)$ & $-0.24 \%$ \\
4 & $8510.295(13)$ & $-0.10 \%$ \\
5 & $7853.491(41)$ & $-7.72 \%$ \\
6 & $*$ & - \\
$\begin{array}{l}\text { Note. *EM Laplace is unable to compute a maximum likelihood estimate within the parameter space. Unable to produce EM Laplace } \\
\text { results. }\end{array}$
\end{tabular}

\section{Research Question 1: Is there a predictive relationship between high school mathematics course enrollment patterns and degree attainment?}

Reviewing the breadth of the curriculum at each high school, the average number of courses above Algebra 2 was 4.03 with a standard deviation of 2.46 and a range of 7 and a minimum of zero. Regarding the rigor of the curriculum, the average percent of students enrolled in AP Calculus or Statistics across the 31 high schools was $2.91 \%$ with 
a standard deviation of 3.07 and a range of 11.59 with a minimum of zero. Although it was hypothesized that breadth and rigor can be used as predictors for persistence, it was only the percent of racial/ethnic minorities in a high school that had a statistically significant effect on degree attainment or continuous enrollment. This seemed to suggest that one could not conclude that there was a predictive relationship between high school mathematics course enrollment patterns and degree attainment; however, the fact that the number of remedial math attempts served as a predictor for lack of persistence, it pointed to high school academic preparation playing a key role in degree attainment as noted in other studies (Adelman, 2006; Gamoran, 1987; Oakes, 1994; Useem, 1992a, 1992b). It was also important to consider that the student population in this study was very different from those students who leave high school and enter directly in a 4-year institution. The latter group was most likely taking the advanced mathematics curriculum such as the AP classes, college dual enrollment classes or mathematics classes within the International Baccalaureate program.

\section{Research Question 2: Is there a predictive relationship between community college enrollment patterns in mathematics courses and degree attainment?}

A review of mathematics placement and remedial coursework at the community college was required to answer this question. While the high school practices and environment contextual variables did not have statistical significance, in regard to math placement and remedial math and English coursework, the intercepts for community college math proportion $\left(\gamma_{50}=0.01563, t=9.399, p\right.$-value $\left.<0.001\right)$ and remedial math attempts $\left(\gamma_{60}=-0.3335, t=-8.054, p\right.$-value $\left.<0.001\right)$ both had $p$-values less than 0.001 signifying there was a strong predictive relationship between these variables and degree attainment. 


\section{Research Question 3: Is there a predictive relationship between a student's high school curriculum and his or her degree attainment?}

Regarding high school and degree attainment, there were only 13 of the 31 schools for which $50 \%$ or more of the students earned at least an Associate degree or were still enrolled in the study's timeframe with $65.3 \%$ being the highest rate of degree attainment (see Table 4.11). Ten of these schools were traditional high schools, 1 was a technical center high school, and the remaining 2 were alternative high schools. Regarding demographics, these schools on average had about $11.5 \%$ less racial/ethnic minorities and about 3.4\% less students on free- and reduced-lunch. Looking at school grade ratings, 4 of these schools were A-rated, 2 were B-rated, and 5 were C-rated. The alternative high schools did not have school grades. Intriguingly, this spread in the school grade ratings seemed to underscore the need to look at the available curriculum.

Reviewing the opportunities to take rigorous mathematics courses, schools averaged four courses above Algebra 2 while some offered none or as many as 7 courses above Algebra 2. There was also wide variability in AP enrollment with some schools having no students taking AP math and one school having $12 \%$ of their students enrolled. This variability in opportunity severely limited some students' trajectories (Useem, 1992b) and the choice to be college bound without sufficient preparation fed students into a cycle of remediation that was difficult to overcome (Roth, Crans, Carter, Ariet, and Resnick, 2000). At a descriptive level, these varied opportunities "structure inequality" as Oakes (1994) succinctly described. 


\section{Research Question 4: Is there a predictive relationship between the school's racial/ethnic demographics or socioeconomic status and degree attainment?}

Concerning the racial/ethnic demographics and socioeconomic status of the high schools, the percent of minority students in a high school $\left(\gamma_{03}=-0.008116, t=-3.555\right.$, $\mathrm{p}<0.001$ ) was the only institutional effect that served as a predictor of persistence. The curriculum breadth and curriculum rigor institutional-level variables did not appear to be predictors of degree attainment. So, while the breadth and rigor of the curriculum did not materialize as predictors of persistence in this study, the high levels of remedial math attempts pointed to variations at the course level that were not captured in this study. In fact, since these students began their postsecondary careers at the community college, this may be a measure of missed opportunities. That is, these students may not have been exposed to or given the opportunity to attempt rigorous courses.

\section{Theoretical Framework Revisited}

Human capital, social capital and cultural capital have all been used in attempts to explain student achievement. The choices individuals have made about schooling such as where an individual enrolled in school or the types of courses they took in school had the potential to produce desirable outcomes such as an earned high school diploma or college

degree, forms of cultural capital. So, does human capital create cultural capital or social capital or is the reverse true? This study revealed social capital (the availability of the curriculum) may play a role in creating cultural capital, degree attainment. Earning this credential can lead to more learning opportunities to improve one's knowledge and skills, human capital. So, while Becker $(1962,1992)$ demonstrated that human capital contributed to the creation of social capital and cultural capital, one can argue that social 
capital played a role in creating human and cultural capital based upon the results of this study. Coleman (1988) recognized this when he explained individuals were socialized by governing norms which were shaped by their social context. That is, a student made choices about what courses to take based upon what seemed normal for his or her peer group. Lamont and Lareau (1988) discussed how individuals used their social and cultural capital to yield social gains which in a school setting can be placement in advanced courses. Consequently, these actions have led to group inclusion and thereby exclusion. Lamont and Lareau (1988) sought to build upon the work of Pierre Bourdieu and Jean-Claude Passeron in defining cultural capital in this context of exclusion and the power the dominant group exerted on others. Lamont and Lareau (1988) identified four forms of exclusion: self-elimination, overselection, relegation, and direct selection. The students in this study seemed to fall into the self-elimination and relegation categories. In self-elimination, "individuals adjust aspirations to their perceived chances of success" while relegation described those "individuals with less-valued cultural resources [who] end up in less desirable positions and get less out of their education investment" (p. 158). Interestingly enough, the relegated group's “cultural disadvantage [was] manifested under the forms of 'relay mechanisms' such as early, often ill-informed decisions, forced choice, and lost time" (p. 158). The students in this study seemed to be victims of forced choice regarding curriculum selection at the high school which may have been translated into lost time at the community college exhibited by multiple remedial mathematics attempts and a high percentage of students who dropped out of college, perhaps to work to support themselves and/or family. This finding was contrary to Becker's 1992 
argument that humans were rational actors and made choices based upon the economics of the situation.

\section{Summary}

Descriptive statistics were presented for each of the 11 student-level predictor variables as well as the four school-level contextual variables. The four research questions were analyzed at the 0.05 significance level using the final hierarchical generalized linear model. While the unconditional model was analyzed first, the random intercept and random slopes model was used in a step-by-step fashion to improve the fit of the data and to evaluate individual intercepts and slopes related to the independent variables for each high school as they collectively contributed to persistence. Results were analyzed using the Logit-Link Function for the Population-Average model. Table 20 summarized student persistence by high school and Table 17 contained the random intercepts and random slopes from the HGLM analysis. 
Table 20

Student Persistence by High School

\begin{tabular}{cccc} 
High & \multicolumn{2}{c}{ Persist } & \multirow{2}{*}{ Total } \\
\cline { 2 - 3 } School & No & Yes & \\
\cline { 1 - 2 } A & 16 & 15 & 31 \\
B & 35 & 27 & 62 \\
C & 67 & 49 & 116 \\
D & 30 & 29 & 59 \\
E & 28 & 14 & 42 \\
F & 26 & 10 & 36 \\
G & 4 & 2 & 6 \\
H & 1 & 1 & 2 \\
I & 16 & 22 & 38 \\
J & 3 & 0 & 3 \\
K & 48 & 43 & 91 \\
L & 47 & 42 & 89 \\
M & 51 & 96 & 147 \\
N & 12 & 20 & 32 \\
O & 80 & 45 & 125 \\
P & 61 & 68 & 129 \\
Q & 52 & 41 & 93 \\
R & 29 & 29 & 58 \\
S & 50 & 35 & 85 \\
T & 52 & 26 & 78 \\
U & 1 & 1 & 2 \\
V & 85 & 91 & 176 \\
W & 85 & 127 & 212 \\
X & 76 & 60 & 136 \\
Y & 52 & 62 & 114 \\
Z & 97 & 124 & 221 \\
AA & 39 & 32 & 71 \\
BB & 146 & 204 & 350 \\
CC & 11 & 3 & 14 \\
DD & 17 & 19 & 36 \\
EE & 15 & 14 & 29 \\
Total & 1332 & 1351 & 2683
\end{tabular}




\section{CHAPTER V}

\section{CONCLUSIONS and RECOMMENDATIONS}

In this study, the researcher analyzed the mathematics course-taking patterns of secondary students in an urban Florida school district in order to determine their relationships with a student's continuous enrollment or successful attainment of at least an Associate degree. Racial/ethnic demographic and socioeconomic profiles of high schools and their linkages to degree attainment were also analyzed.

\section{Conclusions}

While Reys, Dingman, Nevels, and Teuscher (2007) have reported an increase in high school mathematics curriculum standards in 39 states, Barth (2002) and Terenzini et al. (2001) encouraged policymakers to foster an environment in which state and local strategies are required to enable systemic change across the K-12, community college, and state university sectors. Useem (1992a) also asserted that while national databases definitely serve a purpose, they did not capture the complex path a student navigated from high school to college on a local level. This study attempted to disaggregate local data using 11 independent variables (Race - Black, Ethnicity - Hispanic, gender, delayed entry, first-year credits earned, entry math placement level at the community college, community college math proportion, remedial math attempts, percent of remedial English coursework as compared to all English coursework taken, summer credits earned, and socioeconomic status as defined by being need-based financial aid recipient) at the student-level and four contextual variables (high school practice in terms of breadth and rigor of mathematics curriculum and high school environment in terms of the percentage of students on free and reduced lunch as well as the percentage of racial/ethnic minorities 
in each high school) to unearth what factors were significant predictors of degree attainment for students who begin their higher education path at the community college.

Success in higher education was shown to be a function of one's academic preparation as identified in several studies at the national level (Adelman, 2006; Adelman, 1999) and the state level (Burris, Heubert, and Levin, 2006; Venezia, Kirst, and Antonio, 2003; Roth, Crans, Carter, Ariet, and Resnick, 2000). This study contributed to the need for local data as the research aim was to answer the following four research questions:

Research Question 1: Is there a predictive relationship between high school mathematics course enrollment patterns and degree attainment?

Research Question 2: Is there a predictive relationship between community college enrollment patterns in mathematics courses and degree attainment? Research Question 3: Is there a predictive relationship between a student's high school curriculum and his or her degree attainment?

Research Question 4: Is there a predictive relationship between the school's racial/ethnic demographics or socioeconomic status and degree attainment? To answer these questions, data on the class of 2002 graduates were collected and analyzed including course enrollment patterns at the local community college from 20022008.

For research question 1 on high school course-taking patterns, the analysis revealed that seven of the predictor variables at the student-level (Black students, gender, socioeconomic status, first-year credits earned, community college math proportion, remedial math attempts, and summer credits earned) had significant t-ratios at the $\mathrm{p}<$ 0.05 level. Aside from the three demographic and family background variables, two of 
the remaining four statistically significant predictor variables were math related which aligned with the findings of Roth et al. (2000) and Adelman (2006) whose studies revealed that the highest influence on academic achievement and thereby degree attainment was a student's mathematics high school performance. On the other hand, neither the breadth nor the rigor contextual variables under High School Practices was linked to degree attainment. That is, no relationship was found between the average high school course-taking patterns and a student's degree attainment. This seemed contradictory since the number of remedial math attempts linked to degree attainment implied a student's academic preparation in the high school was somehow intertwined with degree attainment.

For research question 2 on community college course-taking patterns, the analysis revealed that four of the predictor variables at the student-level (community college math proportion, remedial math attempts, first-year credits earned, and summer credits earned) had significant t-ratios at the $\mathrm{p}<0.05$ level. The statistically significant summer credit accumulation and first-year credits earned findings were consistent with the results in Adelman's 2006 Toolbox Revisited study that indicates these two variables give students sufficient momentum to persist toward degree attainment. Further, the lack of good academic preparation in mathematics haunted these students as they required remedial coursework and made multiple attempts at remedial classes, which was also problematic.

For research question 3 on high school curriculum, on average $(n=31)$, high schools offered about 4 courses above Algebra 2 and $2.91 \%$ of students enrolled in AP Calculus or Statistics. However, the truth was possibly obscured by the fact that while the courses were leveled above Algebra 2, the content was probably not at the same level 
as noted by Adelman (2006). Additionally, the study sample was adjusted to look at students in a specific county that began their postsecondary education at the local community college. Therefore, the findings were possibly skewed by removing the students who were admitted to 4-year institutions because of their higher levels of academic achievement. None of the high school curriculum contextual variables on breadth and rigor emerged as statistically significant variables. This was a surprising discovery as the aforementioned studies all indicated that school effects influenced degree attainment and that the strongest predictor for degree attainment was academic preparation.

For research question 4 on high school racial/ethnic demographics or socioeconomic status, only one (percent of racial/ethnic minorities in a high school) of the four contextual variables (breadth, rigor, percent minority, and percent on free and reduced lunch) was a statistically significant contributor to the model for student persistence towards degree attainment. This result did not fully align with the findings of Adelman (2006), Gamoran (1987), Oakes (1994), and Useem (1992a, 1992b).

\section{Recommendations}

The results of this study suggested that high schools have abandoned these students to be picked up by the community colleges in addition to abandoning those students who did not attempt to enter the doors of the community college. There were several recommendations to consider for future research regarding the high school mathematics curriculum, cross-sector collaboration, the postsecondary mathematics curriculum, research methods, study replicability, and the study's theoretical framework. While only one of the high school environment variables was a statistically significant 
contributor to students' degree attainment and two of the three community college coursework predictor variables were math related, it highlighted the disconnect that existed between the K-12 and postsecondary sectors as measured by the high levels of remediation that were still needed upon entry into the community college. While this study mimicked the Burris, Heubert, and Levin (2006) study to use student enrollment in AP Calculus or AP Statistics as measures for rigor, one recommendation that may further enlighten related studies is to highlight and include the accelerated courses in the definition of rigor, such as those in the International Baccalaureate (IB) program or those offered for dual enrollment. Students who successfully completed the IB exam or the dual enrollment course earned college credit upon admission to a Florida college or university which contributes to degree attainment. When applying this recommendation, researchers should include the entire student body to determine the differences in paths for students going to the university versus the community college.

On faculty, more faculty collaboration is needed to address this misalignment as suggested by Barth (2002). Barth (2002) noted that mathematics faculty were "startled" by the fact that they were teaching the same Algebra I course even though they were from different institutions along the K-20 educational pipeline - middle schools, high schools, community college, and the local university. Also, recall that Haycock, Barth, Mitchell, and Wilkins (1999) pointed out that "over the last decade, college-level courses...have been the fastest growing part of the high school curriculum [while] at the same time, the biggest growth in the college curriculum has been in high school-level courses!” (p. 30). This realization was reflected in the remedial course offerings in higher educational institutions. Higher education policymakers and practitioners should design and offer 
professional development to teach high school and college-level faculty how to foster learner-centered environments and facilitate learning to allow students to take more ownership of the learning process. Further, while this study was retroactive, future research should also include measures on teacher effects such as their academic backgrounds and attitudes.

Regarding postsecondary mathematics courses, further evaluation and restructuring of math learning outcomes and course delivery is needed, particularly with gatekeeper algebra-based courses. This study underscored the need to disaggregate national and state level data. While the results were mixed, the analysis of local data generated useful information for local collaboration and policy recommendations. As the students in this study were only those 2002 high school graduates who began their postsecondary education at a community college, using the course enrollment patterns of some of the Class of 2002 could have contributed to mixed results. Hence, attempts should be made to include course enrollment patterns of students at the postsecondary level regardless of where they begin their pursuit of higher education. As it was difficult to secure such a sizeable data set, it is recommended for states to start conducting analyses on degree completion with a wider lens to include all high school graduates in a particular class to evaluate postsecondary enrollment and completion rates on a local basis. Future research studies should also include measures to capture student aspirations and expectations, parental educational level, parental involvement, employment status of students, and grade point average analysis as recommended by many scholars (Adelman, 2006; Astin, 1975; Cofer and Somers, 2001; Ingels, Planty, and Bozick, 2005; Terenzini, Cabrera and Bernal, 2001). 
When designing a study, one should be cautious about the amount of variables chosen for consideration and their collective relationship to the dependent variable. Prior to running HLM analyses, researchers should take a proactive approach in managing possible non-convergence issues by running correlation models, such as Pearson-r or curvilinear, to eliminate variables that may add "noise" in the model and cause frustration for the researcher. Additionally, one should strengthen the research method by running a comparable ordinary least squares (OLS) linear regression model with the same dependent variable and key independent variables and compare outcomes as a measure to avoid Type VI errors as was strongly encouraged by Newman, Newman, and Salzman (2010). If the separate model produces the same results, then the researcher's findings are reinforced. Whereas if the OLS model produces different results, the researcher has more to determine on where the differences occur and why. For this study, an OLS linear regression model was set up to compare outcomes with the dependent variable as the percent of students within a high school to persist and two independent variables on the curriculum rigor and percent of minority students in a high school. The following model was used:

$$
\operatorname{pctPERSIST}=b_{l}(\text { CURRICULUMRIGOR })+b_{2}(\text { pctMINORITY })+a
$$

where $b$ s were the regressions coefficients for the respective predictor variables and $a$ was the regression constant. SPSS 18.0 was used to run this analysis and the results reinforced the findings of the HGLM analysis conducted in this study (See Table 21). That is, the pctMINORITY contextual variable emerged with strong statistical significance as a predictor of student persistence as it did in the HGLM analysis. 
Table 21

Ordinary Least Squares Comparison Model Results

Coefficients

\begin{tabular}{|c|c|c|c|c|c|c|}
\hline \multirow[t]{3}{*}{ Model } & & & & \multicolumn{3}{|l|}{ Standardized } \\
\hline & & \multicolumn{2}{|c|}{ Unstandardized Coefficients } & \multirow{2}{*}{$\frac{\text { Coefficients }}{\text { Beta }}$} & \multirow[b]{2}{*}{$t$} & \multirow[b]{2}{*}{ Sig. } \\
\hline & & $B$ & Std. Error & & & \\
\hline \multirow[t]{3}{*}{1} & (Constant) & 62.776 & 6.603 & & 9.508 & .000 \\
\hline & currRigor & .675 & .666 & .158 & 1.014 & .319 \\
\hline & pctMinority & -.328 & .094 & -.541 & -3.472 & .002 \\
\hline
\end{tabular}

Note. Dependent Variable: pctPERSIST

Moreover, Newman, McNeil, and Fraas (2004) asserted that researchers should include the probabilities for future researchers to replicate studies. Interestingly enough, they shared a straightforward approach through the use of the alpha level. This was important with studies that can impact large amounts of people especially in educational settings and as it relates to closing achievement gaps. It gave the researcher practical knowledge to determine the degree to which the same results can be achieved in replication studies. For example, in this study, there were several variables with a pvalue less than 0.001 . The practical significance of these results would not be known if the replicability chance were not simultaneously reported. In fact, readers can take away false assumptions that if they repeated the study, which was conducted at 0.05 alpha level, 100 times, 95 of their trials would be statistically significant. Newman, McNeil, and Fraas (2004) corrected this assumption and reported the chance as "only slightly above the 50-50 level" (p. 37) for the 0.05 alpha level. The chance of replicability increased to above $90 \%$ for the 0.001 alpha level, which occurred for some of the variables in this study (community college math proportion, remedial math attempts, summer credits earned, and percent minority attending the high school). Thus, there is a high level of confidence that future replication studies will find that these variables will be statistically 
significant. In sum, researchers should act responsibly and not only report the results, but also its practical use.

In conclusion, community college faculty and administrators have accepted the cooling out process and now, the new cooling out process, for far too long. By reviewing mathematics course-taking patterns at the high school and community college levels on a local basis, this study revealed that certain students (Blacks, males) lacked sufficient human and social capital to persist and complete a college degree, a form of cultural capital. The availability of an advanced mathematics curriculum at a specific high school can be seen as a form of social capital. For the students in this study, there was a broad range (0 to 7 ) in the number courses offered above Algebra 2 at the 31 high schools. As cultural capital itself plays a hidden role in class stratification, the role that cultural capital played for this study sample was revealed in the lessened degree attainment for Black students. Again, one should remember that race as a variable is easier to measure than micro-processes occurring within schools as noted by Lareau and Weininger (2003), but by no means indicates race is the reason for smaller degrees of student achievement. Additionally, while this study did not find linkages between high curriculum practices and college persistence, it did find high levels of remediation at the community college level. More local research is needed to determine what occurs in the high school regarding curriculum availability, content, and rigor that may be related to high levels of remediation at the community college. Based upon the results of this study, one conjecture could be that these students were left out of the college bound track where they would gain exposure to advanced curriculum which has been shown to increase students' chances of completing degrees. With these recommendations, hopefully 
educators can find ways to reverse these trends on a local and ultimately a national level, strengthen the educational pathways for students, and propel them to degree completion. 


\section{REFERENCES}

Adelman, C. (1999). Answers in the toolbox: Academic intensity, attendance patterns, and bachelor's degree attainment. Washington, DC: U.S. Department of Education. Retrieved from http://www.ed.gov/pubs/Toolbox/toolbox.html

Adelman, C. (2006). The toolbox revisited: Paths to degree completion from high school through college. Washington, DC: U.S. Department of Education. Retrieved from http://www2.ed.gov/rschstat/research/pubs/toolboxrevisit /toolbox.pdf

Advisory Committee on Student Financial Assistance. (2006). The toolbox and student aid policy. Retrieved from http://www2.ed.gov/about/bdscomm/list/acsfa /acsfapolicybriefmarch2006.pdf

American Mathematical Association of Two-Year Colleges, Blair, R. (Ed). (2006). Beyond crossroads: Implementing mathematics standards in the first two years of college. Memphis, TN: AMATYC.

Anderson, G., Alfonso, M., \& Sun, J. (2006). Rethinking cooling out at public community colleges: An examination of fiscal and demographic trends in higher education and the rise of statewide articulation agreements. Teachers College Record, 108(3), 422-451.

Apple, M.W. (1995). Education and power. (2nd ed.) New York, NY: Routledge.

Astin, A. (1975). Preventing students from dropping out. San Francisco, CA: JosseyBass Publishers.

Auerbach, S. (2002). "Why do they give the good classes to some and not to others?" Latino parent narratives of struggle in a college access program. Teachers College Record, 104(7), 1369-92.

Ayalon, H. (2003). Women and men go to university: Mathematical background and gender differences in choice of field in higher education. Sex Roles, 48(5/6), $277-$ 290.

Barth, P. (Ed.) (2002). Add it up: Mathematics education in the U.S. does not compute. Thinking K-16, 6(1), 1-23.

Baydar, N. Brooks-Gunn J., \& Furstenberg, F.F. (1993). Early warning signs of functional illiteracy: Predictors in childhood and adolescence. Child Development, 64(3), 815-829.

Becker, G.S. (1962). Investment in human capital: A theoretical analysis. The Journal of Political Economy, 70(5), 9-49. 
Becker, G.S. (1992). Human capital and the economy. Proceedings of the American Philosophical Society, 136(1), 85-92.

Bendickson, M.M. (2004). The impact of technology on community college students' success in remedial/developmental mathematics. Retrieved from http://etd.fcla.edu/SF/SFE0000591/MBendicksonDiss062504.pdf.

Blakeslee, J. (2005). Inequality in America: What role for human capital policies? Focus, 23(3), 1-10.

Borglum, K. \& Kubala, T. (2000). Academic and social integration of community college students: A case study. Community College Journal of Research and Practice, 24, 567-576.

Bourdieu, P. \& Passeron, J. (1990). Reproduction in Education, Society and Culture. London, England: SAGE Publications Ltd.

Bowles, S. \& Gintis, H. (1975). The problem with human capital theory-A marxian critique. The American Economic Review, 65(2), 74-82.

Bransford, J., Sherwood, R., Vye, N., et al. (1986). Teaching thinking and problem solving. American Psychologist, 41(10), 1078-1089.

Brenner, M.E., Mayer, R.E., Moseley, B., Brar, T., Duran, R., Reed, B.S., et al. (1997). Learning by understanding: The role of multiple representations in learning algebra. American Educational Research Journal, 34(4), 663-689.

Brint, S., \& Karabel, J. (1989). The diverted dream: Community colleges and the promise of educational opportunity in America, 1900-1985. New York, NY: Oxford University Press.

Broward College. (2006). Fall Student Survey. Retrieved from http://www.broward.edu /facts/SupportingContent/Fall\%202006\%20Student\%20Survey.pdf

Bruner, J. (2011). Nobel laureates by country and prize. Retrieved from http://www .forbes.com/sites/jonbruner/2011/10/05/nobel-prizes-and-american-leadership-inscience-infographic/

Burris, C.C., Heubert, J.P., \& Levin, H.M. (2006). Accelerating mathematics achievement using heterogeneous grouping. American Educational Research Journal, 43(1), 105-136.

Butler, D. (2002). Qualitative approaches to investigating self-regulated learning: Contributions and challenges.Educational Psychologist, 37(1), 59-63. 
Cabrera, A.F., Castaneda, M.B., Nora, A. \& Hengstler, D. (1992). The convergence between two theories of college persistence. The Journal of Higher Education, 63(2), 143-164.

Cabrera, A.F., Nora, A. \& Castaneda, M.B. (1993). College persistence: Structural equations modeling test of an integrated model of student retention. Journal of Higher Education, 64 (2), 123-139.

Cabrera, A.F. (1994). Logistic regression analysis in higher education: An applied perspective. In John C. Smart (ed.), Higher Education: Handbook of Theory and Research (225-256), Vol. 10. New York: Agathon Press.

Chall, J. (2000). The academic achievement challenge. New York, NY: The Guilford Press.

Clark, B. (1960). The "cooling-out" function in higher education. The American Journal of Sociology, 65,(6), 569-576.

Clark, B. The open door college, New York, NY: McGraw-Hill, 1965.

Cofer, J. and Somers, P. (2001). What influences student persistence at two-year colleges? Community College Review, 29(3), 56-77.

Cohen, A. M., \& Brawer, F. B. (1996). The American community college (3rd ed.). San Francisco, CA: Jossey-Bass, Inc.

Committee on the Function of Mathematics in General Education of the Commission on Secondary School Curriculum (1940). Mathematics in general education. New York, NY: D. Appleton-Century Company, Inc. Retrieved from http://www .mathcurriculumcenter.org/PDFS/CCM/originals/math_gen_ed_report.pdf

Crosnoe, R. \& Huston, A. (2007). Socioeconomic status, schooling, and the developmental trajectories of adolescents. Developmental Psychology,43(5), 1097-1110.

Cross, B. E. (2003). Learning or unlearning racism: Transferring teacher education curriculum to classroom practices. Theory into Practice, 42(3), 203-209.

Cunha, F. \& Heckman, J. (2007). The technology of skill formation. The American Economic Review, 97(2), 31-47.

Darling-Hammond, L. (1998). Teachers and teaching: Testing policy hypotheses from a national commission report. Educational Researcher, 27(1), 5-15. 
Dedrick, R. F., Ferron, J. M., Hess, M. R. Hogarty, K. Y., Kromrey, J. D., Lang, T. R., Niles, J. D., \& Lee, R. S. (2009). Multilevel modeling: A review of methodological issues and applications. Review of Educational Research, 79(1), 69-102.

DeMaris, A. (1995). A tutorial in logistic regression . Journal of Marriage and the Family, 57 (4), 956-968.

DesJardins, S.L., McCall, B.P., Ahlburg, D.A., and Moye, M.J. (2002). Adding a timing light to the 'Toolbox.' Research in Higher Education, 43(1), 83-114.

Dewey, J. (1916 ). Democracy and education. New York, NY: McMillan.

Dougherty, K. (1994). The contradictory college: The conflict origins, impacts, and futures of the community college. Albany, NY: State University of New York Press.

Dowd, A. C. \& Coury, T. (2006). The effect of loans on the persistence and attainment of community college students. Research in Higher Education, 47(1), 33-62.

Doyon, P. (2001). A review of higher education in modern Japan. Higher Education 41(4), 443-470.

Dumais, S.A. (2002). Cultural capital, gender, and school success: The role of habitus. Sociology of Education, 75(1), 44-68.

Education, Audiovisual \& Culture Executive Agency (Eurydice). (2009). Higher education in Europe 2009: Developments in the Bologna process. Brussels, Belgium. Retrieved from http://eacea.ec.europa.eu/education/eurydice/documents/ thematic_reports/099EN.pdf

Farkas, G., Grobe, R.P., Sheehan, D., Shuan, Y.(1990). Cultural resources and school success: Gender, ethnicity, and poverty groups within an urban school district. American Sociological Review, 55(1), 127-142.

Field, A. (2009). Discovering statistics using SPSS (3rd ed.). Thousand Oaks, CA: Sage Publications, Inc.

Florida Department of Education (2003). High school graduation options - Senate bill 30a: Retrieved from http://www.fldoe.org/ese/newgrad/high5all.pdf

Florida Department of Education (2003). Keeping the open door open: Community college enrollments and trends. Retrieved from http://www.fldoe.org/gr/pdf /presentations/12-11-03_Community_College_Enrollment_Trends_and _Estimates.pdf 
Florida Department of Education (2006). New high school graduation requirements, "it's a major opportunity!" Retrieved from http://info.fldoe.org/docushare/dsweb /Get/Document-3883/k12_06_116memo.pdf

Florida Department of Education (2005). PK20 Education Data Warehouse. Retrieved from http://edwapp.doe.state.fl.us/doe/

Gamoran, A. (1987). The stratification of high school learning opportunities. Sociology of Education, Vol. 60, No. (3), 135-155.

Ginsburg, H.P. \&Russell, R.L. (1981). Social class and racial influences on early mathematical thinking. Monographs of the Society for Research in Child Development, 46( 6), 1-69.

Harker, R. K., Mahar, C., \& Wilkes, C. (Eds.) (1990). An Introduction to the work of Pierre Bourdieu: The practice of theory. New York, NY: St. Martin's Press.

Haveman, R. \& Wolfe, B. (1995). The determinants of children's attainments: A review of methods and findings. Journal of Economic Literature, 33(4), 1829-1878.

Haycock, K., Barth, P., Mitchell, R., \& Wilkins, A. (Eds.). (1999). Ticket to nowhere: The gap between leaving high school and entering college and highperformance jobs. Thinking K-16, 3(2), 1-31.

Hershberg, T. (1996). Human capital development: America's greatest challenge. The Annals of the American Academy of Political and Social Science, 544: 43-51.

Herzog, S. (2005). Measuring determinants of student return vs. dropout/stopout vs. transfer: A first-to-second year analysis of new freshmen. Research in Higher Education, 46(8), 883-928.

House, J. D. (2000). Academic background and self-beliefs as predictors of student grade performance in science, engineering and mathematics. International Journal of Instructional Media, 27 (2), 207.

Hox, J. J. (2002). Multilevel analysis: Techniques and applications. Mahwah, NJ: Lawrence Erlbaum Associates, Publishers.

Hox, J. J. \& Maas, C. J. M. (2005). Multilevel analysis. Encyclopedia of Social Measurement, 2, 785-793.

Hoyt, J.E. (1999). Remedial education and student attrition. Community College Review, $27(2), 51-72$. 
Hu, S. \& St. John, E.P. (2001). Student persistence in a public higher education system: Understanding racial and ethnic differences. The Journal of Higher Education, 72(3), 265-286.

Ingels, S.J., Planty, M., \& Bozick, R. (2005). A Profile of the American high school senior in 2004: A first look-Initial results from the first follow-up of the Education Longitudinal Study of 2002 (ELS:2002) (NCES 2006-348). U.S. Department of Education, National Center for Education Statistics. Washington, DC: U.S. Government Printing Office.

Jaffe, A.B. \& Trajtenberg, M. (1996). Flows of knowledge from universities and federal laboratories: Modeling the flow of patent citations over time and across institutional and geographic boundaries. Proceedings of the National Academy of Sciences of the United Stares of America, 93(23), 12671-12677.

Kinchen, O. A. (1936). Chronicles of Oklahoma, 14 (3), Retrieved from http://digital.library.okstate.edu/Chronicles/v014/v014p312.html

Kliebard, Herbert M. (2004). The struggle for the American curriculum, 1893-1958. New York: Routledge Falmer.

Kreft, I. \& De Leeuw, J. (1998). Introducing multilevel modeling. Thousand Oaks, CA: Sage Publications, Inc.

Lamont, M. \& Lareau, A. (1988). Cultural capital: Allusions, gaps and glissandos in recent theoretical developments. Sociological Theory, 6(2), 153-168.

Lareau, A. \& Weininger,E.B. (2003). Cultural capital in educational research: A critical assessment. Theory and Society, 32(5/6), 567-606.

Lee, J. \& Bowen, N.K. (2006). Parent involvement, cultural capital, and the achievement gap among elementary school children. American Educational Research Journal, 43(2), 193-218.

Link, A.S. (Ed.) (1974). The papers of Woodrow Wilson. Princeton, NJ: Princeton University Press.

List of Nobel laureates by country (n.d.). In Wikipedia. Retrieved from http://en.wikipedia.org/wiki/List_of_Nobel_laureates_by_country

Little, T. D., Schnabel, K. U., Baumert, J. (2000). Modeling longitudinal and multilevel data: Practical issues, applied approaches, and specific examples. Mahwah, NJ: Lawrence Erlbaum Associates, Publishers.

Lucas, S. R. (1999). Tracking inequality. New York: Teachers College Press. 
Marin, P. \& Lee, E.K. (2003). Appearance and reality in the Sunshine State: The Talented 20 Program in Florida. Massachusetts: The Civil Rights Project, Harvard University.

Matthews, W., Carpenter, T. P., Lindquist, M. M. \& Silver, E. A. (1984). The third national assessment: Minorities and mathematics. Journal for Research in Mathematics Education, 15(2), 165-171.

Moses, R.P. \& Cobb, Jr., C.E. (2001). Radical equations: Civil rights from Mississippi to the Algebra Project. Boston: Beacon Press.

Musoba, G.D. \& Baez, B. (2008). The Cultural Capital of “Cultural Capital.” In John Smart and William Tierney, eds., Higher Education: Handbook of Theory and Research. Bronx: Agathon Press.

National Commission on Excellence in Education (1983). A Nation at Risk: The Imperative for Educational Reform. Washington, DC: U.S. Department of Education.

Newman, I. \& Newman, C. (1994). Conceptual statistics for beginners. Maryland: University Press of America, Inc.

Newman, I., McNeil, K., \& Fraas, J. (2004). Two methods of estimating a study's replicability. Mid-Western Educational Researcher, 19(2), 36-40.

Newman, D., Newman, I., \& Salzman (2010). Comparing OLS and HLM models and the questions they answer: Potential concerns for type VI errors. Multiple Linear Regressions Viewpoints, 36(1).

Nguyen, A.N. \& Taylor, J. (2003). Post-high school choices: New evidence from a multinomial logit model. Journal of Population Economics, 16(2), 287-306.

Oakes, J. (1985). Keeping track: How schools structure inequality. New Haven, CT: Yale University Press.

Oakes, J. (1992). Can tracking research inform practice? Technical, normative, and political considerations. Educational Researcher, 21(4), 12-21.

Oakes, J. (1994). More than misapplied technology: A normative and political response to Hallinan on tracking. Sociology of Education, 67, (2), 84-91.

Oakes, J., Wells, A. S., Jones, M., \& Datnow, A. (1997). Detracking: The social construction of ability, cultural politics, and resistance to reform. Teachers College Record, 98(3), 482-510. 
Oklahoma Department of Education, The eighteenth biennial report of the state superintendent of public instruction (Oklahoma City, 1940). Retrieved on from http://junior-college-history.org/Sources/Oklahoma.html

Okun, M. A., Ruehlman, L., \& Karoly, P. (1991). Application of investment theory to predicting part-time community college student intent and institutional persistence/departure behavior. Journal of Educational Psychology, 83(2), 212220.

Pajares, F. (1996). Self-efficacy beliefs in academic settings. Review of Educational Research. 66(4), 543-579.

Pascarella, E.T., Pierson, C.T., Wolniak, G.C., \& Terenzini, P.T. (2004). First-generation college students: Additional evidence on college experiences and outcomes. The Journal of Higher Education, 75(3), 249-284.

Paulsen, M.B. \& St. John, E.P. (2002). Social class and college costs: Examining the financial nexus between college choice and persistence. The Journal of Higher Education, 73(2), 189-236.

Pedersen, R. (2005). Conflicting interests in the funding of the early two-year college. New Directions for Community Colleges, 2005(132), 5-17.

Peng, C.-Y. J., So, T. S. H., Stage, F. K., \& St. John, E. P. (2002). The use and interpretation of logistic regression in higher education journals: 1988-1999. Research in Higher Education, 43(3), 259-293.

Peng, C.-Y. J., Lee, K. L., \& Ingersoll, G. M. (2002). An introduction to logistic regression analysis and reporting. The Journal of Educational Research, 96(1), 314.

Perin, D. (2002). The location of developmental education in community colleges: A discussion of the merits of mainstreaming vs. centralization. Community College Review, 30(1), 27-44.

Porter, S.R. \& Swing, R.L. (2006). Understanding how first-year seminars affect persistence. Research in Higher Education, 47(1), 89-109.

Portes, A. (1998). Social capital: Its origins and applications in modern sociology. Annual Review of Sociology, 24, 1-24.

Press, S.J. \& Wilson, S. (1978). Choosing between logistic regression and discriminant analysis. Journal of the American Statistical Association, 73(364), 699- 705.

Raudenbush, S. W. \& Bryk, A. S. (2002). Hierarchical linear models: Applications and data analysis methods ( $2^{\text {nd }}$ ed.). Thousand Oaks, CA: Sage Publications, Inc. 
Reyes, L.H. \& Stanic, G.M.A. (1988). Race, sex, socioeconomic status, and mathematics. Journal for Research in Mathematics Education, 19 (1), 26-43.

Reys, B.J., Dingman, S., Nevels, N., \& Teuscher, D. (2007). High school mathematics: State-level curriculum standards and graduation requirements. Retrieved from http://www.mathcurriculumcenter.org/PDFS/HSreport.pdf

Roscigno, V.J. \& Ainsworth-Darnell, J.W. (1999). Race, cultural capital, and educational resources: Persistent inequalities and achievement returns. Sociology of Education, 72(3), 158-178.

Roth, J., Crans, G.G., Carter, R.L., Ariet, M., \& Resnick, M.B. (2000). Effect of high school course-taking and grades on passing a college placement test. The High School Journal, 84(2), 72-87.

Rumberger, R.W. \& Palardy, G. J. (2004). Multilevel models for school effectiveness research. In D. Kaplan (Ed.), Handbook on quantitative methodology for the social sciences (pp. 235-258). Thousand Oaks, CA: Sage.

Sackett, P.R., Hardison, C.M., \& Cullen, M.J. (2004). On interpreting stereotype threat as accounting for African American-White differences on cognitive tests. American Psychologist, 59(1), 7-13.

School Board of Broward County (2001). 2001-2002 Twentieth day enrollment report: Enrollment by level and by grade. Retrieved from http://www.broward.k12.fl.us /schoolboundaries/Counts/0102/OverAllByLevel\&Grd2.pdf

Senk, S. \& Thompson, D. (2003). Standards-based school mathematics curricula: What are they? What do students learn? New Jersey: Lawrence Erlbaum Associates.

Shieh, Y. \& Fouladi, R.T. (2003). The effect of multicollinearity on multilevel modeling parameter estimates and standard errors. Educational and Psychological Measurement,69(6), 951-985.

State Junior College Advisory Board (1963). Florida's community junior colleges: Their contributions and their future - A report of a study of five years of growth 1957-1962. Tallahassee, FL: State Department of Education.

Steele, C.M. (1997). A threat in the air: How stereotypes shape intellectual identity and performance. American Psychologist 52, 613-629.

St. John, E.P., Musoba, G.D., Simmons, A.B. (2003). Keeping the promise: The impact of Indiana's twenty-first century scholars program. The Review of Higher Education, 27(1), 103-123. 
Sullivan, A. (2001). Cultural capital and educational attainment. Sociology, 35 (4), 893912.

Terenzini, P.T., Cabrera, A.F., \& Bernal, E.M. (2001). Swimming against the tide: The poor in American higher education. New York, NY: College Entrance Examination Board.

Titus, M.A. (2006). Understanding the influence of the financial context of institutions on student persistence at four-year colleges and universities. Journal of Higher Education. 77(2), 353-375.

Useem, E.L. (1992a). Getting on the fast track in mathematics: School organizational influences on math track assignment. American Journal of Education, 100(3), 325-353.

Useem, E.L. (1992b). Middle schools and math groups: Parents' involvement in children's placement. Sociology of Education, 65(4), 263-279.

Vassar, R.L. (Ed.). (1965). Social history of American education. (Vol. 1): Colonial times to 1860 . Chicago, IL: Rand McNally.

Venezia, A. M.W. Kirst, and A.L. Antonio. (2003). Betraying the college dream: How disconnected K-12 and postsecondary education systems undermine student aspirations. Palo Alto, CA: The Bridge Project, Stanford Institute for Higher Education Research.

Vinovskis, M. A. (1970). Horace Mann on the economic productivity of education. The New England Quarterly, 43(4), 550-571.

Watanabe, M. (2007). Lessons from a teacher inquiry group about tracking: Perceived student choice in course-taking and its implications for detracking reform. Teachers College Record, 109(9), 2136-70.

Waycaster, P. (2001). Factors impacting success in community college developmental mathematics courses and subsequent courses. Community College Journal of Research and Practice, 25(5-6), 403-416.

Wells, A. S. \& Oakes, J. (1996). Potential pitfalls of systemic reform: Early lessons from research on detracking. Sociology of Education, 69, 135-143.

Willis, P. E. (1977). Learning to labor: How working class kids get working class jobs. New York, NY: Columbia University Press.

World Intellectual Property Organization (WIPO) (2008). World patent report: A statistical review. Retrieved from http://www.wipo.int/export/sites/www/ipstats /en/statistics/patents/pdf/wipo_pub_931.pdf 
Yando, R., Seitz, V., \& Zigler, E. (1979). Intellectual and personality characteristics of children: Social-class and ethnic-group difference. Hillsdale, NJ: Erlbaum.

You, S. (2007). Exploring school effects on the college preparation of high school students. Retrieved from http://www.airweb.org/images/you_730_proposal.pdf. 


\section{APPENDIX}

Table A1

Remedial Math Attempts

\begin{tabular}{c|c|c}
\hline Attempts & Frequency & Percent \\
\hline 0 & 1316 & 49.0 \\
\hline 1 & 660 & 24.6 \\
\hline 2 & 423 & 15.8 \\
\hline 3 & 204 & 7.6 \\
\hline 4 & 66 & 2.5 \\
\hline 5 & 11 & .4 \\
\hline 6 & 3 & .1 \\
\hline Total & 2683 & 100.0 \\
\hline
\end{tabular}


Table A2

Pearson Correlations

\begin{tabular}{|c|c|c|c|c|c|c|c|c|c|c|}
\hline Hispanic & Persist & Gender & $\begin{array}{c}\text { Delayed } \\
\text { Entry }\end{array}$ & $\begin{array}{l}\text { First- } \\
\text { Year } \\
\text { Credits }\end{array}$ & $\begin{array}{l}\text { Entry } \\
\text { Math } \\
\text { Level }\end{array}$ & $\begin{array}{c}\text { Comm. } \\
\text { College } \\
\text { Math } \\
\text { Proportion }\end{array}$ & $\begin{array}{c}\text { Remedial } \\
\text { Math } \\
\text { Attempts }\end{array}$ & $\begin{array}{c}\text { Percent } \\
\text { Remedial } \\
\text { English }\end{array}$ & $\begin{array}{c}\text { Summer } \\
\text { Credits } \\
\text { Earned }\end{array}$ & SES \\
\hline
\end{tabular}

\begin{tabular}{|c|c|c|c|c|c|c|c|c|c|c|c|c|c|}
\hline \multirow[t]{3}{*}{ Black } & $r$ & 1 & $-.349^{* *}$ & $-.121^{* *}$ & .037 & $.070^{* *}$ & $-.045^{*}$ & $-.243^{* *}$ & $-.118^{* *}$ & $.226^{* *}$ & $.181^{* *}$ & .013 & $.241^{* *}$ \\
\hline & Sig. & & .000 & .000 & .055 & .000 & .019 & .000 & .000 & .000 & .000 & .498 & .000 \\
\hline & $N$ & 2683 & 2683 & 2683 & 2683 & 2683 & 2683 & 2683 & 2683 & 2683 & 2683 & 2683 & 2683 \\
\hline \multirow[t]{3}{*}{ Hispanic } & $r$ & $-.349^{* *}$ & 1 & .031 & -.032 & -.001 & .026 & -.036 & .015 & .025 & -.027 & .005 & .005 \\
\hline & Sig. & .000 & & .112 & .093 & .954 & .182 & .060 & .431 & .192 & .159 & .801 & .779 \\
\hline & $N$ & 2683 & 2683 & 2683 & 2683 & 2683 & 2683 & 2683 & 2683 & 2683 & 2683 & 2683 & 2683 \\
\hline \multirow[t]{3}{*}{ Persist } & $r$ & $-.121^{* *}$ & .031 & 1 & $.118^{* *}$ & $-.051^{* *}$ & $.228^{* *}$ & $.351^{* *}$ & $.428^{* *}$ & $-.266^{* *}$ & $-.297^{* *}$ & $.443^{* *}$ & $.054^{* *}$ \\
\hline & Sig. & .000 & .112 & & .000 & .008 & .000 & .000 & .000 & .000 & .000 & .000 & .005 \\
\hline & $N$ & 2683 & 2683 & 2683 & 2683 & 2683 & 2683 & 2683 & 2683 & 2683 & 2683 & 2683 & 2683 \\
\hline \multirow[t]{3}{*}{ Gender } & $r$ & .037 & -.032 & $.118^{* *}$ & 1 & .013 & $.047^{*}$ & .010 & $.115^{* *}$ & .017 & $-.080^{* *}$ & $.101^{* *}$ & $.109^{* *}$ \\
\hline & Sig. & .055 & .093 & .000 & & .491 & .015 & .604 & .000 & .388 & .000 & .000 & .000 \\
\hline & $N$ & 2683 & 2683 & 2683 & 2683 & 2683 & 2683 & 2683 & 2683 & 2683 & 2683 & 2683 & 2683 \\
\hline \multirow{3}{*}{$\begin{array}{l}\text { Delayed } \\
\text { Entry }\end{array}$} & $r$ & $.070^{* *}$ & -.001 & $-.051^{* *}$ & .013 & 1 & $-.176^{* *}$ & .014 & -.026 & -.025 & .005 & -.025 & .003 \\
\hline & Sig. & .000 & .954 & .008 & .491 & & .000 & .472 & .181 & .204 & .789 & .193 & .867 \\
\hline & $N$ & 2683 & 2683 & 2683 & 2683 & 2683 & 2683 & 2683 & 2683 & 2683 & 2683 & 2683 & 2683 \\
\hline \multirow{3}{*}{$\begin{array}{l}\text { First-Year } \\
\text { Credits }\end{array}$} & $r$ & $-.045^{*}$ & .026 & $.228^{* *}$ & $.047^{*}$ & $-.176^{* *}$ & 1 & $.126^{* *}$ & $.352^{* *}$ & $-.110^{* *}$ & $-.116^{* *}$ & $.248^{* *}$ & $.081^{* *}$ \\
\hline & Sig. & .019 & .182 & .000 & .015 & .000 & & .000 & .000 & .000 & .000 & .000 & .000 \\
\hline & $N$ & 2683 & 2683 & 2683 & 2683 & 2683 & 2683 & 2683 & 2683 & 2683 & 2683 & 2683 & 2683 \\
\hline
\end{tabular}

*. Correlation is significant at the 0.05 level (2-tailed). **. Correlation is significant at the 0.01 level (2-tailed). 

Table A2

Pearson Correlations

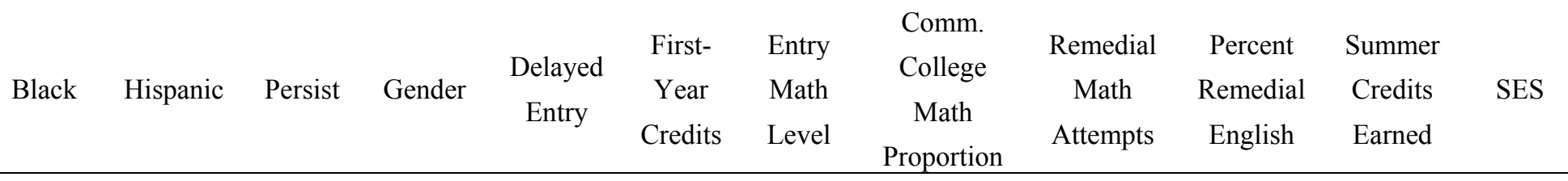

\begin{tabular}{|c|c|c|c|c|c|c|c|c|c|c|c|c|c|}
\hline \multirow{4}{*}{$\begin{array}{l}\text { Entry Math } \\
\text { Level }\end{array}$} & \multirow[b]{2}{*}{$r$} & \multirow[b]{2}{*}{$-.243^{* *}$} & \multirow[b]{2}{*}{-.036} & \multirow[b]{2}{*}{$.351^{* *}$} & \multicolumn{9}{|c|}{ Proportion } \\
\hline & & & & & .010 & .014 & $.126^{* *}$ & \multirow[t]{2}{*}{1} & \multirow{2}{*}{$\begin{array}{r}.355^{* *} \\
.000 \\
\end{array}$} & \multirow{2}{*}{$\begin{array}{r}-.786^{* *} \\
.000 \\
\end{array}$} & \multirow{2}{*}{$\begin{array}{r}-.457^{* *} \\
.000 \\
\end{array}$} & \multirow{2}{*}{$\begin{array}{r}.121^{* *} \\
.000 \\
\end{array}$} & \multirow{2}{*}{$\begin{array}{r}-.127^{* *} \\
.000 \\
\end{array}$} \\
\hline & Sig. & .000 & .060 & .000 & .604 & .472 & .000 & & & & & & \\
\hline & $N$ & 2683 & 2683 & 2683 & 2683 & 2683 & 2683 & 2683 & 2683 & 2683 & 2683 & 2683 & 2683 \\
\hline Comm. & $r$ & $-.118^{* *}$ & .015 & $.428^{* *}$ & $.115^{* *}$ & -.026 & $.352^{* *}$ & $.355^{* *}$ & 1 & $-.363^{* *}$ & $-.267^{* *}$ & $.307^{* *}$ & .003 \\
\hline College & Sig. & .000 & .431 & .000 & .000 & .181 & .000 & .000 & & .000 & .000 & .000 & .887 \\
\hline $\begin{array}{l}\text { Math } \\
\text { Proportion }\end{array}$ & $N$ & 2683 & 2683 & 2683 & 2683 & 2683 & 2683 & 2683 & 2683 & 2683 & 2683 & 2683 & 2683 \\
\hline \multirow{3}{*}{$\begin{array}{l}\text { Remedial } \\
\text { Math } \\
\text { Attempts } \\
\end{array}$} & $r$ & $.226^{* *}$ & .025 & $-.266^{* *}$ & .017 & -.025 & $-.110^{* *}$ & $-.786^{* *}$ & $-.363^{* *}$ & 1 & $.373^{* *}$ & $-.076^{* *}$ & $.109^{* *}$ \\
\hline & Sig. & .000 & .192 & .000 & .388 & .204 & .000 & .000 & .000 & & .000 & .000 & .000 \\
\hline & $N$ & 2683 & 2683 & 2683 & 2683 & 2683 & 2683 & 2683 & 2683 & 2683 & 2683 & 2683 & 2683 \\
\hline \multirow{3}{*}{$\begin{array}{l}\text { Percent } \\
\text { Remedial } \\
\text { English } \\
\end{array}$} & $r$ & $.181^{* *}$ & -.027 & $-.297^{* *}$ & $-.080^{* *}$ & .005 & $-.116^{* *}$ & $-.457^{* *}$ & $-.267^{* *}$ & $.373^{* *}$ & 1 & $-.163^{* *}$ & $.058^{* *}$ \\
\hline & Sig. & .000 & .159 & .000 & .000 & .789 & .000 & .000 & .000 & .000 & & .000 & .003 \\
\hline & $N$ & 2683 & 2683 & 2683 & 2683 & 2683 & 2683 & 2683 & 2683 & 2683 & 2683 & 2683 & 2683 \\
\hline \multirow{3}{*}{$\begin{array}{l}\text { Summer } \\
\text { Credits } \\
\text { Earned }\end{array}$} & $r$ & .013 & .005 & $.443^{* *}$ & $.101^{* *}$ & -.025 & $.248^{* *}$ & $.121^{* *}$ & $.307^{* *}$ & $-.076^{* *}$ & $-.163^{* *}$ & 1 & $.123^{* *}$ \\
\hline & Sig. & .498 & .801 & .000 & .000 & .193 & .000 & .000 & .000 & .000 & .000 & & .000 \\
\hline & $N$ & 2683 & 2683 & 2683 & 2683 & 2683 & 2683 & 2683 & 2683 & 2683 & 2683 & 2683 & 2683 \\
\hline \multirow[t]{3}{*}{ SES } & $r$ & $.241^{* *}$ & .005 & $.054^{* *}$ & $.109^{* *}$ & .003 & $.081^{* *}$ & $-.127^{* *}$ & .003 & $.109^{* *}$ & $.058^{* *}$ & $.123^{* *}$ & 1 \\
\hline & Sig. & .000 & .779 & .005 & .000 & .867 & .000 & .000 & .887 & .000 & .003 & .000 & \\
\hline & $N$ & 2683 & 2683 & 2683 & 2683 & 2683 & 2683 & 2683 & 2683 & 2683 & 2683 & 2683 & 2683 \\
\hline
\end{tabular}

*. Correlation is significant at the 0.05 level (2-tailed). **. Correlation is significant at the 0.01 level (2-tailed). 
VITA

\title{
AVIS RICHARDS PROCTOR
}

\author{
1993 \\ B.S., Mathematics Education \\ Florida A\&M University \\ Tallahassee, FL \\ 1994 \\ M.S.T., Mathematics \\ Florida Atlantic University \\ Boca Raton, FL \\ $1993-2000$ \\ Secondary Mathematics Teacher \\ Pine Crest School \\ Fort Lauderdale, FL \\ $2000-2003$ \\ Assistant Professor of Mathematics \\ Broward Community College \\ Coconut Creek, FL \\ 2003 - $2009 \quad$ Mathematics Department Chairperson/Associate Dean \\ Broward Community College \\ Coconut Creek, FL \\ 2009 - present $\quad$ Associate Vice President, Academic Affairs \\ Broward College \\ Fort Lauderdale, FL
}

